\title{
Emeet/Inca: captura e acesso de informação multimídia em reuniões distribuídas
}

\author{
Wagner da Silva Bila
}

Orientadora: Profa. Dra. Maria da Cirą̧a Campos Pimentel

Dissertação aprescntada ao Instituto de Ciências Matcmáticas $\mathrm{c}$ de Computação - ICMC -USP. como parte dos requisitos para oblenção do título de Mestre em Ciências de Computação e Matcrática Computacional

USP - São Carlos

$\mathrm{Março} / 20(02$ 


\section{A Comissão Julgadora:}

Profa. Dra. Maria da Graça ('ampos Pimentel

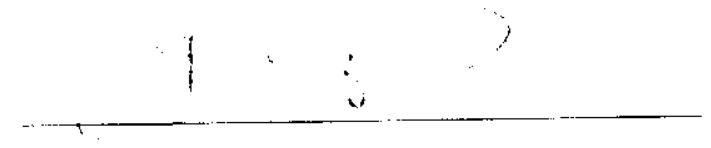

Prof. Dr. Jauvane Cavalcante de Ohveira

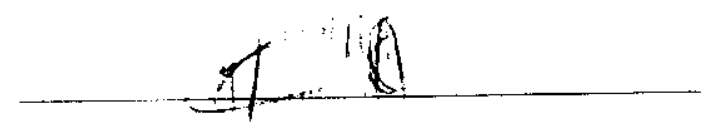

Prof: Dr. Luis C'arlos Trevelin

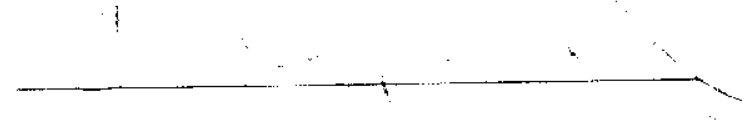




\section{DEDICATÓRıA}

Dedico a meus pais, Cornélio e Sidelínia, a minha querida namorada Daniela, a minha sempre admirada orientadora Maria da Graça Campos Pimentel e aos meus inestimáveis amigos Pedro e Daniel, por toda a compreensão e apoio. 


\section{AGRADECIMENTOS}

Primeiramente, agradeço a Deus por me permitir chegar a este momento da minha vida e por sempre me acompanhar, mesmo nos momentos mais dificeis.

Aos meus pais que sempre acreditaram em mim e sempre me incentivaram. Saibam que o incentivo de vocês é melhor do que qualquer outra compensação, seja ela financeira ou não.

A minha querida e sempre amada Daniela, pela compreensão de todos os momentos em que estive ausente e pelo apoio irrestrito que sempre me deu.

A minha orientadora predileta Maria da Graça Campos Pimentel, pela compreensão, dedicação e amizade.

A todos os amigos do laboratório intermidia, os quais sempre me lembrarei com muito carinho.

Aos amigos Pedro e Daniel, por me acolherem em São Carlos em um periodo no qual eu já não morava mais nessa cidade.

A todos que direta ou indiretamente contribuíram para a realização deste trabalho. 
Sistemas baseados na captura de experiências ao vivo têm sido investigados em diversos contextos. O presente trabalho teve como objetivo investigar mecanismos para a captura de informação multimídia em ambientes de reuniões de modo a permitir a geração de documentos hipermídia associados na World Wide Web. O foco do trabalho é na captura e no acesso à informação multimídia associada a reuniões distribuídas síncronas. A investigação resultou no levantamento de requisitos necessários para a construção de uma ferramenta instrumentada para capturar informação multimídia associada; no levantamento das limitações existentes para a implementação da ferramenta; na modelagem e na implementação de uma ferramenta, $e M e e t / I n C A$, que atende aos requisitos levantados, consideradas as limitações identificadas. 
Computing systems based on the capture of live experiences have been investigated in several contexts. This work aimed at investigating mechanisms for capturing multimedia information in meeting environments so as to allow the generation of multimedia enhanced hyperdocuments in the World Wide Web. The focus of the work has been in the capture and access of multimedia information associated to synchronous distributed meetings. The results include: investigation of the requirements demanded from an application instrumented to automatically capture multimedia information in the distributed meetings domain; investigation of the current limitations imposed when such an application is implemented; modeling and implementation of the $e M e e t / I n C A$ application that, given the limitations discussed, attend the requirements. 


\section{INDICE}

1. INTRODUÇÃOO.

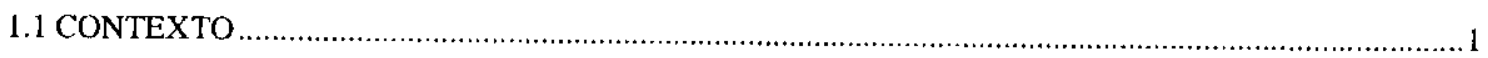

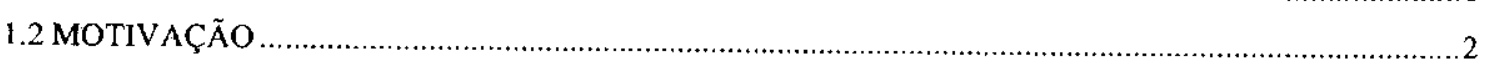

1.3 OBJETIVO

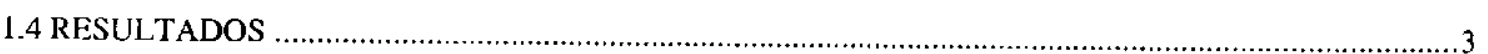

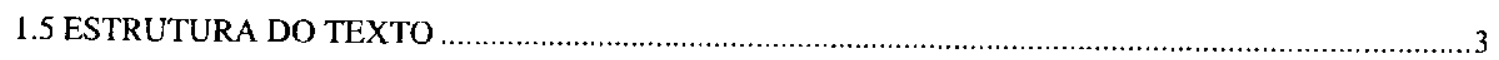

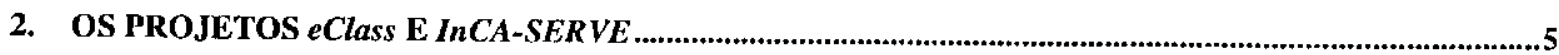

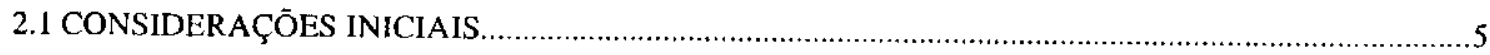

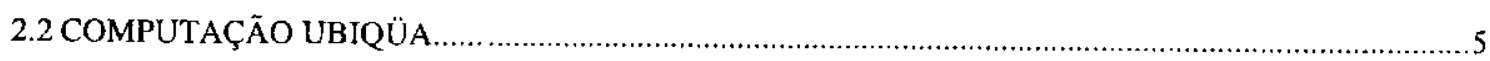

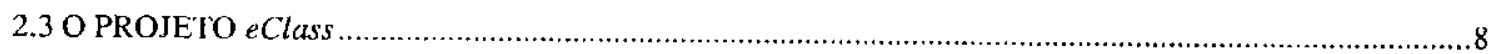

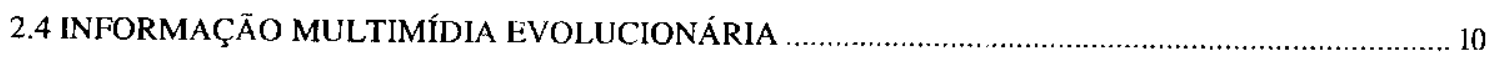

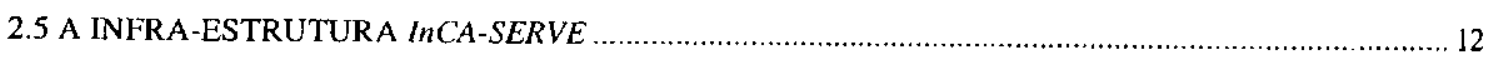

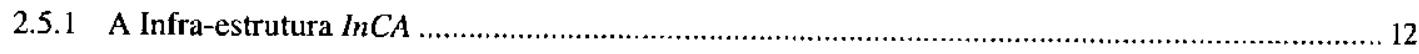

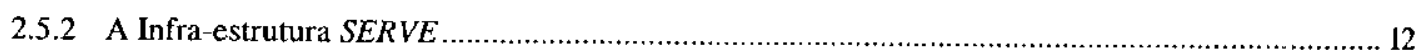

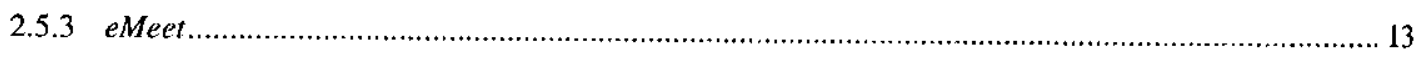

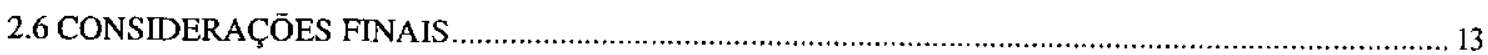

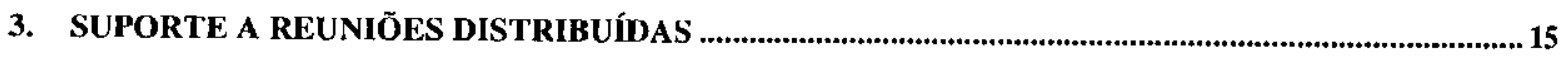

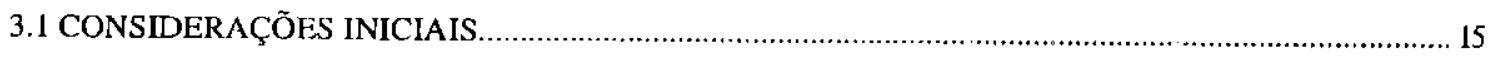

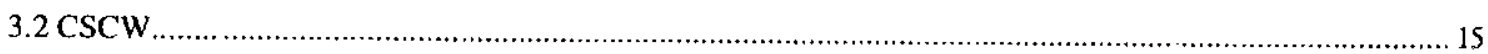

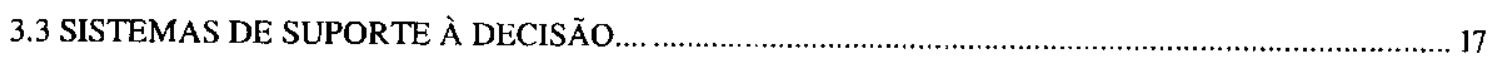

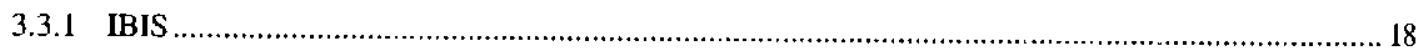

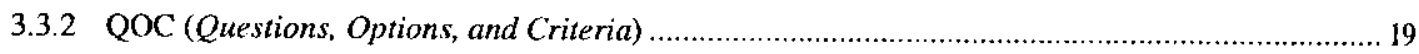

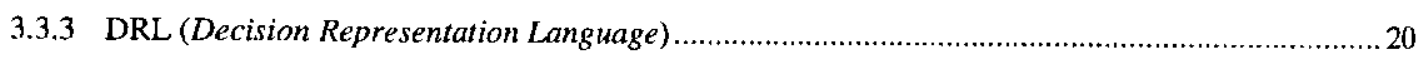

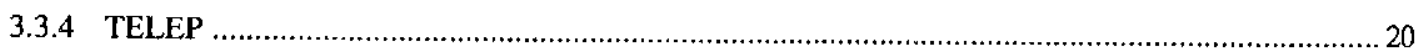

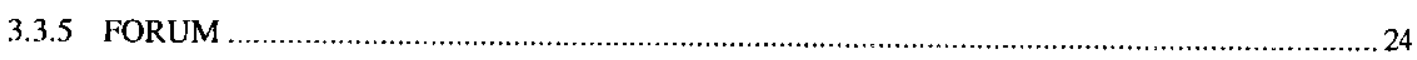

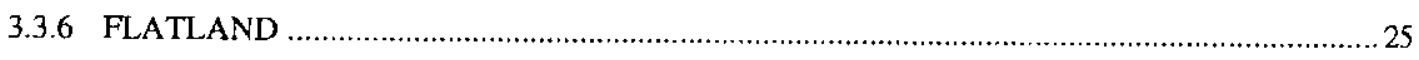

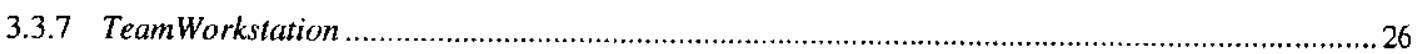

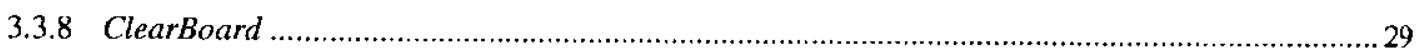

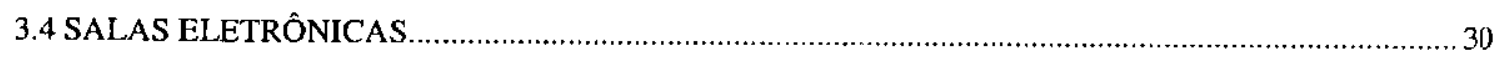

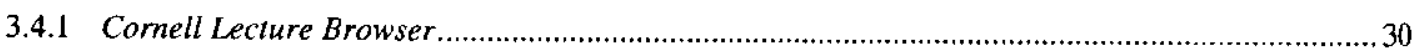

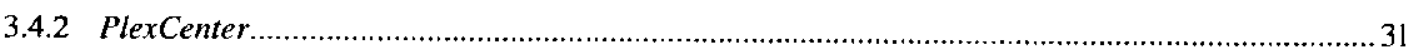

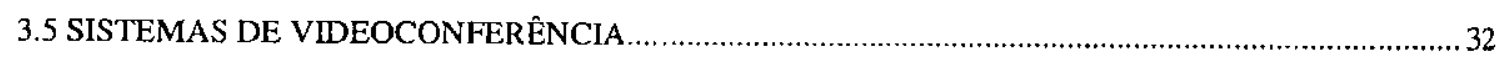

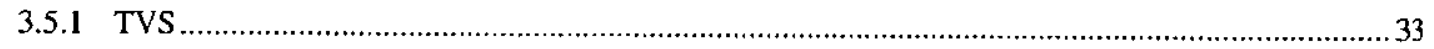

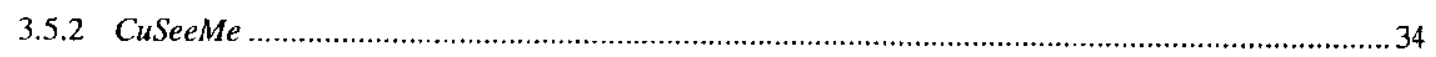

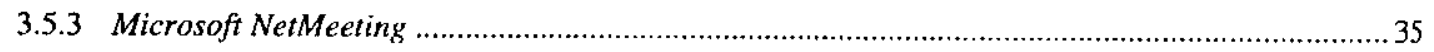


$3.5 .+$ IVS

3.6 CONSIDERAÇÕES FINAIS.

4. eMeet/InCA: ASPECTOS DE IMPLEMENTAÇÃO

4.1 CONSIDERAÇÕES INICIAIS. 40

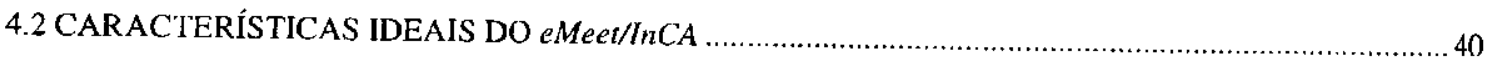

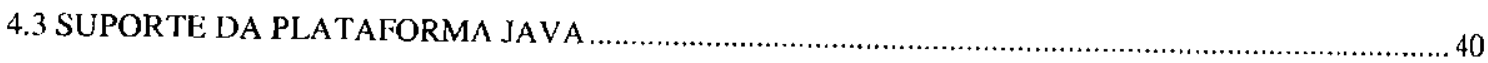

4.3.1 A API JMF

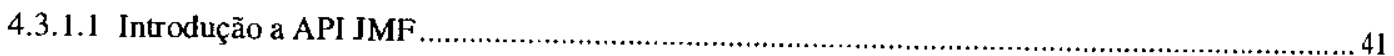

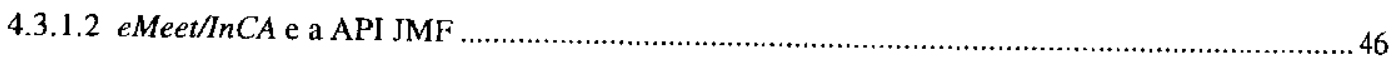

4.3.1.3 Limitações da API JMF.......................................................................................... 51

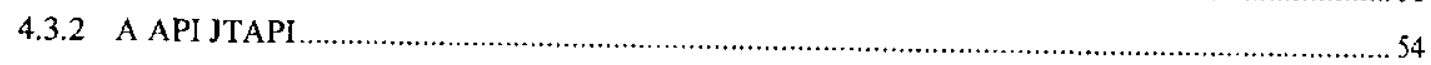

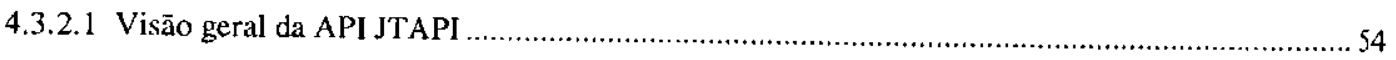

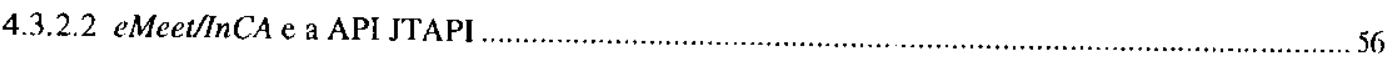

4.3.3 JAVA Web Start e a Integraçāo do Sistema com a Web .............................................................. 57

4.3.3.1 eMeet/InCA e JAVA Web Start ...................................................................................5

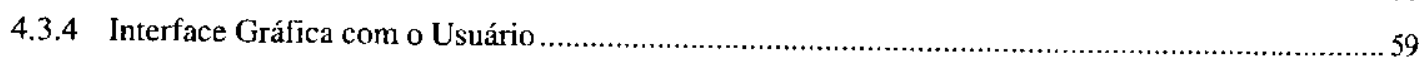

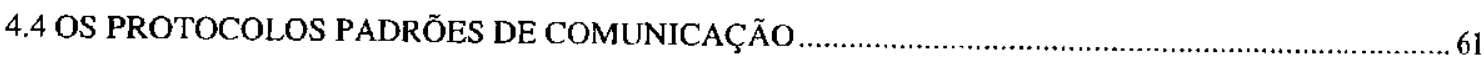

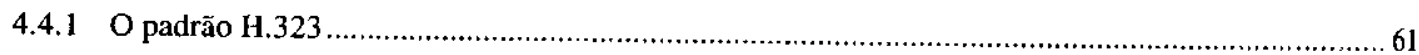

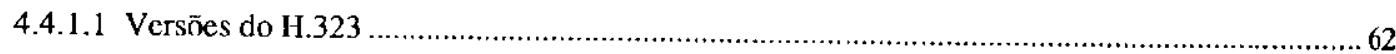

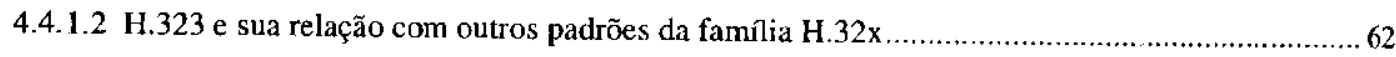

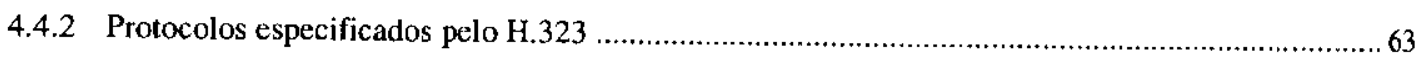

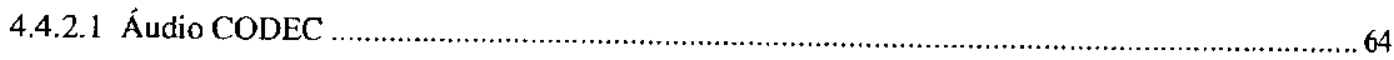

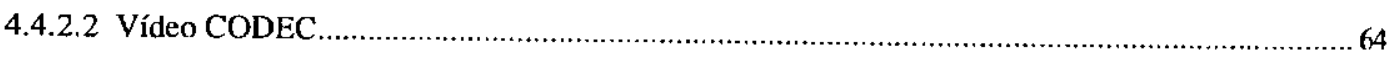

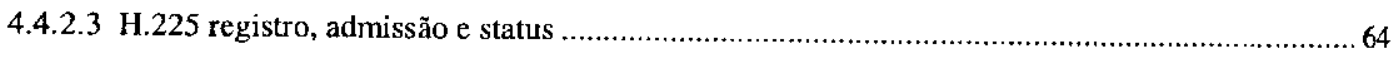

4.4.2.4 H.225 sinalização de chamada ........................................................................................64

4.4.2.5 H.245 sinalização de controle............................................................................................ 65

4.4.2.6 Protocolo de transporte em tempo real (RTP) ......................................................................65

4.4.2.7 Protocolo de controle de transporte em tempo real (RTCP) ...................................................65

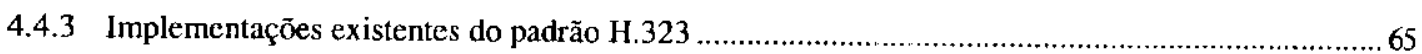

4.4.4 O eMeet/InCA como um terminal H.323 .........................................................................67

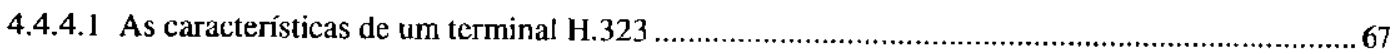

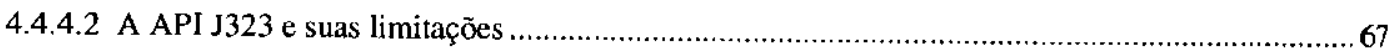

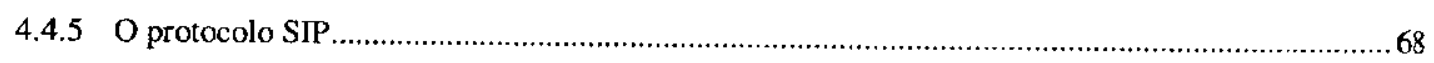

4.4.6 eMeet/InCA e a escolha dos protocolos de comunicação ...........................................................69

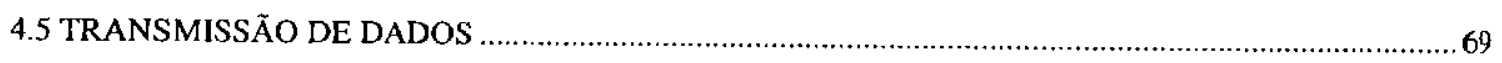

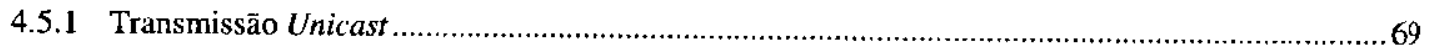

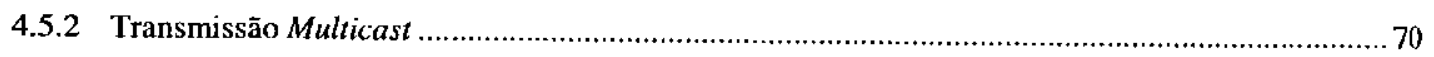

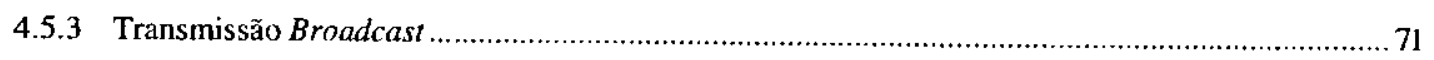

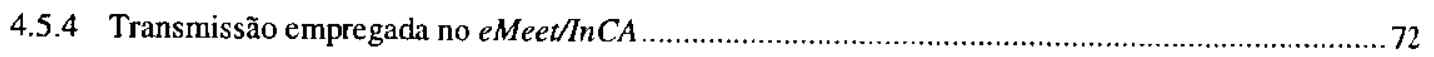


4.6 SINCRONI. AÇĀO INTERMÍDIA

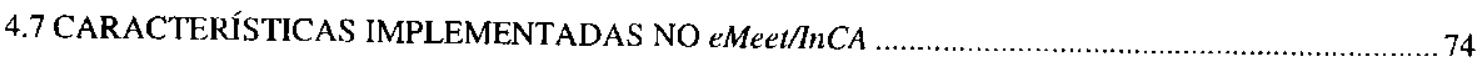

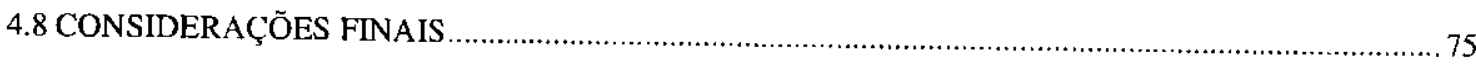

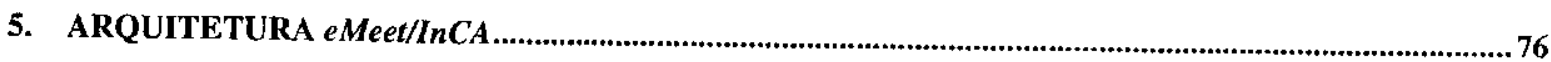

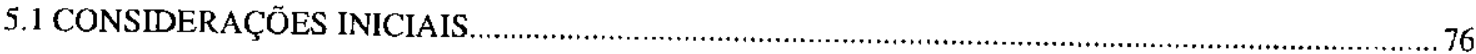

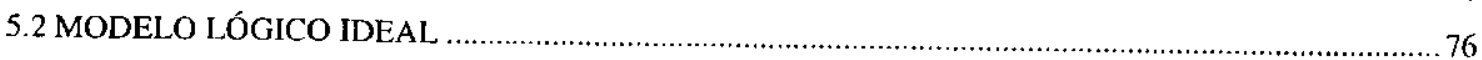

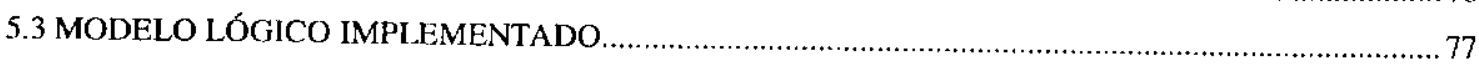

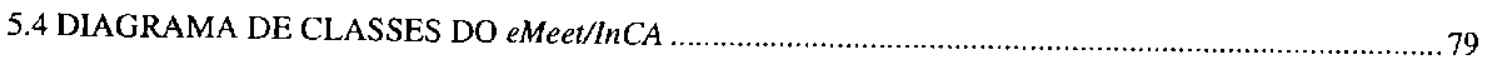

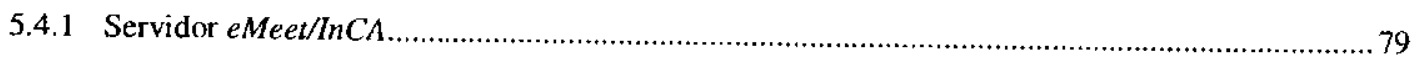

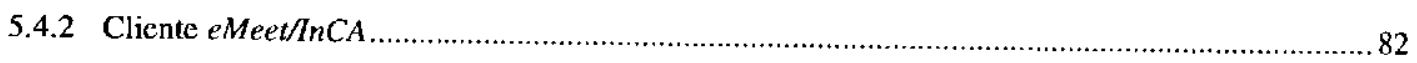

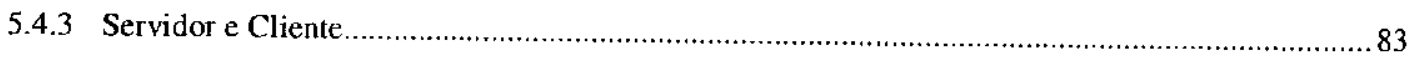

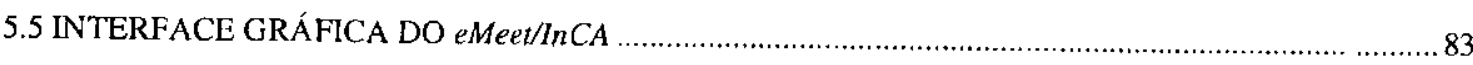

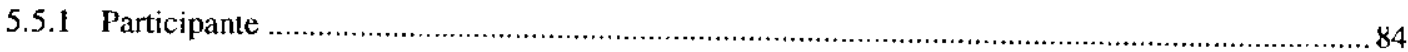

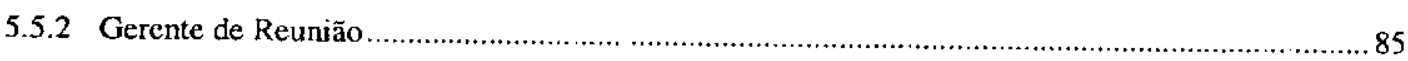

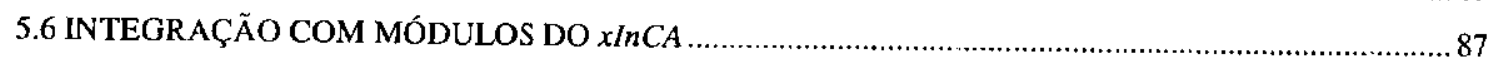

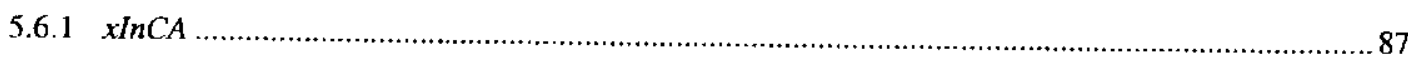

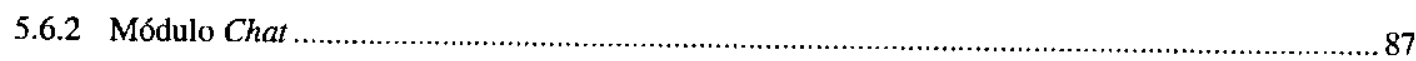

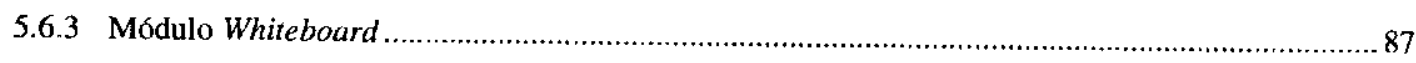

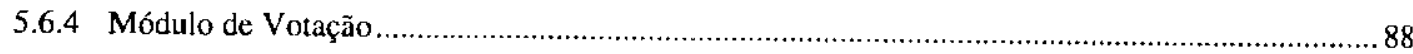

5.7 DADOS CAPTURADOS PARA A GERAÇÃO DE HIPERDOCUMENTOS ……................................... 88

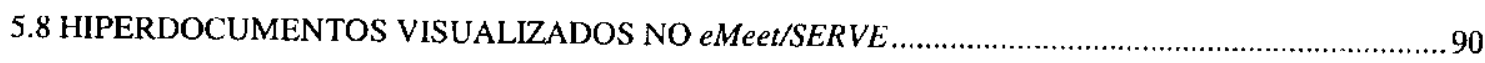

$5.9 e M e e t / n C A$ EM UM CENÁRIO DE REUNIÕES PRESENCIAIS ...................................................... 90

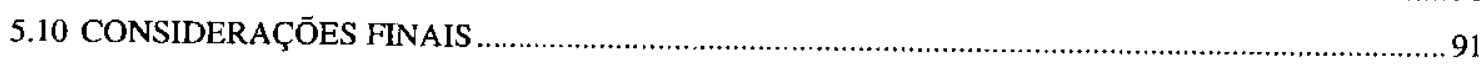

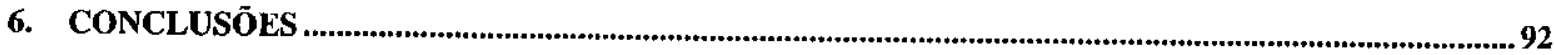

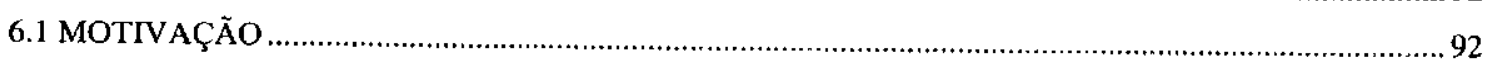

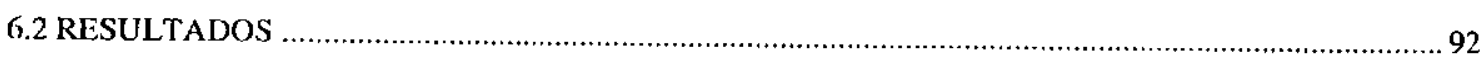

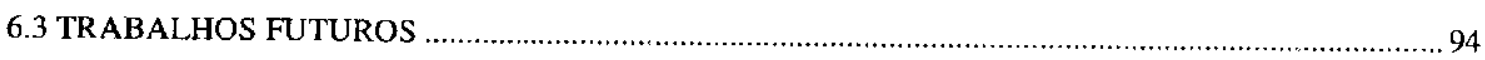

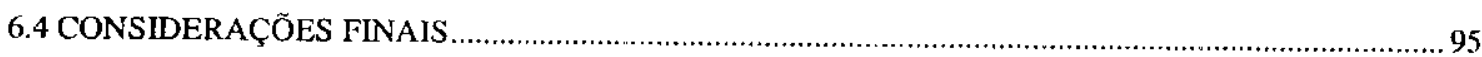

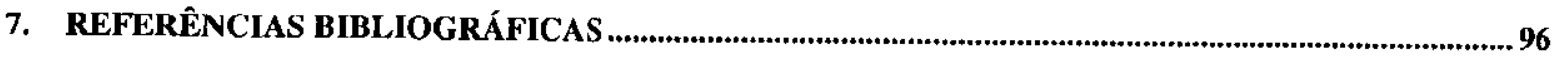




\section{INDICE DE FIGURAS}

Figura 2.1 - Alguns dispositivos de computação ubíqua (http://www.mimio.com/meetings) .......6

Figura 2.2 - Protótipo do ambiente eClass (http://www.cc.gatcch.edu/fce/eclass)....................... 8

Figura 2.3 - Documento produzido automaticamente depois de uma sessão de captura no eClass

(http://www.cc.gatech.edu/fce/eclass/overview) .................................................... 9

Figura 2.4 - Uma sala típica do ambiente eClass (http://www.cc.gatech.edu/fce/eclass) ............ 10

Figura 2.5 - Espiral representando o crescimento contínuo e concêntrico da informação

multimídia evolucionária (Pimentel et. al., 2001) .......................................................... 11

Figura 2.6 - A aplicação eMeet para suporte a reuniões ......................................................... 13

Figura 3.1 - Classificação espaço/tempo dos sistemas CSCW (Ellis et al., 1991) ...................... 16

Figura 3.2 - A notação IBIS gráfica (gIBIS) e um exemplo de diagramação de um problema de tomada de decisão (http://www.gdss.com/wp/IBIS.htm) ........................................... 18

Figura 3.3 - Diagrama QOC (http://www.xrce.xerox.com/publis/cam-trs/pdf/1991/epc-1991136.pdf)

Figura 3.4 - Diagrama QOC para a tomada de decisão (http://www.xrce.xerox.com/publis/cam-

trs/pdf/1991/epc-1991-136.pdf).

Figura 3.5 - Diagrama da Linguagem de Representação de Decisão (DRL) (Lee \& Lai, 1990).. 20

Figura 3.6 - Uma visão geral da estrutura do sistema TELEP (Jancke et al., 2000) .................... 22

Figura 3.7 - Visão de um usuário remoto do sistema TELEP (Jancke et al., 2000)....................22

Figura 3.8 - Display de sala de apresentação do sistema TELEP (Jancke et al., 2000) ............... 23

Figura 3.9 - Janela de perguntas dos participantes ao palestrante (Jancke et al., 2000) ...............23

Figura 3.10 - Janela de chat disponível para os participantes do evento (Jancke et al., 2000).... 23

Figura 3.11 - Mecanismo de votação implementado no sistema TELEP (Jancke et al., 2000) ....24

Figura 3.12 - Interface do sistema FORUM da Sun Microsystems com seus participantes

(http://research.sun.com/coco/forum/ForumHome.html) .............................................22

Figura 3.13 - Layout da tela principal do FLATLAND (White et al., 2000) .............................. 26

Figura 3.14 - Componentes do sistema FLATLAND e suas relações (White et al., 2000) .........26

Figura 3.15 - Visão geral do funcionamento e dos módulos do TeamWorkStation-1

(http://web.media.mit.edu/ ishii/TWS.html) .

Figura 3.16 - Tela principal do TeamWorkStation-1 com a visualização dos documentos

compartilhados e dos co-autores do projeto (http://web.media.mit.edu/ ishii/TWS.html).. 28 
Figura 3.17 - O TeamWorkStation-2 sendo utilizado (http://web.media.mit.edu/ ishii/TWS.html)

Figura 3.18 - Tela principal do TeamWorkStation-2 (http://web.media.mit.edu/ ishii/TWS.html)

Figura 3.19 - Metáfora do ClearBoard: conversa através do desenho em uma grande prancheta de vidro (http://web.media.mit.edu/ ishii/CB.html)

Figura 3.20 - O ClearBoard sendo utilizado em uma interação remota entre dois participantes (http://web.media.mit.edu/ ishii/CB.html)

Figura 3.21 - Interface do Cornell Lecture Browser ao usuário, contando com a visualização do palestrante e os slides utilizados (http://www4.cs.cornell.edu/LectureBrowser) ................... 31

Figura 3.22 - O CoLab, sala do sistema PlexCenter (Ellis et al., 1991) ................................... 32

Figura 3.23 - Interface do TVS com o usuário (Oliveira, 1996) ……......................................... 33

Figura 3.24 - Interface original do CuSeeMe (Dorcey, 1995) .................................................. 34

Figura 3.25 - A interface do CuSeeMe Web (http://www.cuseeme.com/products).................... 35

Figura 3.26 - Tela principal do Microsoft Netmeeting, um dos softwares pioneiros de conferência

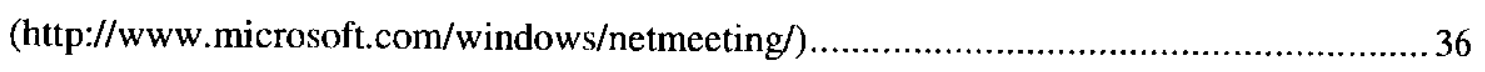

Figura 3.27 - A interface gráfica do IVS (INRIA Videoconferencing System) (http://www-

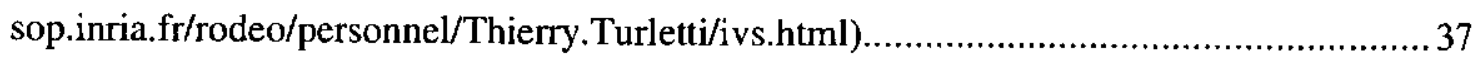

Figura 4.1 - Modelo de processamento de mídia adotado pela API JMF (Sun, 1999a)...............42

Figura 4.2 - Abstração real da arquitetura da API JMF (Sun, 1999a) ........................................ 46

Figura 4.3 - Registro da API JMF 2.1.1a ......................................................................... 47

Figura 4.4 - Atribuições do servidor controle de reunião da aplicação $e M e e t / I n C A$....................48

Figura 4.5 - Algoritmo de sumarização de uma reunião .............................................................49

Figura 4.6 - Participante 1 recebendo as mídias de áudio e vídeo de todos os outros participantes

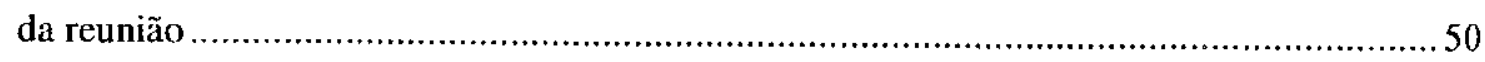

Figura 4.7 - JMF Customizer, aplicativo da API JMF para a configuração dos recursos a serem suportados pela API

Figura 4.8 - Procedimento indicado pelo manual de referência da API JMF 2.1.1a

(http://java.sun.com/products/java-media/jmf/2.1.1/guide) para que, a partir de um Data Source consiga-se empregá-lo paralelamente a múltiplas tarefas ........................................53

Figura 4.9 - Abordagem alternativa para solucionar uma das deficiências da API JMF .............54

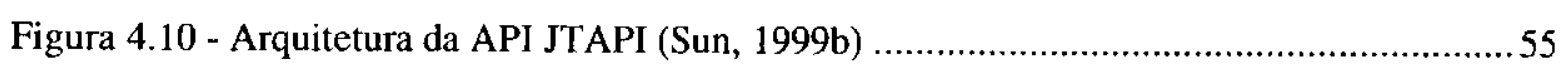


Figura 4.11 - Interação entre a API JTAPI, uma aplicação ou applet, a máquina virtual c os dispositivos telefônicos que a máquina possa ter (Sun, 1999b) .......................................56

Figura 4.12 - Arquitetura da tecnologia JAVA Web Start (Sun, 2001b) ................................58

Figura 4.13 - Tela inicial do eMeet/SERVE (Eleutério, 2002) .............................................59

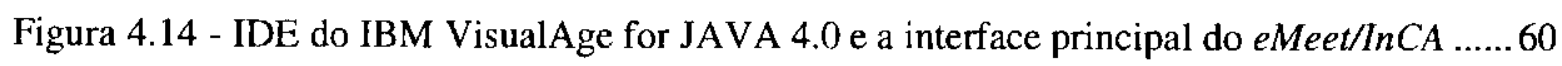

Figura 4.15 - Terminais H.323 em uma rede por pacotes (IEC, 1999) ......................................61

Figura 4.16 - Pilha de protocolos de um terminal H.323 (IEC, 1999) ......................................63

Figura 4.17 - Transmissão de dados Unicast ....................................................................... 70

Figura 4.18 - Transmissão Multicast ............................................................................. 71

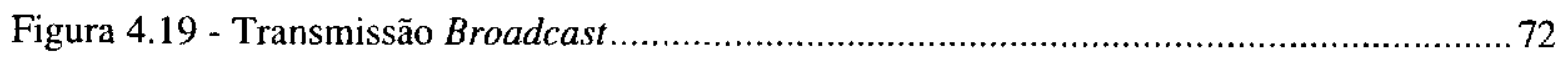

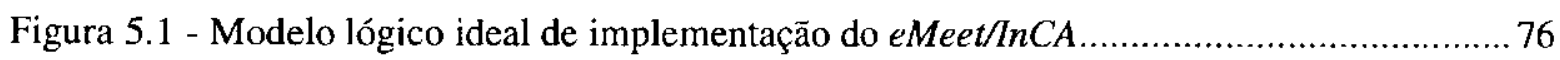

Figura 5.2 - Modelo lógico implementado no eMeet/InCA ................................................... 77

Figura 5.3 - Impacto causado por uma possível utilização da API J323 na versão atual do

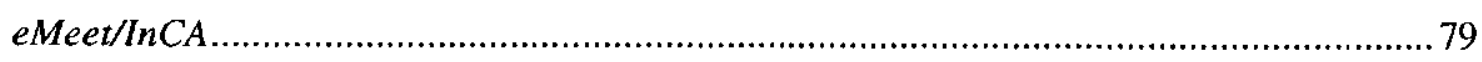

Figura 5.4 - Diagrama de classes UML da estrutura interna do servidor $e M e e t / \operatorname{lnCA} \ldots \ldots \ldots \ldots . . . . .80$

Figura 5.5 - Exemplo de um arquivo de configuração eMeetd.conf ........................................ 81

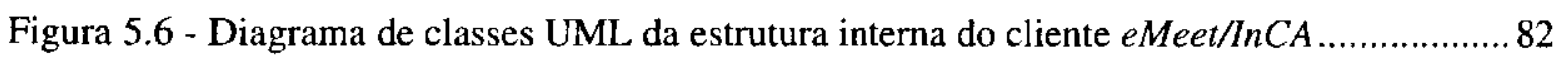

Figura 5.7 - Diagrama de classes UML da estrutura completa do eMeet/InCA atual ................. 83

Figura 5.8 - Interface gráfica do cliente $e M e e t / I n C A$ para um participante de uma reunião........ 84

Figura 5.9 - Interface gráfica do gerenciador do processo de gravação da reunião...................... 86

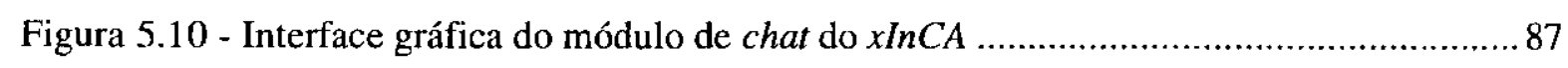

Figura 5.11 - Interface gráfica original do módulo whiteboard do $x \operatorname{InCA}$................................. 88

Figura 5.12 - Base de dados do eMeet/SERVE (Eleutério, 2002) .......................................... 89

Figura 5.13 - Interface de visualização de uma reunião recuperada pelo eMeet/SERVE (Eleutério,

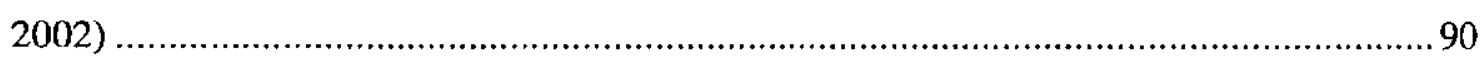




\section{ÍNDICE DE TABELAS}

Tabela 4.1 - Formatos mais comuns de vídeo (Sun, 1999a). .43

Tabela 4.2 - Formatos mais comuns de áudio (Sun, 1999a) .43

Tabela 4.3 - Formatos suportados na API JMF utilizando o protocolo RTP (Sun, 2001a)......... 44

Tabela 4.4 - Dispositivos de captura suportados pela API JMF 2.1.1a (Sun, 2001a) .45 


\subsection{CONTEXTO}

Diariamente participamos de diversas experiências (aulas, eventos, reuniões, etc.) que exigem nossa atenção para que possamos assimilar informações úteis para o nosso aprendizado (seja ele pessoal ou profissional). Não muito raramente deparamo-nos com situações nas quais nossa atenção é desviada, seja por um simples instante, fazendo com que percamos a inteligibilidade do que está acontecendo, ou sendo discutido, ao nosso redor naquele momento. Para tais situações e levando-se em conta que uma pessoa normal não consegue assimilar e memorizar todas as informações existentes em uma experiência corriqueira, vários sistemas baseados na captura de experiências cotidianas têm sido investigados. Um dos primeiros trabalhos desenvolvidos neste sentido, focalizando a captura de reuniões tradicionais, foi o ambiente DOLPHIN (Streitz et al., 1997) (Haake et al., 1994). Um ano depois, surgia um trabalho da Xerox PARC que enfocava este mesmo assunto (Minneman et al., 1995).

Os sistemas de suporte a reunião têm como finalidade dar suporte às constantes reuniões, comumente realizadas em instituições ou corporações, e que têm por objetivo a discussão de problemas e tomadas de decisões. Tais sistemas são considerados como "sistemas cooperativos" e podem ser divididos basicamente em dois grupos: sistemas de suporte à decisão (GDSS Group Decision Support System) e salas eletrônicas. Os sistemas de suporte à decisão são sistemas interativos que possuem mecanismos especiais para votação, geração de idéias, perguntas e identificação de alternativas para a solução de problemas. Salas eletrônicas possuem ambientes especiais estruturados com hardware e software para o apoio de reuniões face-a-face $e$ que podem compreender várias estações de trabalhos interligadas em rede, além do uso de equipamentos de áudio, vídeo e projetores. Como exemplos de sistemas cooperativos de suporte a reunião tem-se o IBIS (Conklin \& Begeman, 1987), QOC (Shum \& Hammond, 1994), DRL (Lee, 1990), TELEP (Jancke et al., 2000), FORUM da Sun (Isaacs \& Tang, 1997), FLATLAND do MSR - Microsoft Research Center (White et al., 2000) e produtos comerciais como o CENTRA (Centra Symposium Software, http://www.centra.com), NetPodium 
(http://www.netpodium.com, e o PlaceWare (PlaceWare Conference Center, http://www.placewarc.com). Como exemplos de salas eletrônicas tem-se o PlexCenter Planning and Decision Support Laboratory da Universidade do Arizona (Ellis et al., 1991) e o SHLL (Chen et al., 1999).

Visando o contexto educacional, incluindo a captura de áudio, vídeo e anotações durante uma apresentação, encontram-se o Cornell Lecture Browser (Mukhopadhyay \& Smith, 1999) e os projetos dos pesquisadores do Microsoft Research Center (White et al., 1998) e do Georgia Institute of Technology (Abowd, 1999) (Abowd et al., 1998a, b). Neste último, o trabalho vem sendo desenvolvido desde julho de 1995, sendo denominado eClass (inicialmente conhecido como Classroom 2000) e conta com um ambiente de sala de aula instrumentado com dispositivos de captura para a geração automática de documentos multimídia com infra-estrutura para a World Wide Web (Brotherton et al., 1998b), dando ênfase à transparência dos processos automáticos de captura e autoria dos documentos multimídia (Brotherton et al., 1998a).

\subsection{MOTIVAÇÃo}

A motivação do trabalho aqui reportado foi o de explorar mecanismos para a captura de informação multimídia em ambientes de reuniões de modo a permitir a geração de documentos hipermídia associados.

Algumas características implícitas ao contexto de reuniōes incluem:

- Reuniões podem ser distribuídas;

- Reuniões apresentam grande quantidade de interação entre os seus membros;

- Reuniões apresentam vários fluxos de informação multimídia e de controle, devido à participação ativa dos vários membros do grupo;

- Reuniões podem ser suportadas por módulos de agendamento para sua organização e comunicação;

- Reuniões destinadas à tomada de decisões necessitam de mecanismos de votação;

\footnotetext{
${ }^{1}$ Neste texto World Wide Web é referenciada por Web.
} 
- Reuniões, ao terminarem, precisam da geraçáo de um resumo das atıvidades a serem distribuídas entre os membros.

Aplicações de suporte a reuniões, presenciais ou distribuídas, tradicionalmente não suportam a captura automática da informação multimídia associada de modo a permitir a geração de documentos que correspondem ao registro da reunião.

\subsection{OBJETIVO}

O presente trabalho teve como objetivo investigar mecanismos para a captura de informação multimídia em ambientes de reuniōes de modo a permitir a geração de documentos hipermídia associados. O foco do trabalho foi na captura e no acesso à informação multimídia associada a reuniões distribuídas síncronas.

\subsection{RESULTADOS}

A investigação resultou:

- no levantamento de requisitos necessários para a construção de uma ferramenta que, suportando reuniões distribuídas, seja instrumentada para capturar informação multimídia associada;

- no levantamento das limitações existentes para a implementação atual de tal ferramenta na linguagem JAVA;

- na modelagem e na implementação de uma ferramenta que atenda aos requisitos levantados, consideradas as limitações identificadas.

A geração de hiperdocumentos multimídia, a partir da informação capturada, é tratada no contexto do trabalho de mestrado desenvolvido por Pedro Monteiro da Silva Eleutério (Eleutério \& Pimentel, 2001).

\subsection{ESTRUTURA DO TEXTO}

No restante do plano, o Capítulo 2 descreve conceitos de computação ubíqua e informação multimídia evolucionária, são apresentados os projetos eClass e eMeet, além da infra-estrutura InCA-SERVE; no Capítulo 3 são introduzidos conceitos de trabalho cooperativo suportado por 


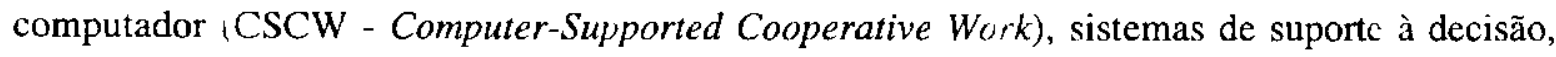
salas eletrônicas e sistemas de videoconferência; já no Capítulo 4 são apresentados os aspectos utilizados na implementação do eMeet/InCA; no Capítulo 5 é apresentada a arquitetura da aplicação $e M e e t / I n C A$; no Capítulo 6 são apresentadas conclusões referentes ao desenvolvimento do projeto; por fim, no Capítulo 7 são apresentadas as referências bibliográficas relevantes a esse projeto e a essa dissertação. 


\subsection{CONSIDERAÇÕES INICIAIS}

Neste capítulo são abordados conceitos de computação ubíqua que podem vir a ser empregados no $e M e e t / h C A$; é apresentado o projeto $e$ Class que demonstrou falhas conceituais para o suporte a reuniões distribuídas e originou a motivação de se construir uma ferramenta como o eMeet/InCA; também é discutido o conceito de informação multimídia evolucionária, que é um conceito implícito em uma aplicação como o eMeet/InCA; e a infra-estrutura de software para a captura e acesso de informações, a InCA-SERVE, a qual foi utilizada como referência para a idealização conceitual do $e M e e t / \operatorname{lnCA}$.

\subsection{COMPUTAÇÃO UBíQUA}

Weiser, em 1991, introduziu a área de computação ubíqua (ubicomp) com sua visão futurística de ambientes equipados com infra-estrutura computacional que provê serviços e informaçōes quando e onde se deseje (Weiser, 1991). Nos últimos anos, muitos pesquisadores têm contribuído para que isso aconteça e para que esta tecnologia possa ajudar em atividades cotidianas. Weiser previu uma proliferação de diversos dispositivos, em várias escalas de tamanho e complexidade. Essa proliferação tem ocorrido através da utilização em massa de dispositivos como hand-helds (PDA's - Personal Digital Assistant), tablets e pads digitais, laptops e lousas eletrônicas (whiteboards), apoiada pelo desenvolvimento e implementação da infra-estrutura para o suporte da computação móvel. A Figura 2.1 mostra alguns desses dispositivos : (a) um pad, (b) um tablet e (c) uma lousa eletrônica. 


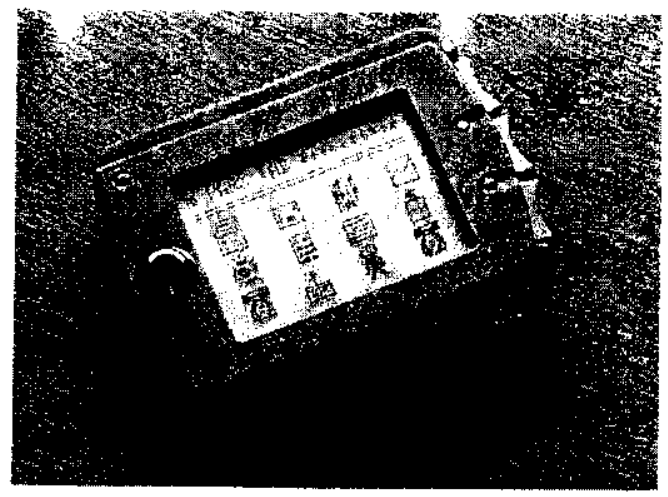

(a)

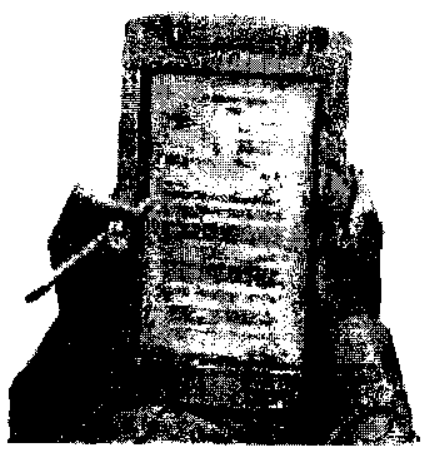

(b)

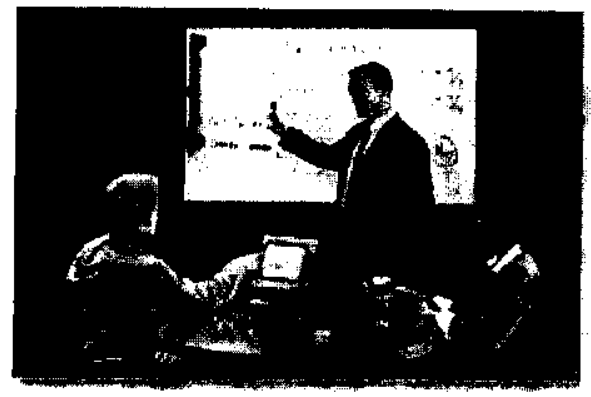

(c)

Figura 2.1 - Alguns dispositivos atuais de computação ubiqua: (a) um pad (http://nano.xerox.com/parctab), (b) um tablet (http://www.fxpal.com/xlibris) e (c) uma lousa eletrônica (http://www.mimio.com/meetings).

Com a proliferação de tais dispositivos houve também o aparecimento de novas aplicações computacionais a fim de se explorar o uso desses novos recursos. Existem três temas ligados diretamente ao desenvolvimento de tais aplicações: interfaces naturais, computação consciente de contexto e captura e acesso de atividades humanas.

Interfaces naturais são interfaces de comunicação entre computadores e homens nas quais o paradigma de fundamentação não é o tradicional teclado/mouse/monitor. Interfaces que suportam a comunicação através da fala, escrita manual, movimentos corporais ou qualquer outro tipo de forma mais abstrata de comunicação, são consideradas interfaces naturais. $\grave{A}$ medida que a utilização dos dispositivos de computação ubíqua cresça no nosso dia a dia, maior será a demanda e a necessidade de se ter interfaces naturais nas quais a comunicação seja fácil, rápida e eficaz, um dos desafios da área de interação homem-computador (HCI - Human Computer Interaction) que Abowd e Mynatt abordam (Abowd \& Mynatt, 2000). 
Computação consciente de contexto visa a associação de ‘tividades humanas (contextualização de informação) a serviços computacionais, com o intuito de expandi-los e facilitá-los. Um dos tipos mais comuns de contextualização de informação é a localização espacial associada a uma aplicação computacional. A utilização de um sistema de posicionamento global (GPS) em um veículo, associada a uma aplicação computacional na qual possa traduzir as coordenadas de forma inteligível ao motorista, é um exemplo de contextualização de informação espacial e de um sistema computacional consciente de contexto. Há muitas outras formas de informações contextuais além da localização espacial, sendo que a maioria dos sistemas conscientes de contexto não incorpora noções de tempo, história, outras pessoas que nāo sejam o próprio usuário e muitas outras informações disponíveis no ambiente. Abowd e Mynatt (Abowd et al., 2001) descrevem uma maneira de se obter tais informações a partir de cinco questões, os chamados "cinco W's": Who (quem), What (o que), Where (onde), When (quando) e Why (porquê).

Captura e acesso de atividades humanas têm, fundamentalmente, a finalidade de auxiliar o ser humano a recordar experiências passadas. É humanamente impossível se lembrar de todos os detalhes de uma aula, um debate, uma reunião ou de uma simples conversa. Baseando-se nisso, a captura dessas informações de forma estruturada, para o posterior acesso com a finalidade de se rever pontos importantes ou esquecidos, torna-se um foco interessante de aplicação da computação ubíqua. Tanto o eClass quanto o eMeet/InCA são exemplos de aplicações de captura e acesso de informações, envolvendo dispositivos de computação ubíqua.

O eClass utiliza componentes da computação ubíqua como tablets e whiteboards para a construção de seu ambiente, visando a captura das interações existentes em uma sala de aula. Uma das grandes dificuldades encontrada no projeto é manter esta interação transparente para o palestrante. Apesar disso, o eClass consegue ser pouco intrusivo, dando flexibilidade ao palestrante (Abowd, 1999). Já o eMeet/lnCA visa a captura e posterior visualização das informações originárias de uma reunião remota distribuída; utilizando-se de câmeras e microfones para tal finalidade, sendo uma ferramenta ideal para o registro de informações e suporte a decisão. 


\subsection{U PROJETO eClass}

O eClass é um projeto que tem por finalidade o estudo da utilização da computação ubíqua em ambientes de sala de aula tradicionais e que vem sendo desenvolvido desde julho de 1995 no College of Computing do Georgia Institute of Technology (CoC-Gatech), em Atlanta/EUA, e no ICMC/USP desde 1998.

Foi construído um protótipo de um ambiente de sala de aula que contém a infra-estrutura de software necessária para a captura das interações que ocorrem em uma aula típica de uma universidade. Capturando a atividade da sala por várias streams (áudio, vídeo, sequiência de imagens dos slides) e apresentando-as de forma integrada como um hiperdocumento multimídia na $W e b$, não é mais necessário que o aluno perca o seu tempo com anotações, podendo assim, atentar-se mais à explicação do palestrante e nas discussões de classe. O ambiente protótipo original construído pode ser visto na Figura 2.2, contando com projetores, lousas eletrônicas, microfones, câmeras de vídeo e computadores ligados em rede. Todos esses recursos visam a captura das várias mídias existentes durante uma apresentação.

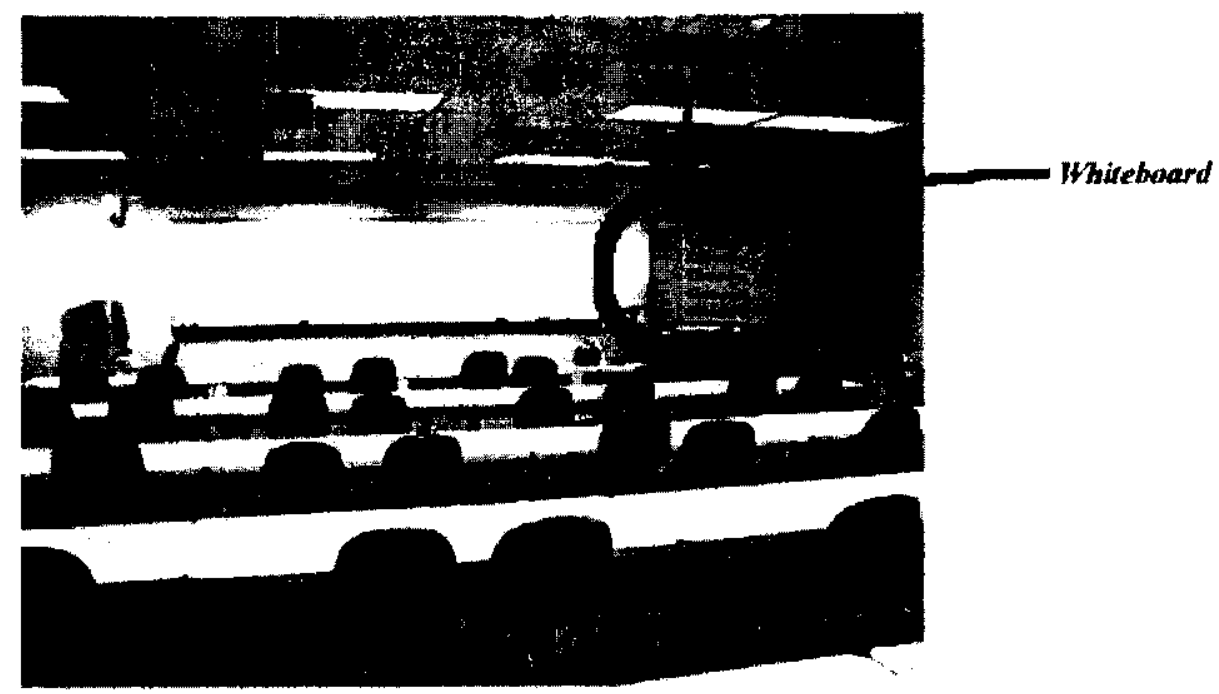

Figura 2.2 - Protótipo do ambiente eClass utilizado a partir de janeiro de 1997 (http://www.cc.gatech.edu/fce/eclass).

Pode ser notado no canto direito da Figura 2.2 que na sala de aula existe uma lousa eletrônica (whiteboard) que possibilita ao professor carregar slides previamente preparados e fazer anotações durante o decorrer da aula. Tais anotações são capturadas e armazenadas por uma 
applet esciita em JAVA, denom nada ZenPad. As inf ‘mações de áudio e/ou vídeo são capturadas usando o Real Encoder( $\bigodot^{2}$ e as visitas a páginas Web são armazenadas por um módulo que tem o papel de um Proxy Web Server. Todas essas atividades (anotações na lousa eletrônica, áudio, vídeo e navegação na $W e b$ ) são associadas a eventos temporais que servirão como índices para a reprodução da aula pela $W e b$, possibilitando uma posterior reprodução e acesso via Web. A Figura 2.4 mostra uma sala de aula do eClass sendo utilizada.

Depois de uma sessão de captura, outra aplicação, denominada StreamWeaver, automaticamente integra as mídias capturadas em um documento HTML (Pimentel et. al., $2000 \mathrm{~b}$ ) que pode ser reproduzido posteriormente, como mostra a Figura 2.3. A interface inclui uma linha do tempo (timeline) que possibilita uma indexação temporal do conteúdo de áudio, vídeos, slides e páginas Web visitadas. Enquanto visualiza-se um slide, é possível clicar nas anotações do professor para que sejam reproduzidos o vídeo e o áudio daquele momento da apresentação. Clicando-se em uma indicação de página Web visitada, um navegador é aberto na localização correspondente (janela superior direita na Figura 2.2). Há também a possibilidade de reprodução sem nenhuma intervenção.

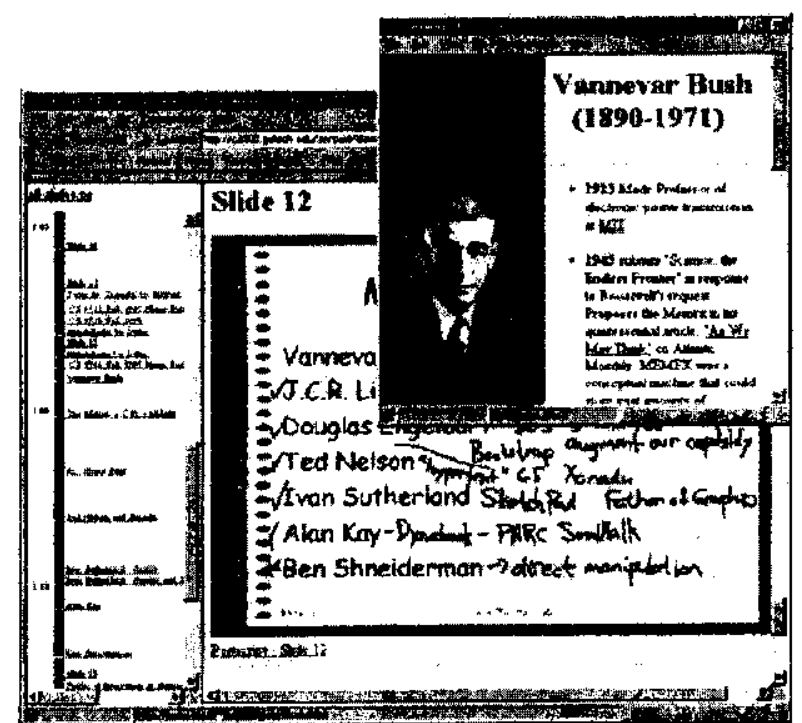

Figura 2.3 - Documento produzido automaticamente depois de uma sessāo de captura no eClass (http://www.cc.gatech.edu/fce/eclass/overview).

\footnotetext{
${ }^{2}$ http://www.real.com
} 
Pode-se observar na Figura 2.3 que a interface utilizada divide o espaço visual de apresentação ao usuário em uma estrutura de quadros (frames), sendo que o frame da direita apresenta uma aula com uma sequiência de slides. Cada slide corresponde às informações escritas pelo professor na lousa eletrônica (whiteboard) durante a apresentação. Várias outras interfaces foram estudadas (Pimentel et al., 2001), entre elas, soluções que dão acesso a serviços de busca, a lista de aulas de cada curso ou de todos os cursos, inserção de anotações (após a aula) a slides individuais ou a aulas como um todo.

O eClass é um projeto que vem sendo pesquisado há mais de 5 anos, tendo dado suporte a mais de 100 cursos e mais de 24 instrutores. É com base nesses números que pode ser medido o seu sucesso e é o que motiva ainda mais a continuação e evolução do mesmo. O eMeet é um ambiente que, como o eClass, permite a captura de informaçōes multimídia para a geração de hiperdocumentos multimídia, tendo como domínio de aplicação, reuniões distribuídas.

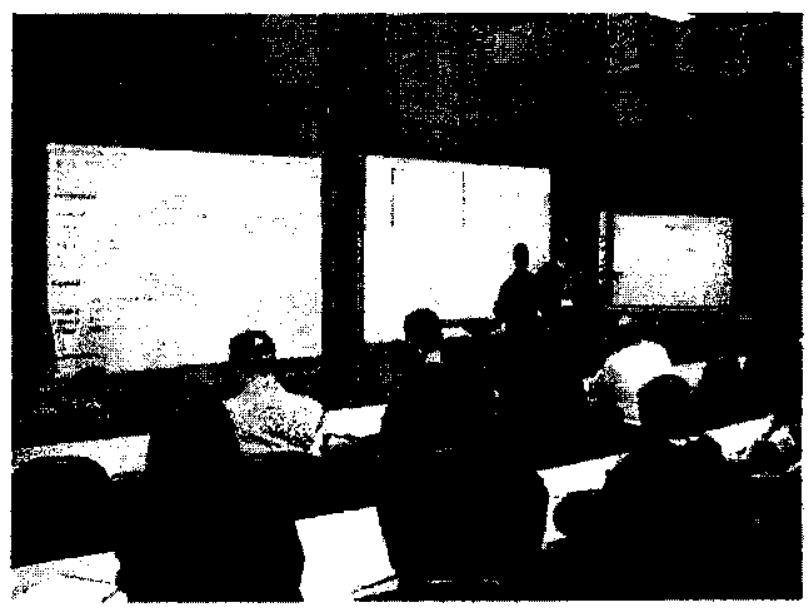

Figura 2.4 - Uma sala típica do ambiente eClass (http://www.cc.gatech.edu/fce/eclass).

\subsection{INFORMAÇÃO MULTIMÍDIA EVOLUCIONÁRIA}

Atividades interativas periódicas que envolvem grupos de pessoas que se reúnem em sessões, tais como reuniões de trabalho regulares, geram novas informações a cada sessão realizada. Entretanto, muitas vezes uma determinada informação só é completa se analisarmos a evolução de sessões passadas. Tal característica deve ser levada em consideração quando se quer automatizar a geração de hiperdocumentos a partir da captura de tais atividades. 
Pelo fato de que cada nova sessão esı́ intrinsecamente relac „onada com outras que fá ocorreram, há a necessidade de que o repositório de informações gerado a partir da captura destas sessões seja capaz de expressar o relacionamento intrínseco entre elas. Com base nisso, é possível a identificação de duas características importantes associadas a este tipo de atividade (Pimentel et al., 2000a) (Pimentel et al., 2001):

- Expansão progressiva: o repositório de informações tende a se expandir continuamente durante todo o tempo da aplicação, sendo esta expansão associada a contribuições dos participantes e que podem ocorrer durante, antes ou depois de cada sessão de captura;

- Referência intrínseca: o material que foi gerado em qualquer destas três fases (antes, durante ou depois do processo de captura) pode referenciar materiais gerados anteriormente.

Por tais características, as tarefas associadas à manipulação dessas informações têm uma certa complexidade, tarefas essas que incluem o armazenamento, a recuperação e a visualização dos dados gerados durante a fase de captura.

Ilustrativamente, tal processo pode ser visualizado através de uma espiral crescente (Pimentel et al., 2001) que denota o crescimento dos dados contidos em um repositório. A informação resultante é referida como uma informação multimídia evolucionária. A Figura 2.5 exemplifica tal processo.

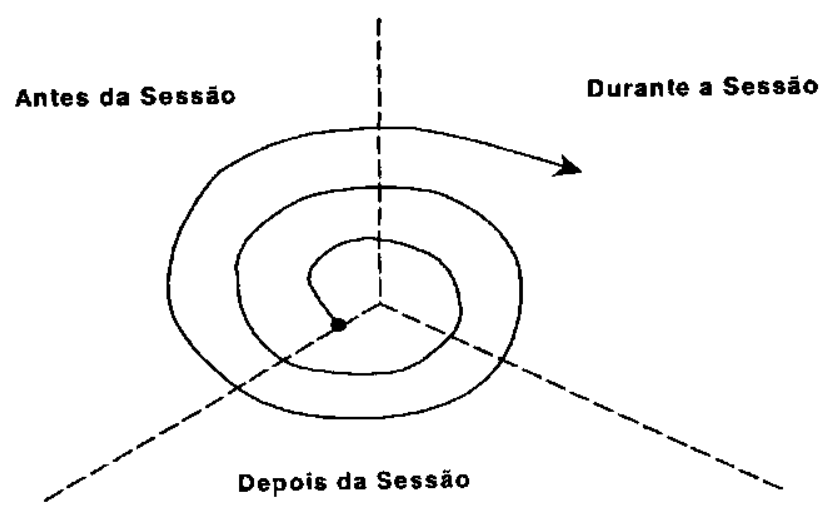

Figura 2.5 - Espiral representando o crescimento contínuo e concêntrico da informaçāo multimídia evolucionária (Pimentel et. al., 2001). 


\subsection{A INFRA-ESTRUTURA INCA-SERVE}

O suporte à informação hipermídia evolucionária está sendo investigado no contexto do projeto InCA-SERVE (Pimentel et al., 1999), descrito a seguir.

\subsubsection{A Infra-estrutura $\ln C A$}

Baseado no módulo de captura e integração de atividades interativas do eClass, está sendo construída uma estrutura mais escalável, extensível e flexível denominada $\ln C A$ (Truong et al, 2001). Além de viabilizar a captura de atividades realizadas em tempo real (ao vivo), essa estrutura deverá prover um modelo de informação extensível para a captura e armazenamento das experiências interativas, suportando informações multimídias evolucionárias.

A infra-estrutura original desenvolvida e implementada pelos pesquisadores da Georgia Tech para o ambiente $e$ Class tem por finalidade suportar o ambiente das atividades envolvidas em uma sala de aula. O trabalho aqui apresentado, o eMeet/InCA, é parte da infra-estrutura $\ln C A$ para o suporte à captura de reuniões distribuídas.

\subsubsection{A Infra-estrutura SERVE}

Uma camada acima da infra-estrutura $\ln C A$ tem-se a infra-estrutura SERVE, que explora os serviços da $\ln C A$ para o armazenamento (Store), extensão (Extend), recuperação (Retrieve) e visualização (Visualize) da informação evolucionária (Evolutionary). Essa infra-estrutura tem por finalidade servir a informação capturada aos usuários, além de suportar serviços especializados oferecidos fora da sessão de captura. No contexto da ferramenta eMeet, foi desenvolvida a ferramenta eMeet/SERVE, responsável pela visualização da informação capturada pelo eMeet/InCA na forma de hiperdocumentos multimídia. A uniāo eMeet/InCA e eMeet/SERVE é que forma a aplicação $e M e e t$ de suporte a reuniões distribuídas. 


\section{5 .3 eMeet}

O presente documento aborda a porção InCA (responsável pela captura, armazenamento e difusão das mídias utilizadas no projeto) do eMeet, referenciada por eMeet/InCA no restante deste texto. O trabalho realizado por Pedro Monteiro da Silva Eleutério é a porção SERVE da aplicaçāo, chamada de eMeet/SERVE (Eleutério \& Pimentel, 2001).

A Figura 2.5 mostra a estrutura lógica da aplicação eMeet implementada e a divisão do trabalho realizada dos participantes do projeto. O eMeet/InCA pode ser visto como o primeiro quadrado da esquerda para a direita, enquanto que o eMeet/SERVE o quadrado a direita.

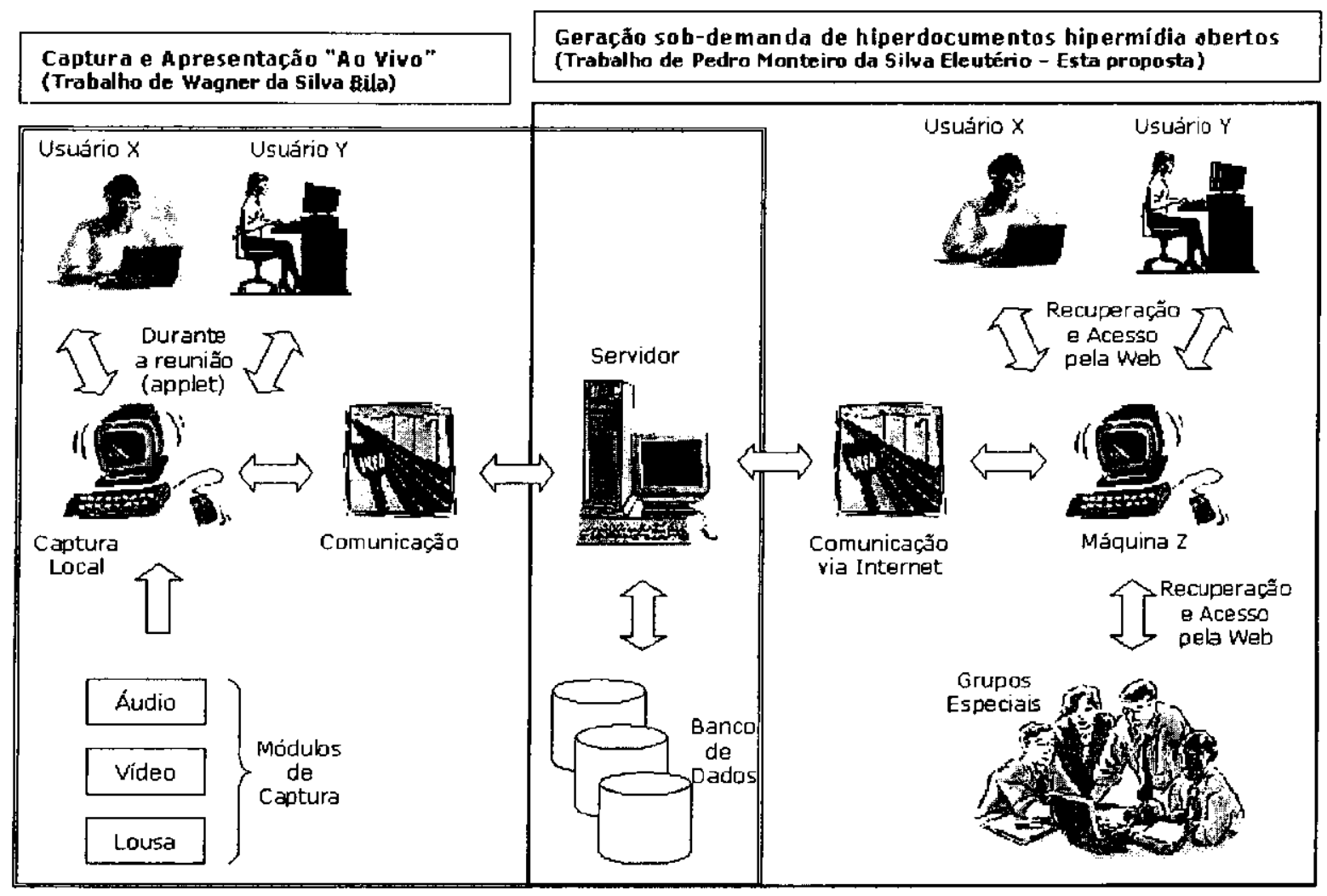

Figura 2.6 - A aplicação eMeet para suporte a reuniões e a divisão de trabalho entre os participantes Wagner da Silva Bila $(e M e e t / I n C A)$ e Pedro Monteiro da Silva Eleutério (eMeet/SERVE).

\subsection{CONSIDERAÇÕES FINAIS}

Suporte de reuniões é um dos domínios de aplicação que tem sido explorado pela área de computação ubíqua. O Projeto InCA-SERVE tem por objetivo investigar os problemas associados 
a construção de infra-estruturas para captura e acesso ce informação multimídı em ambientes instrumentados para a posterior geração de hiperdocumentos multimídia associados. $O$ eMeet/InCA e o eMeet/SERVE correspondem a generalizações do contexto de captura, armazenamento e acesso do eClass, uma aplicação desenvolvida para ambientes de sala de aula tradicionais. O projeto $e M e e t$ implementa a construção das porções das infra-estruturas INCA e $S E R V E$ para o suporte a reuniões distribuídas. O trabalho reportado se desenvolveu no contexto do $e M e e t / I n C A$.

Os próximos capítulos abordam detalhes quanto aos requisitos necessários para a implementação, as tecnologias adotadas para o desenvolvimento do projeto eMeet/InCA, bem como sua arquitetura lógica e estrutural. 


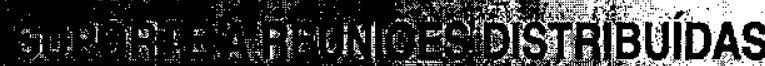

\subsection{CONSIDERAÇÕES INICIAIS}

Neste capítulo são introduzidos os conceitos de trabalho cooperativo com o auxílio do computador (Computer Supported Cooperative Work, ou simplesmente CSCW), são apresentados trabalhos que têm por finalidade o suporte a reuniões distribuídas e que se enquadram como ferramentas de suporte á decisão (GDSS - Group Decision Support System) ou salas eletrônicas. Também são apresentadas ferramentas de videoconferência que utilizam protocolos padrões para o compartilhamento de documentos, whiteboards e transmissão de áudio e vídeo, empregando protocolos regulamentados oficialmente pela ITU (International Telecommunication Union) e CCITT (Comite Consultatif International Telegraphique et.) e que foram desenvolvidos especialmente para a transmissão de áudio e vídeo. A investigação de todas essas aplicações é que possibilitou uma visão geral das tecnologias existentes e que são empregadas na construçāo de ferramentas de suporte a reuniões cooperativas distribuídas, bem como as principais técnicas utilizadas para o suporte à decisão, influenciando a modelagem do eMeet/InCA.

\section{$3.2 \mathrm{CSCW}$}

Muitas das atividades humanas necessitam de mais de uma pessoa para que possam ser realizadas (Macaulay, 1995). Para que as pessoas envolvidas possam trabalhar cooperativamente e interagir entre si, sendo em locais geograficamente iguais ou distribuídos, há a necessidade de que exista um ambiente para o apoio à comunicação entre elas. A um ambiente computacional que proporcione isso e que implemente processos de apoio à cooperação, possibilitando a produção em conjunto e a troca de informações, denomina-se groupware (Ellis et al., 1991). Assim, groupware permite o trabalho cooperativo suportado por computador (CSCW Computer-Supported Cooperative Work) (Borges et al,, 1995) ${ }^{3}$. No nosso dia a dia utilizamos

\footnotetext{
${ }^{3}$ Com base nessa asserção, o $e$ Meet/lnCA é uma aplicação groupware.
} 
aplicações típicas CSCW como e-mail, chat, videoconferênu a e sistemas de co-uutoria colaborativa, como o serviço CoWeb (Guzdial, 1999) (Arruda Jr., 2001). Quanto ao ambiente computacional que apóia as tarefas de ensino e aprendizagem em grupo, pode ser classificado como um sistema cooperativo apoiado por computador (CSCL - Computer Supported Cooperative Learning) (Borges et al., 1995). O eClass é considerado como sendo um sistema CSCL.

Em CSCW pode-se considerar um grupo como sendo uma coleção de pessoas que trabalham juntas numa tarefa comum, podendo ser formado por um número fixo ou variável de indivíduos. Um encontro de membros do grupo que estão presentes fisicamente no mesmo local, é denominado encontro face-a-face. Como os membros de um grupo nem sempre estão no mesmo local de trabalho, ao mesmo tempo, e interagindo com os outros, a introdução de recursos computacionais para o trabalho cooperativo introduziu novas possibilidades de trabalho: em locais e tempos diferentes. Ellis et al (1991) classificam os sistemas CSCW de acordo com distribuição geográfica e temporal integrantes do grupo. Tal classificação pode ser vista na Figura 3.1.

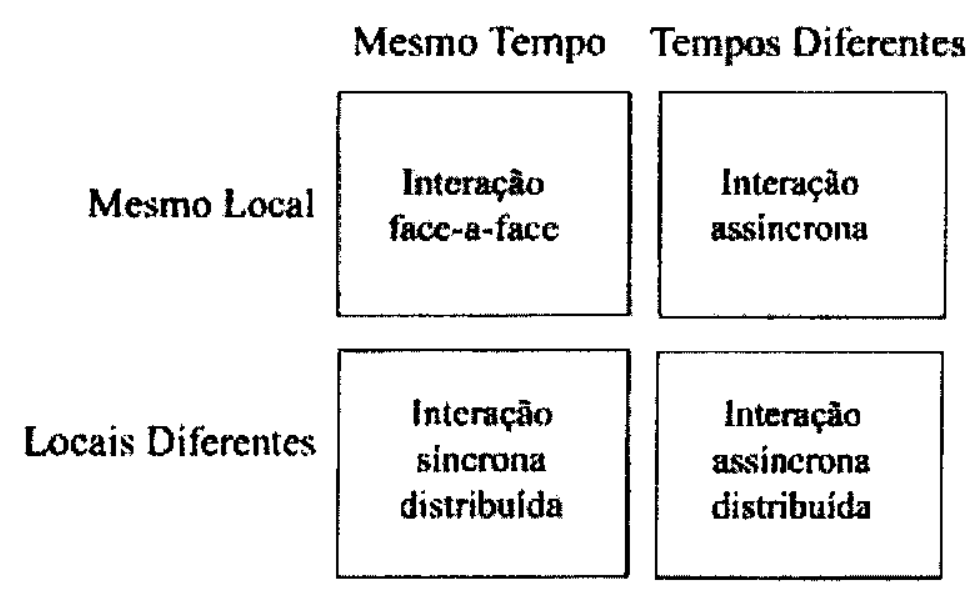

Figura 3.1 - Classificação espaço/tempo dos sistemas CSCW (Ellis et al., 1991)

Quanto à distribuição geográfica, um sistema pode ser presencial ou não-presencial. Um sistema presencial é aquele no qual os membros do grupo estão presentes fisicamente no mesmo local, enquanto que no sistema não-presencial os membros estão em locais diferentes. Já quanto à classificação temporal, um sistema pode ser síncrono ou assíncrono. Síncrono quando as interações ocorrem em tempo real e assíncrono quando as interações ocorrem em tempos diferentes. 
Analisando-se a Figura 3.1, pode-se notar que interações face-a-face ocorrem no mesnıo local e ao mesmo tempo. Já as interações assíncronas ocorrem no mesmo local mas em tempos diferentes. As interações síncronas distribuídas podem ocorrer em vários locais e ao mesmo tempo, enquanto que interações assíncronas distribuídas ocorrem em tempos e locais distintos. Exemplos de interações assíncronas, síncronas distribuídas e assíncronas distribuídas são, respectivamente, quadro de avisos, videoconferência e sistema de $e$-mail eletrônico.

Com base na classificação descrita, o eClass só não possui características de um sistema com interação síncrona distribuída, e é o que este trabalho pretende focar com a implementação do $e M e e t / I n C A$.

A não restrição quanto a tempo e espaço é a principal motivação para a criação e implementação de sistemas cooperativos (Grudin, 1994). Porém, esta não é a única motivação para o desenvolvimento de tais ambientes computacionais que apóiam o trabalho cooperativo (Macedo et al., 1999):

- Pessoas menos extrovertidas podem ser ouvidas e contribuírem para a decisão do grupo, pois o ambiente computacional é impessoal e mais amigável;

- Pessoas mais extrovertidas têm possibilidades menores de dominar as discussões, pois as chances de participações são iguais para todos os participantes;

- Os coordenadores (ou mediadores) das sessões ou os próprios participantes delas podem acompanhar melhor o desempenho e desenvolvimento do trabalho, uma vez quc as contribuições podem ser armazenadas no sistema para serem analisadas posteriormente pelos participantes;

- As pessoas do grupo podem observar estratégias de aprendizagem dos seus próprios companheiros de grupo.

\subsection{SISTEMAS DE SUPORTE À DECISÃO}

Nesta seção serão abordadas as ferramentas de suporte à decisão IBIS (Conklin \& Begeman, 1987), QOC (MacLean et al., 1991), DRL (Lee \& Lai, 1991), TELEP (Jancke et al., 2000), FORUM (Isaacs et al., 1994), FLATLAND (White et al., 1998), TeamWorkstation (Ishii et al., 1994) e o ClearBoard (Ishii et al., 1994). A análise dessas ferramentas possibilitou uma visão clara dos mecanismos de suporte à decisão que o $e M e e t / \operatorname{lnCA}$ deveria implementar, como por exemplo, um mecanismo de votação. 


\subsubsection{IBIS}

O IBIS (Issue-Based Information System) (Conklin \& Begeman, 1987) foi desenvolvido na década de 80 por Horst Rittel e é um ambiente hipertexto para a discussão estruturada de resultados de projeto. O sistema usa um esquema rigoroso de classificação para a organização dos dados. Existem três tipos de nós (resultados, posições e argumentos) e oito tipos de links (respostas a, questões, suporte, objetos para, especialização, generalização, referência a e trocas). Tais elementos foram projetados para serem utilizados na análise de "problemas perversos" : "Problemas perversos têm uma lacuna de formulação definitiva, sendo que o espaço desses problemas não pode scr figurado sem a compreensão dos elementos de solução. Assim sendo, a única maneira para a real comprecnsão de problemas perversos é através de suas resoluções." (Conklin \& Begeman, 1987)

Em 1987, o IBIS já rodava em computadores da linha Apple, mas não suportava gráficos, pesquisas, caminhos, mapas ou atributos de ligação. Begeman e Conklin desenvolveram, posteriormente, o gIBIS, uma versão gráfica do IBIS que rodava em estações Sun. O software dividia o display em quatro janelas fixas, exibindo simultaneamente um mapa (global e local), um índice, conteúdo dos nós e controle do painel. O gIBIS é um ambiente sofisticado no qual inclui-se clusters de nós de ligação, menus sensíveis ao contexto, índices múltiplos (assunto, autor, palavra chave, título), configuração do usuário, filtro de ligações, consultas simples, acesso multiusuário e ponteiros para objetos externos. A Figura 3.2 exemplifica a utilização gráfica do IBIS para a resolução do problema de escolha de um novo sistema computacional. As alternativas $\mathrm{X}$ e $\mathrm{Y}$ são propostas, porém $\mathrm{X}$ tem o empecilho de não suportar os softwares existentes atualmente e $\mathrm{Y}$ é tido como o estado da arte tecnológica. Os ícones representam nós IBIS : "?" significa uma questão, uma lâmpada significa uma idéia (idéias respondem a uma pergunta), “-“ indica um objeto com característica negativa e “+” com característica positiva.

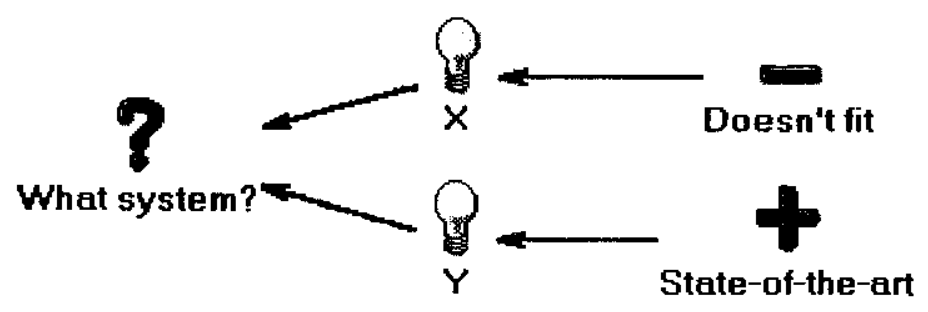

Figura 3.2 - A notação IBIS gráfica ( $($ IBIS) e um exemplo de diagramação de um problema de tomada de decisão (http://www.gdss.com/wp/IBIS.htm). 


\subsubsection{QOC (Questions, Options, and Criteria)}

O QOC (Questions, Options, and Criteria) é uma notação que foi proposta no começo da década de 90 para dar suporte à racionalização da tomada de decisões de um grupo de uma maneira estruturada (MacLean et al., 1991). A notação QOC pode ser utilizada para a criação de um gráfico que representa justificativas que se baseiam em decisões de desenvolvimento.

As Figuras 3.3 e 3.4 mostram exemplos de diagramas QOC para dois tipos de problemas, apresentando questões, as opções de escolha e os critérios para se determinar a melhor solução. De uma maneira geral os gráficos possuem três colunas, cada qual contendo, da esquerda para a direita, questões, opções e critérios de escolha, respectivamente.
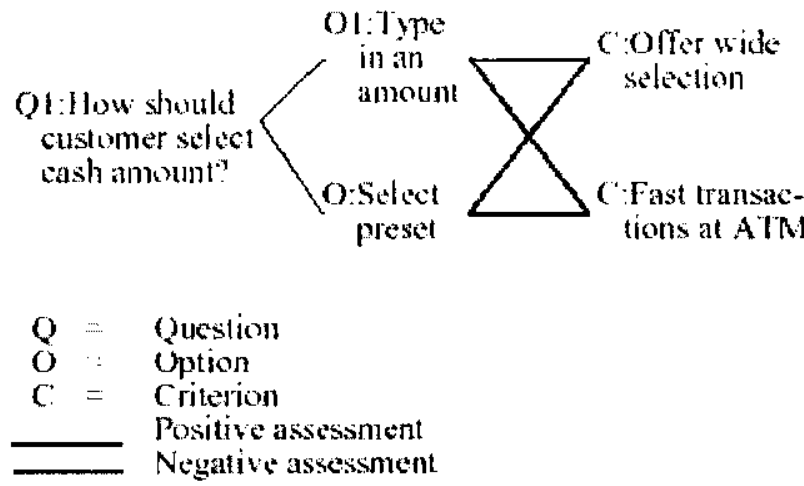

Figura 3.3 - Diagrama QOC para a decisão de quanto dinheiro um cliente deve ter para poder implementar uma rede ATM (http://www.xrce.xerox.com/publis/cam-trs/pdf/1991/epc1991-136.pdf).

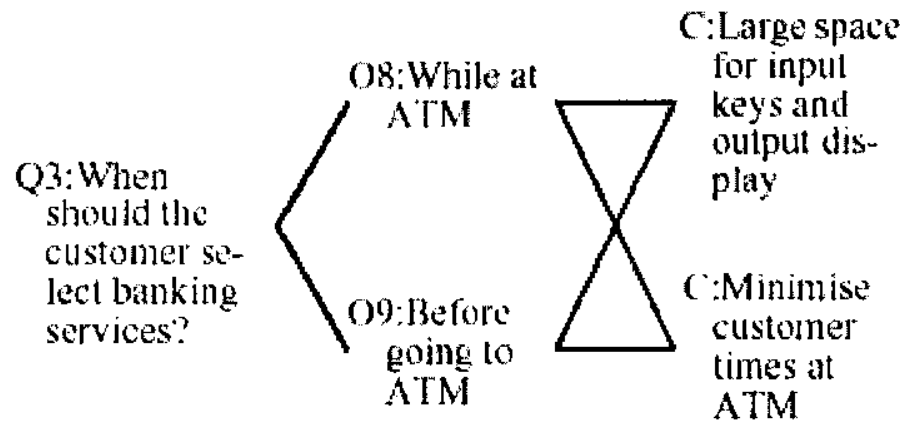

Figura 3.4 - Diagrama QOC para a tomada de decisão quando um cliente pensa em recorrer a serviços bancários (http://www.xrce.xerox.com/publis/cam-trs/pdf/1991/epc-1991136.pdf). 


\subsubsection{DRL (Decision Representation Language)}

O DRL (Decision Representation Language) também é um método proposto para dar suporte à racionalização da tomada de decisões de um grupo de uma maneira estruturada (Lee \& Lai, 1991). Há a introdução de novas construções (como, por exemplo, o nó do tipo "objetivo") que permitem aos participantes explorarem alternativas e reclamações, bem como contestar através de perguntas e opiniões. O DRL também pode ser mapeado em notação QOC. A Figura 3.5 mostra a utilização da linguagem para a decisão de um problema.

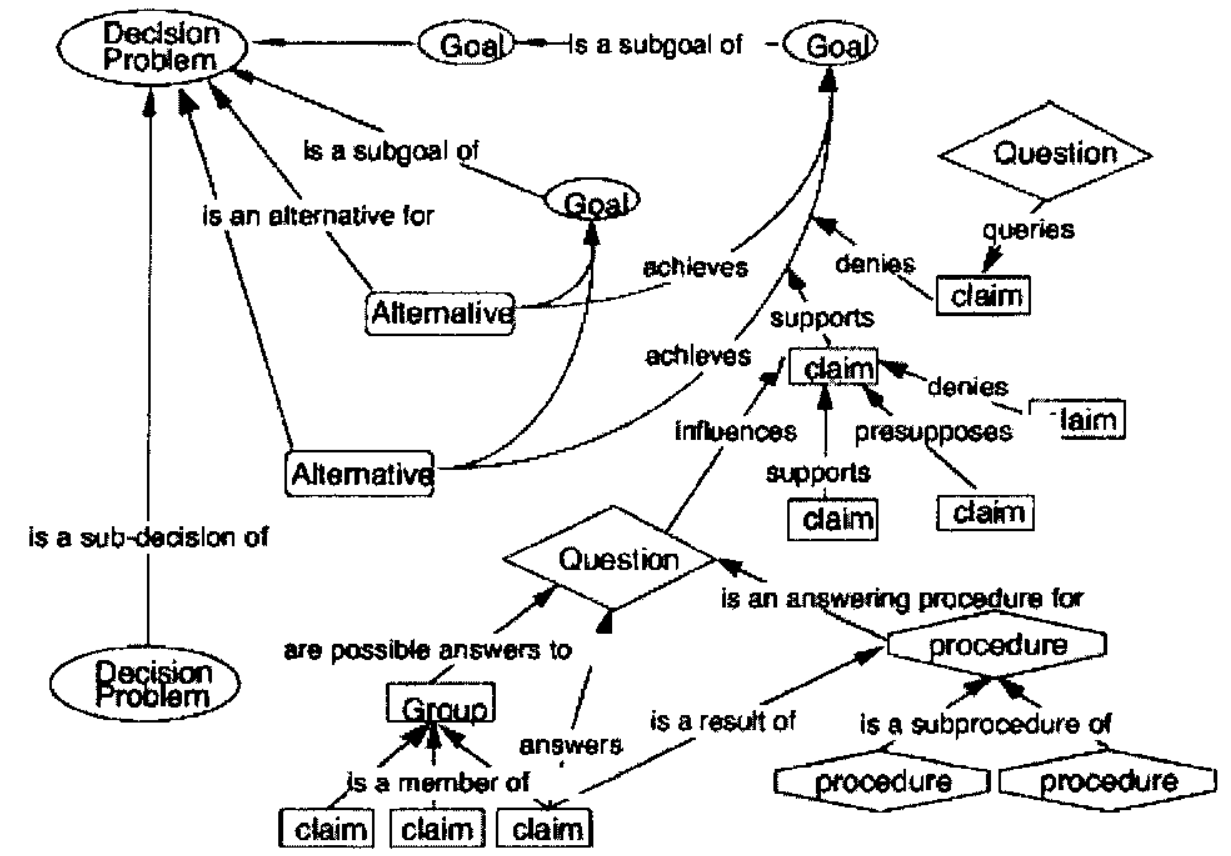

Figura 3.5 - Diagrama da Linguagem de Representaçāo de Decisão (DRL) que conta com questōes e decisōes de problemas para a chegada aos objetivos desejados (Lee \& Lai, 1990).

\subsubsection{TELEP}

O TELEP (Telepresence) é um sistema desenvolvido para prover aos palestrantes e platéias uma grande interatividade em reuniões distribuídas (Jancke ct al., 2000). O sistema foi inicialmente utilizado para seminários e teve uma ótima aceitação pelo público atingido. 
O TELEP possui muitas características importantes que deveriam estar cın outras ferramentas de auxílio às reuniões distribuídas, e que são interessantes de serem empregadas no $e M e e t / l n C A$. Os objetivos iniciais do projeto, segundo (Jancke et al., 2000), foram:

- Atender apresentações com um público ao vivo na sala de aula e um público remoto em computadores desktops;

- A interface com a sala, onde se desenvolve a apresentação, deve beneficiar tanto ao palestrante quanto ao público;

- Atender um público remoto de média escala (menos de 100 pessoas), com acesso ao computador mas não necessariamente com uma câmera e microfone;

- Suportar um visitante sem experiência prévia com o TELEP. O visitante não deve utilizar o teclado;

- Executar em uma rede com banda e requisitos computacionais adequados para a execução do sistema TELEP; portanto, é mais conveniente a utilização de difusão multicasting de dados pela rede e menor resolução de vídeo aos participantes remotos.

Um diagrama esquemático da estrutura do sistema TELEP é apresentado na Figura 3.6. Nele estão representados os clientes remotos (parte inferior da figura) e a sala de palestra (parte superior), onde se localiza o apresentador. Existem dois sistemas que são executados em paralelo. O primeiro, que é mostrado no lado esquerdo da figura e faz a difusão a vários participantes de uma apresentação passiva. Há a captura das streams de áudio e vídeo geradas pelo palestrante que são difundidas para os participantes remotos. A difusão é baseada no Windows Media Server $^{\circledR 4}$, juntamente com os slides. O segundo sistema é mostrado no lado direito da figura, sendo responsável pela produção da imagem dos participantes remotos, suas questões e uma pequena janela para os participantes remotos, como pode ser visto a esquerda da Figura 3.7. A difusão desses dados é feita através de um servidor de colaboração ou através de um sistema multicast de difusão de vídeo, caso a comunicação multicast seja suportada entre os participantes.

\footnotetext{
${ }^{4}$ http://www.microsoft.com
} 


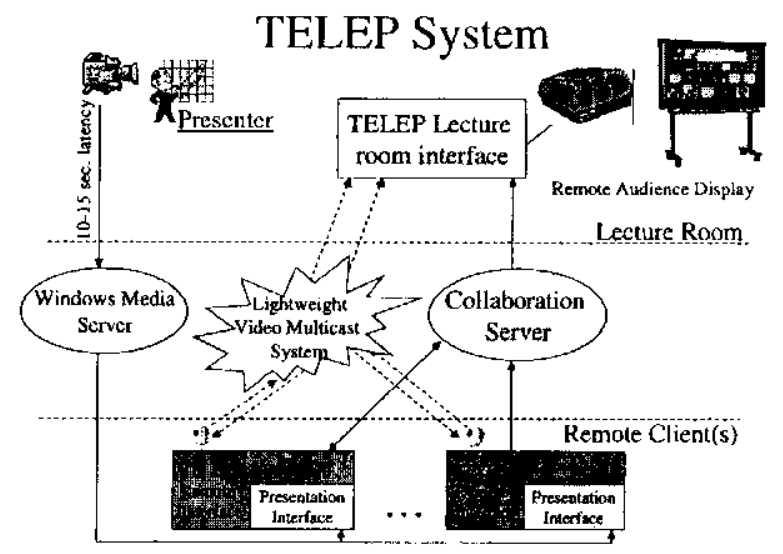

Figura 3.6 - Uma visāo geral da estrutura do sistema TELEP (Jancke et al., 2000).

O sistema possui uma interface bem amigável com o usuário participante da reunião, como pode ser visto na Figura 3.7, podendo-se visualizar c ouvir o palestrante, ver páginas web visitadas e slides utilizados.

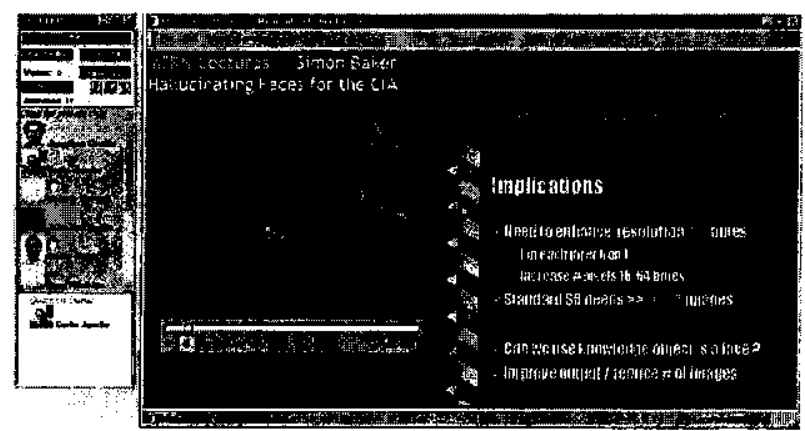

Figura 3.7 - Visão de um usuário remoto do sistema: janela do TELEP à esquerda, a página da web com video, áudio e slides à direita (Jancke et al., 2000).

No display de sala de apresentação do sistema é possível a visualização dinâmica de cada participante do evento, como mostra a Figura 3.8. Já nas Figuras 3.9 e 3.10, vemos as facilidades de pergunta de um participante ao palestrante c chat entre os participantes, respectivamente. 


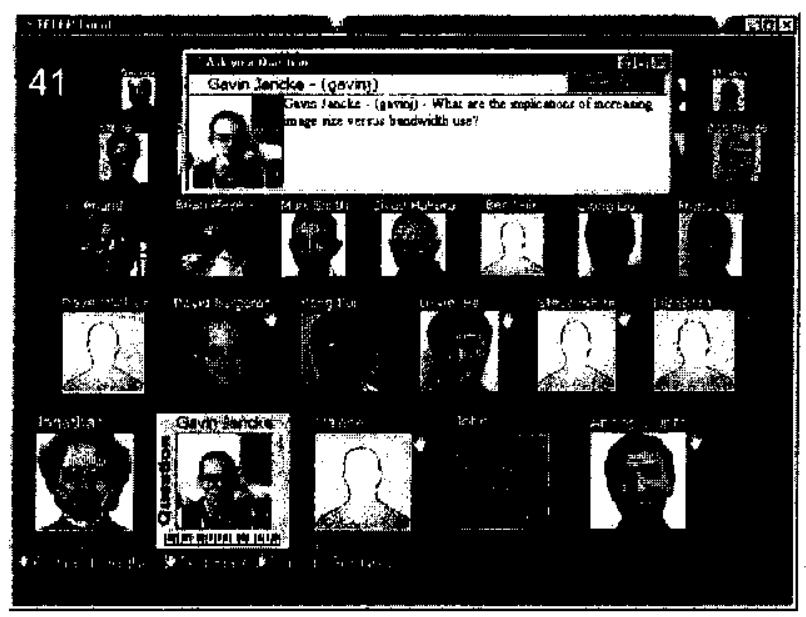

Figura 3.8 - Display de sala de apresentação do sistema TELEP (Jancke et al., 2000).

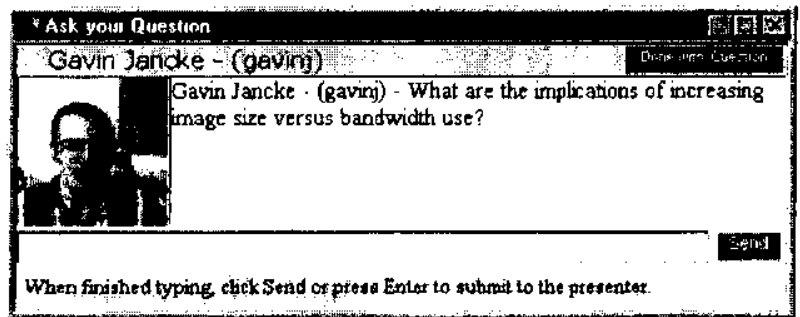

Figura 3.9 - Janela de perguntas dos participantes ao palestrante (Jancke et al., 2000).

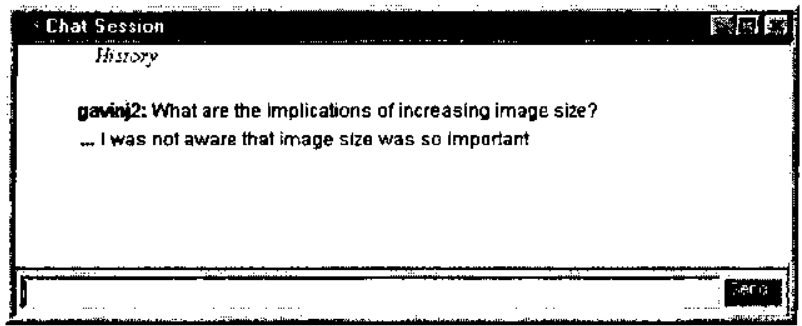

Figura 3.10 - Janela de chat disponivel para os participantes do evento, tornando real as "conversas de bastidores" (Jancke et al., 2000).

Como ferramenta de suporte à decisão, o TELEP implementa um mecanismo de votação. Na tela de cada participante é possível a visualização da resposta a uma determinada pergunta por parte dos outros participantes. Um ícone no formato de uma mão é mostrado do lado direito de cada participante a fim de ficar claro a sua posição mediante a uma pergunta realizada. Tal interface de votação é mostrada na Figura 3.11. 


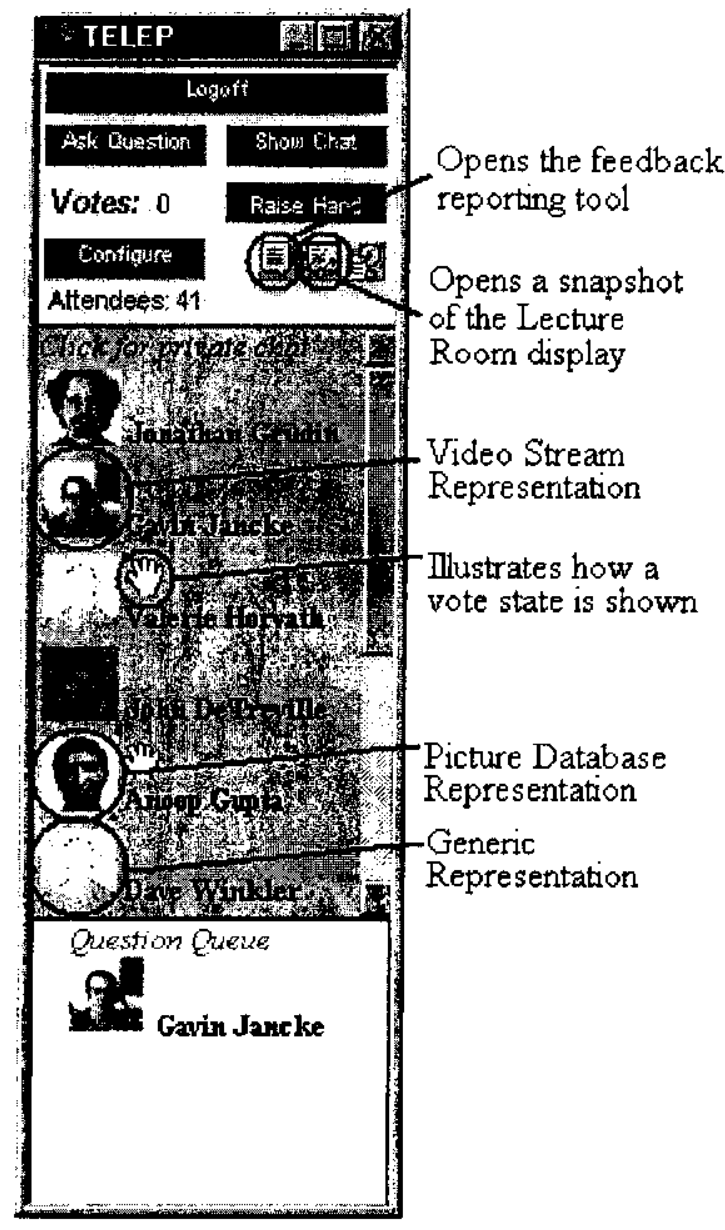

Figura 3.11 - Mecanismo de votação implementado no sistema TELEP (Jancke et al., 2000).

\subsubsection{FORUM}

O projeto FORUM, da Sun Microsystems (Isaacs et al., 1994), é uma ferramenta que faz a difusão (broadcast) de áudio, vídeo e slides, em tempo real, de um orador, sendo possível que a platéia interaja com o orador ou com participantes da própria platéia de diversas maneiras. Segundo (Isaacs et al., 1994), o maior desafio foi possibilitar interações efetivas ao mesmo tempo em que grandes obstáculos eram introduzidos pela natureza distribuída do ambiente, 0 grande número de participantes do grupo e o papel assimétrico dos participantes.

O FORUM, cuja interface é mostrada na Figura 3.12, teve grande sucesso em possibilitar apresentações efetivas nos casos em que o tópico abordado demandava uma grande interação com o público ou quando o propósito da conversa era meramente informal e nāo demandava 
grande atenção dos participantcs. Ainda hoje existem projetos de exploração e melhorias do projeto FORUM.

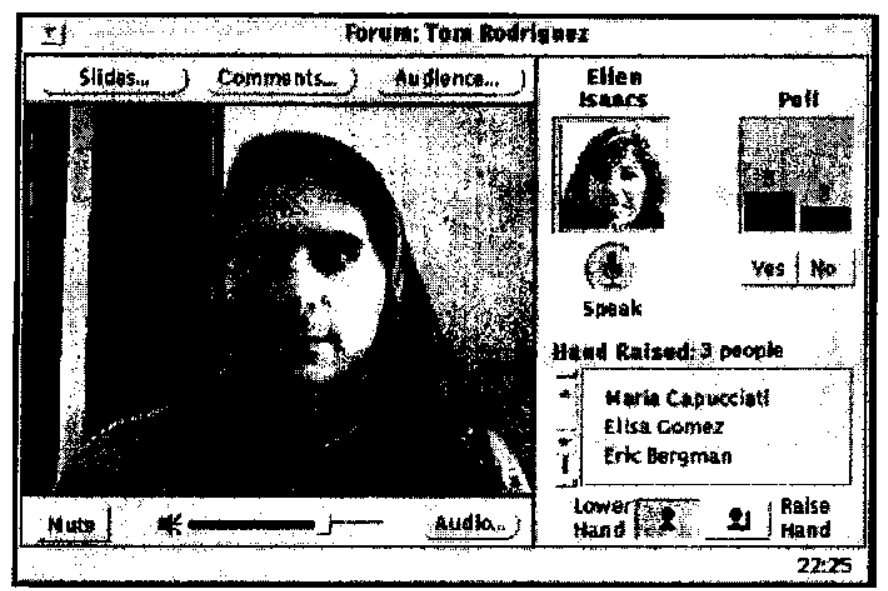

Figura 3.12 - Interface do sistema FORUM da Sun Microsystems com seus participantes (http://research . sun.com/coco/forum/ForumHome.html).

\subsubsection{FLATLAND}

FLATLAND (White et al., 1998) é uma aplicação cliente-servidor, multi-thread e distribuída que tenta sobrepujar as latências e sincronização de áudio, vídeo c outras streams de difusão ao vivo. Também é um ambiente robusto de prototipação, facilitando o teste de características e interfaces de novos projetos.

O FLATLAND foi construído com base em várias tecnologias existentes. Utiliza-se das streams de áudio e vídeo do Microsoft NetShow ${ }^{\odot 5}$, com uma coleção de mecanismos de feedback que permitem ao apresentador receber respostas de seus participantes. A Figura 3.13 mostra o layout da tela principal do FLATLAND, segundo a visão do apresentador. O público também tem uma visão similar mas sem algumas das funcionalidades de controle.

\footnotetext{
${ }^{5} \mathrm{http}: / / \mathrm{www}$. microsoft.com/windows/windowsmedia/default.asp
} 


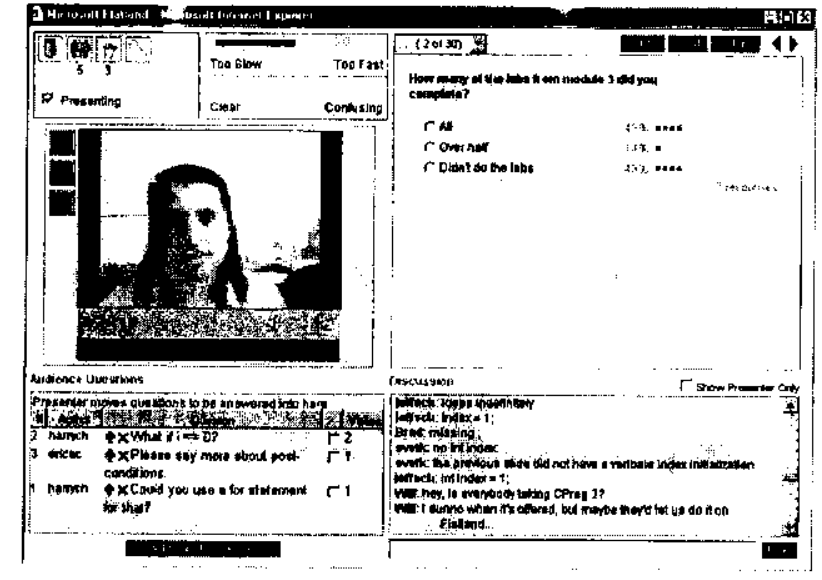

Figura 3.13 - Layout da tela principal do FLATLAND (White et al., 2000).

A Figura 3.14 mostra os componentes do FLATLAND e seus relacionamentos. O apresentador (parte superior direita da figura), comunica-se com o público utilizando o NetShow video e alguns módulos do Flatland (centro da figura). Os participantes (parte inferior da figura) podem passar questões, respostas e requisitar respostas do apresentador.

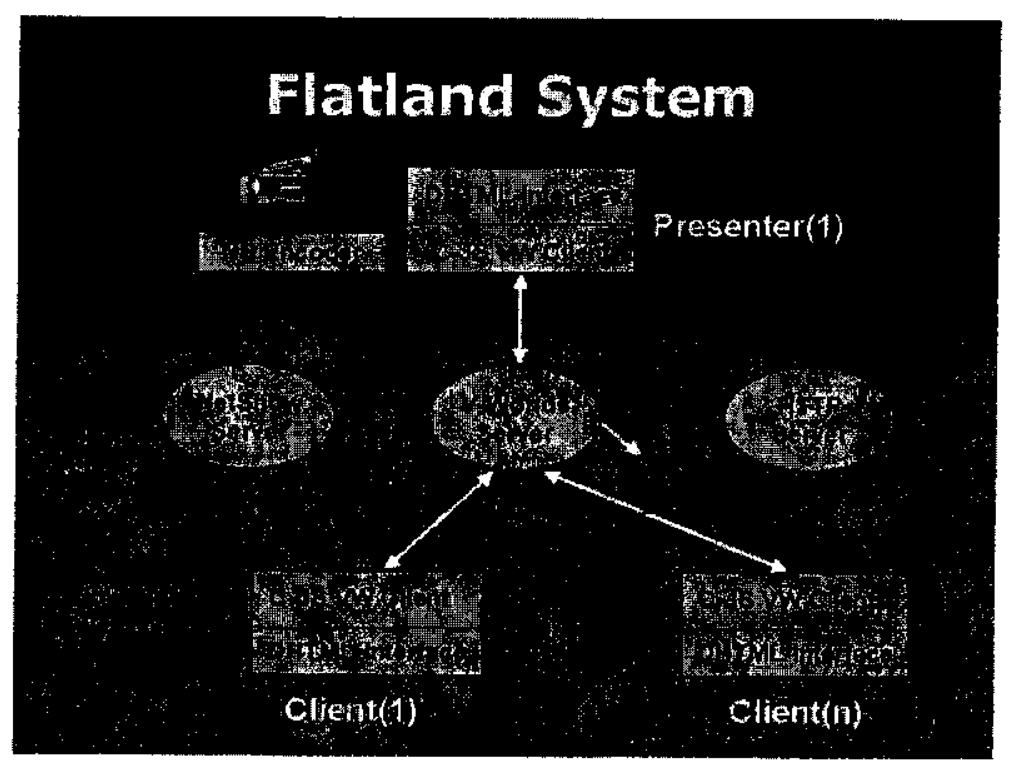

Figura 3.14 - Componentes do sistema FLATLAND e suas relações (White et al., 2000).

\subsubsection{TeamWorkstation}

Geralmente, em um projeto envolvendo um grupo de pessoas, grande parte do trabalho é feita sem o auxílio dos computadores ou utilizando-se diversos sistemas computacionais, fazendo com 
que o grupo desenvolva seu próprio critério de desenvolvimentu. O uso de uma prancheta de trabalho, mesmo quando é utilizado um sistema computacional em conjunto, é muito freqüente e nenhum dos dois pode substituir um ao outro. Portanto, quando se deseja criar espaços de trabalhos compartilhados em tempo real, dependendo da tarefa e da mídia de informação a ser compartilhada (papel ou arquivo de computador), os co-autores podem escolher entre computadores ou pranchetas, e trocar de um para outro livremente. A escolha de uma pessoa deveria ser independente das demais. Membros de um grupo deveriam poder usar uma variedade de ferramentas heterogêneas (ferramentas manuais e baseadas em computador) no espaço de trabalho compartilhado e simultaneamente. Para realizar tais objetivos, foi desenvolvido o TeamWorkStation-1 (TWS-1) (Ishii et al., 1994).

As Figuras 3.15 e 3.16 ilustram o TeamWorkStation- 1 em utilização. O sistema consiste em um monitor que possibilita a visualização dos co-autores, juntamente com a informação de áudio gerada por cada participante, e o compartilhamento de documentos que são colocados em uma prancheta. A imagem destes documentos é capturada através de uma câmera de vídeo e transmitida aos outros co-autores do projeto. A imagem resultante é uma sobreposição de todas as informações de vídeo dos co-autores, possibilitando uma autoria simultânea e conjunta.

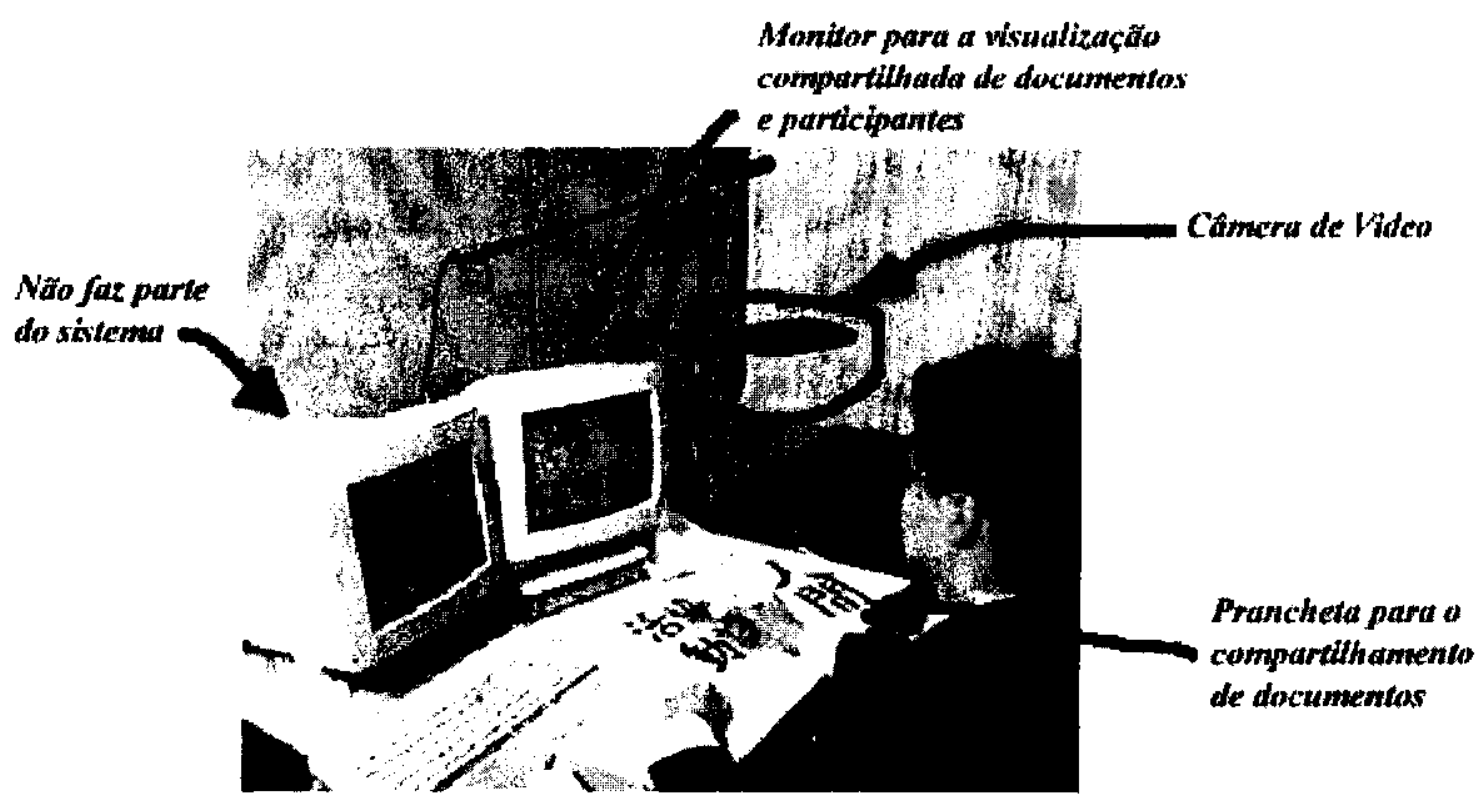

Figura 3.15 - Visão geral do funcionamento e dos módulos do TeamWorkStation-1 (http://web.media.mit.edu/ ishii/TWS.html). 


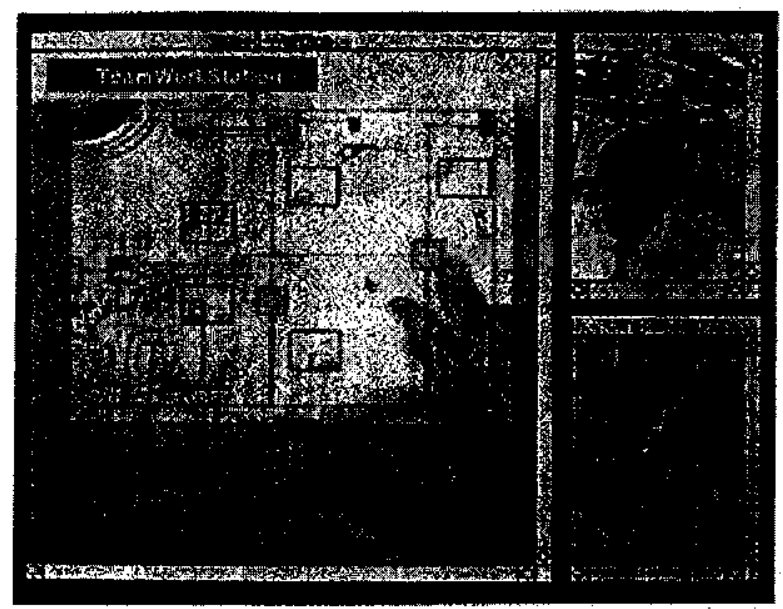

Figura 3.16 - Tela principal do TeamWorkStation-1 com a visualizaçāo dos documentos compartilhados e dos co-autores do projeto (http://web.media.mit.edu/-ishii/TWS.html).

O conceito chave da idéia do TWS-1 é a sobreposição de camadas de imagens individuais de cada ambiente de trabalho. O TWS- 1 combina duas ou mais imagens de vídeo em tempo real das telas físicas dos computadores, usando uma técnica de sintetização de vídco. Camadas translúcidas sobrepostas permitem aos usuários a combinação de seus ambientes de trabalho e o manuseio de ambas as telas, facilitando, assim, a comunicação entre os desenvolvedores.

O aprimoramento do TWS-1 veio com o TeamWorkStation-2 (TWS-2), o qual foi desenvolvido para prover um ambiente em banda larga usando a tecnologia ISDN (N-ISDN). As Figuras 3.17 e 3.18 mostram um exemplo do funcionamento do TWS-2.

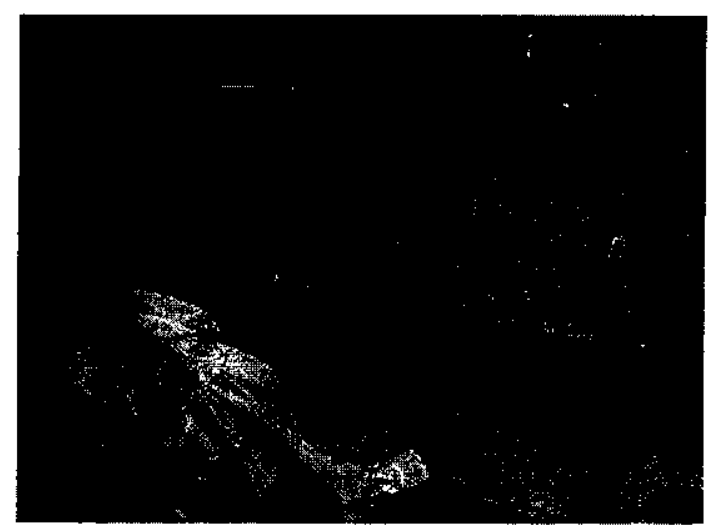

Figura 3.17 - O TeamWorkStation-2 sendo utilizado. O sistema tem os mesmos principios funcionais do TeamWorkStation-1 (http://web.media.mit.edu/ ishii/TWS.html). 


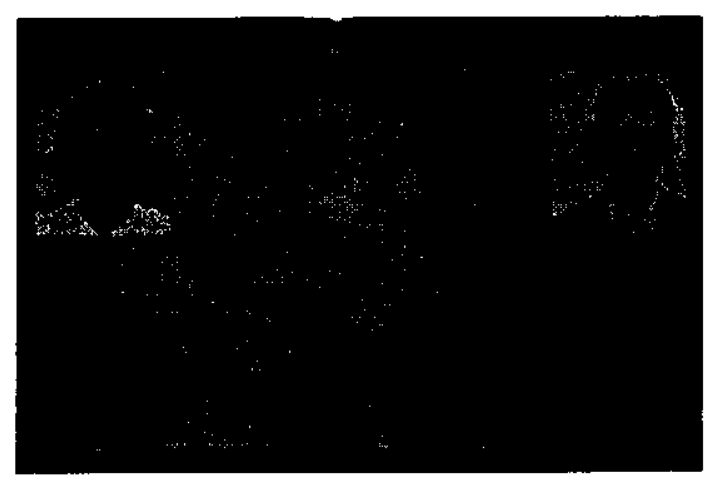

Figura 3.18 - Tela principal do TeamWorkStation-2, mostrandos os desenvolvedores do projeto e suas anotações compartilhadas (http://web.media.mit.edu/ ishii/TWS.html).

\subsubsection{ClearBoard}

O ClearBoard, uma versão aprimorada do TeamWorkStation, foi desenvolvido a fim de integrar espaços interpessoais e ambientes de trabalho compartilhados de forma única (Ishii et al., 1994). O objetivo principal do ClearBoard é permitir que um par de usuários possa mudar de um ambiente de espaço interpessoal e ambientes de trabalho compartilhados usando habilidades familiares do dia a dia como gestos dos parceiros, movimentos da cabeça, contato visual e foco de visualização. A metáfora principal do ClearBoard é a conversa através do desenho em uma grande prancheta de vidro, ilustrado na Figura 3.19. A Figura 3.20 ilustra a utilização do ClearBoard, contando com dois participantes que compartilham anotações.

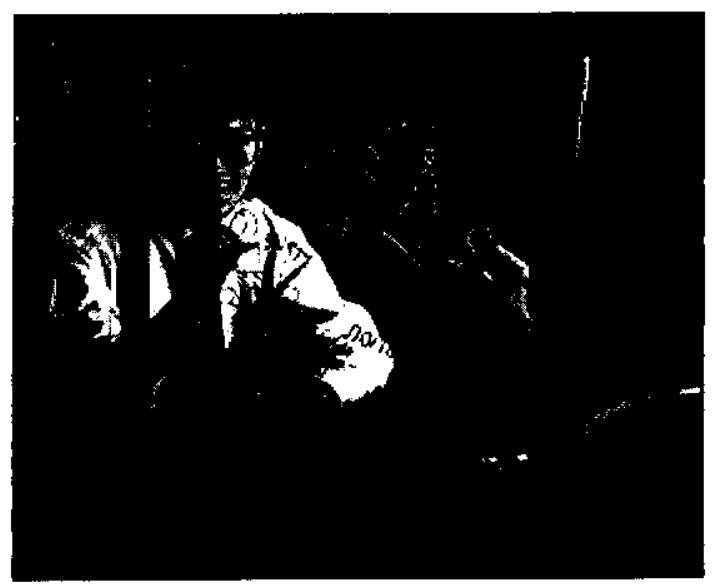

Figura 3.19 - Metáfora do ClearBoard: conversa através do desenho em uma grande prancheta de vidro (http://web.media.mit.edu/ ishii/CB.html). 


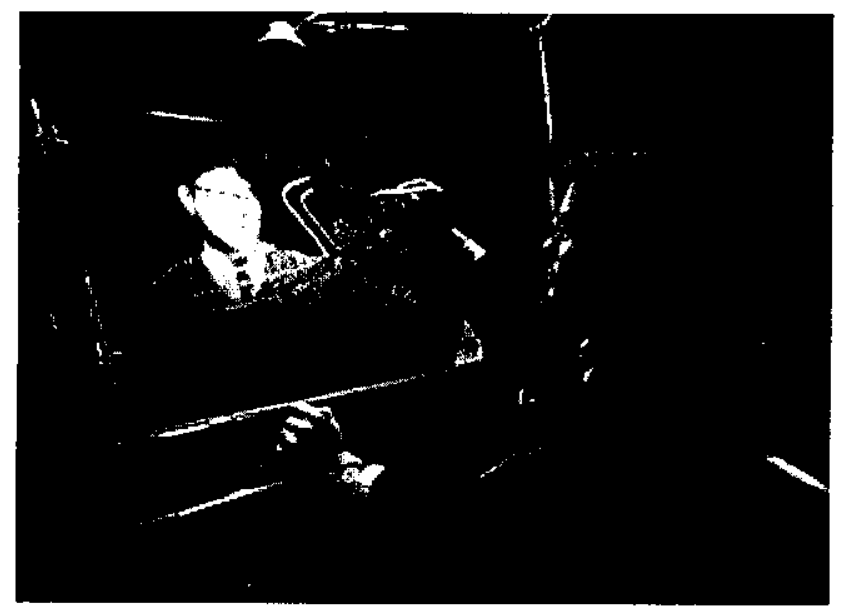

Figura 3.20 - O ClearBoard sendo utilizado em uma interação remota entre dois participantes (http://web.media.mit.edu/ ishii/CB.html).

\subsection{SALAS ELETRÔNICAS}

Nesta seção são apresentados os projetos Cornell Lecture Browser (Mukhopadhyay \& Smith, 1999) e o PlexCenter Planning and Decision Support Laboratory (Ellis ct al., 1991). Ambos são sistemas de salas eletrônicas que foram investigados a fim de agregar conceitos de funcionalidades que poderiam ser utilizados no projeto do eMeet/InCA.

\subsubsection{Cornell Lecture Browser}

O Cornell Lecture Browser é uma aplicação baseada na tecnologia web para a visualização de seminários, palestras, aulas e outros tipos tradicionais de apresentação (Mukhopadhyay \& Smith, 1999). O objetivo principal do Lecture Browser é a automação da criação de apresentações multimídia de alta qualidade. Não há um operador de câmera nem uma edição pós-produção para a criação das apresentações.

O software do Lecture Browser é dividido em três módulos. O módulo de captura, que automaticamente captura as apresentações ao vivo; o módulo de edição, que edita automaticamente o vídeo capturado; e o servidor que mostra o resultado da apresentação multimídia sincronizada através da World Wide Web.

A Figura 3.21 mostra a interface com a qual um usuário acessa uma apresentação multimídia gravada pelo Lecture Browser. Pode-se ver as áreas para a visualização de vídeo, juntamente com a reprodução do áudio, no canto superior esquerdo da figura. A indexação dos 
slides é mostrada na parte inferior, os slides ficam do lado direito e há um banner, que fica na parte superior da figura, e que tem a função de mostrar sobre o que está sendo abordado na palestra.

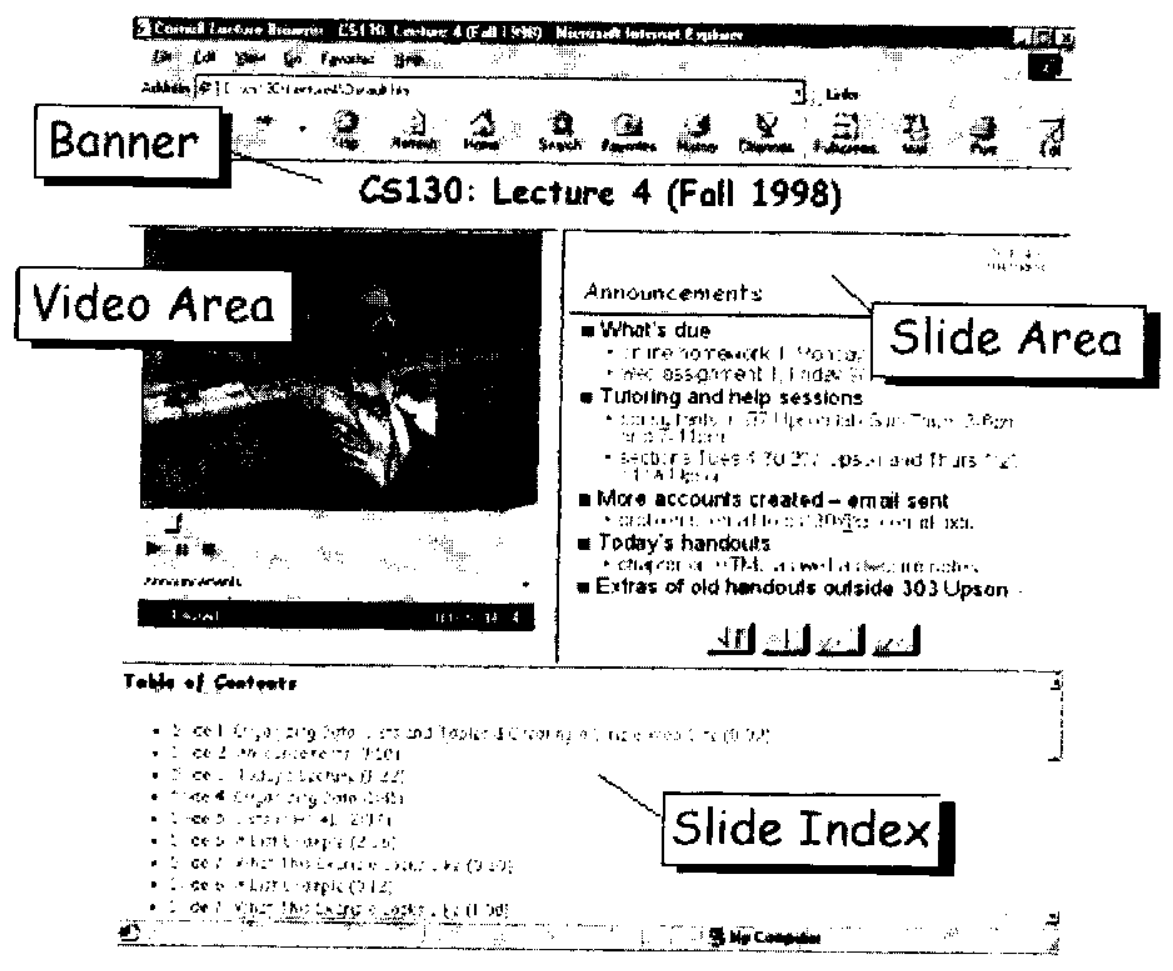

Figura 3.21 - Interface do Cornell Lecture Browser ao usuário, contando com a visualização do palestrante e os slides utilizados (http://www4.cs.cornell.edu/LectureBrowser).

\subsubsection{PlexCenter}

O sistema PlexCenter Planning and Decision Support Laboratory (Ellis et al., 1991), da Universidade do Arizona, foi um sistema composto por uma grande mesa em forma de U com 8 estações de trabalho, um video disk e um sistema de projeção em uma tela grande que poderia mostrar a tela individual de cada estação de trabalho ou uma compilação de todas clas. A mesa era disposta de forma a encorajar a visão e a interação dos usuários. A Figura 3.22 mostra a sala do PlexCenter, chamada de CoLab (Cooperative Laboratory ou Laboratório Colaborativo). 


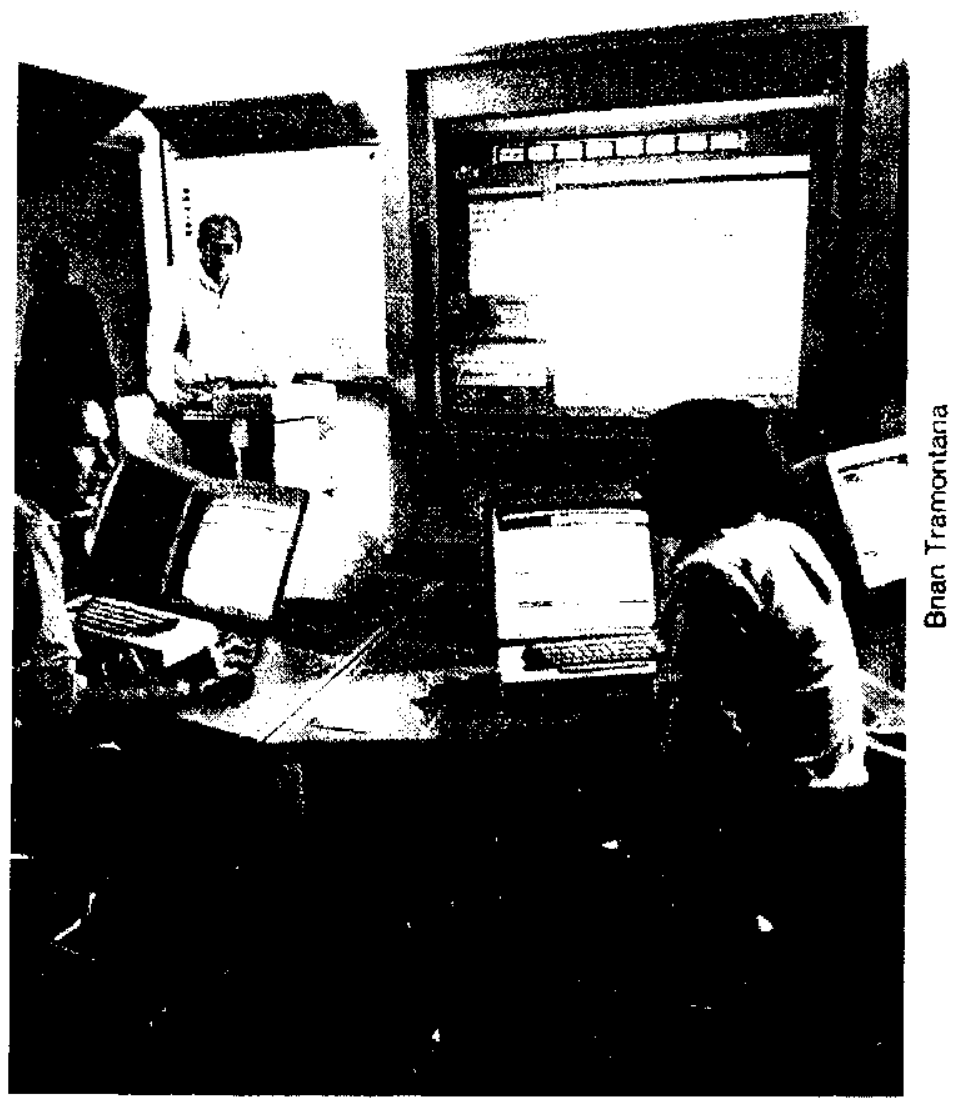

Figura 3.22 - O CoLab, sala do sistema PlexCenter (Ellis et al., 1991).

O sistema PlexCenter pode ser considerado um sistema de reuniões presenciais. O eMeet/InCA também pode ser utilizado para a realização de reuniões presenciais desde que seus participantes estejam localizados em um mesmo ambiente físico. Neste caso, a finalidade do eMeet/InCA é muito parecida a do PlexCenter.

\subsection{SISTEMAS DE VIDEOCONFERÊNCIA}

Nesta seção são abordadas algumas aplicações de videoconferência: o TVS (TeleMídia Videoconferencing System) (Oliveira, 1996), o CU-SeeMe (Dorcey, 1995), o Microsoft NetMeeting (http://www.microsoft.com/windows/netmeeting/) e o IVS (INRIA Videoconferencing System) (http://www-sop.inria.fr/rodeo/personnel/Thierry.Turletti/ivs.html). As aplicações de videoconferência são as que mais se enquandram no perfil de aplicação do eMeet/InCA, merecendo uma especial atenção. 


\subsubsection{TVS}

O TVS (TeleMidia Videoconferencing System) (Oliveira, 1996) foi um sistema de videoconferência desenvolvido através dos estudos realizados no Laboratório TeleMídia do Grupo de Redes e Sistemas Multimídia do Departamento de Informática da PUC-Rio.

Uma das grandes características do TVS é o fato de estar em conformidade com as recomendações ITU-T e padrões ISO pertinentes à transmissão de suas mídias. Assim, o sistema possibilita a transmissão das mídias de áudio e vídeo de forma síncrona e padronizada, a manipulação de documentos multimídia/hipermídia, baseada no Modelo de Contextos Aninhados (MCA) (Soares et al., 1995). O sistema apresenta suporte à votação e envio de mensagens entre participantes, além de permitir uma configuração altamente customizável do ambiente. O controle de acesso ao ambiente é realizado por deteç̧ão de silêncio, para que haja uma maior eficiência com relação à interatividade em uma reunião. A Figura 3.23 mostra a interface do TVS com o usuário.

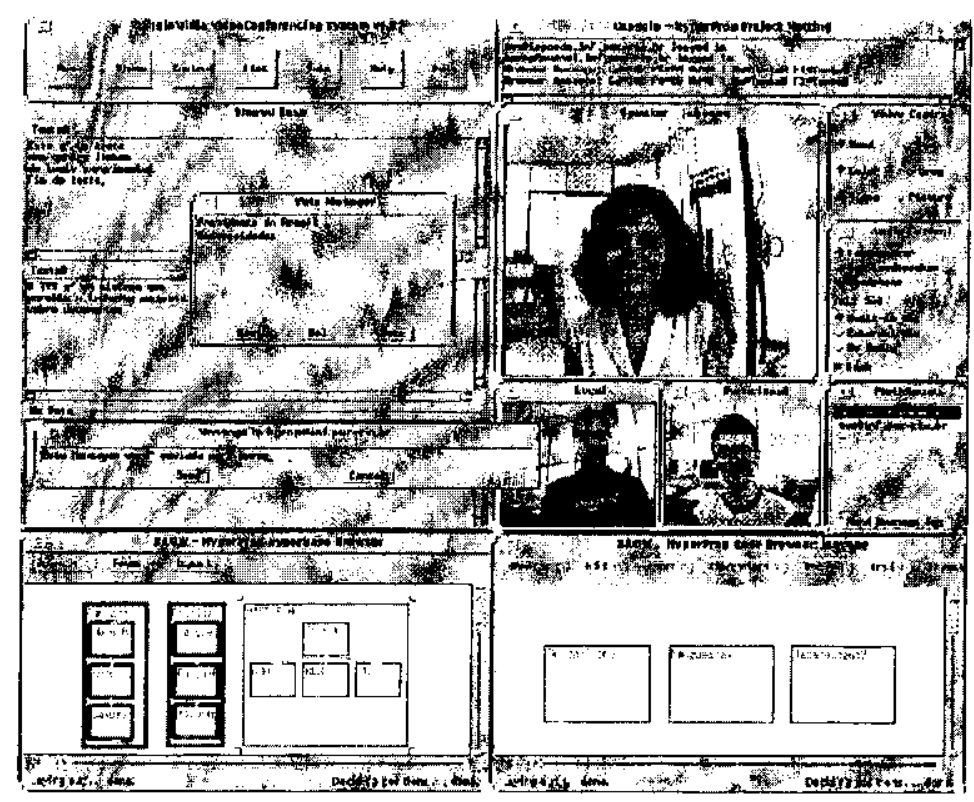

Figura 3.23 - Interface do TVS com o usuário (Oliveira, 1996). 


\subsubsection{CuSeeMe}

O CU-SeeMe (Dorcey, 1995) (Arrowood, 1996) está entre as primeiras aplicações de videoconferência disponíveis para a Internet. Desenvolvido por Tim Dorcey na Universidade de Cornell, EUA, baseia-se no conceito de refletores. Quando um usuário deseja participar de uma conferência, ele deve se conectar a um refletor daquela conferência, informando o identificador da conferência desejada. Caso a conexão seja realizada entre dois participantes apenas, o uso do refletor é opcional.

Os Clientes $\mathrm{CU}$-SeeMe foram desenvolvido para estações Macintosh e Windows, enquanto que refletores foram desenvolvidos para estações UNIX. A interface original do $C U$ SeeMe é mostrada na Figura 3.24. Atualmente existem várias versões comerciais do CuSeeMe, disponíveis a partir do site da CuSeeMe Networks (http://www.cuseeme.com). Na Figura 3.25 tem-se a interface do CuSeeMe Web, uma versão Web da aplicação.
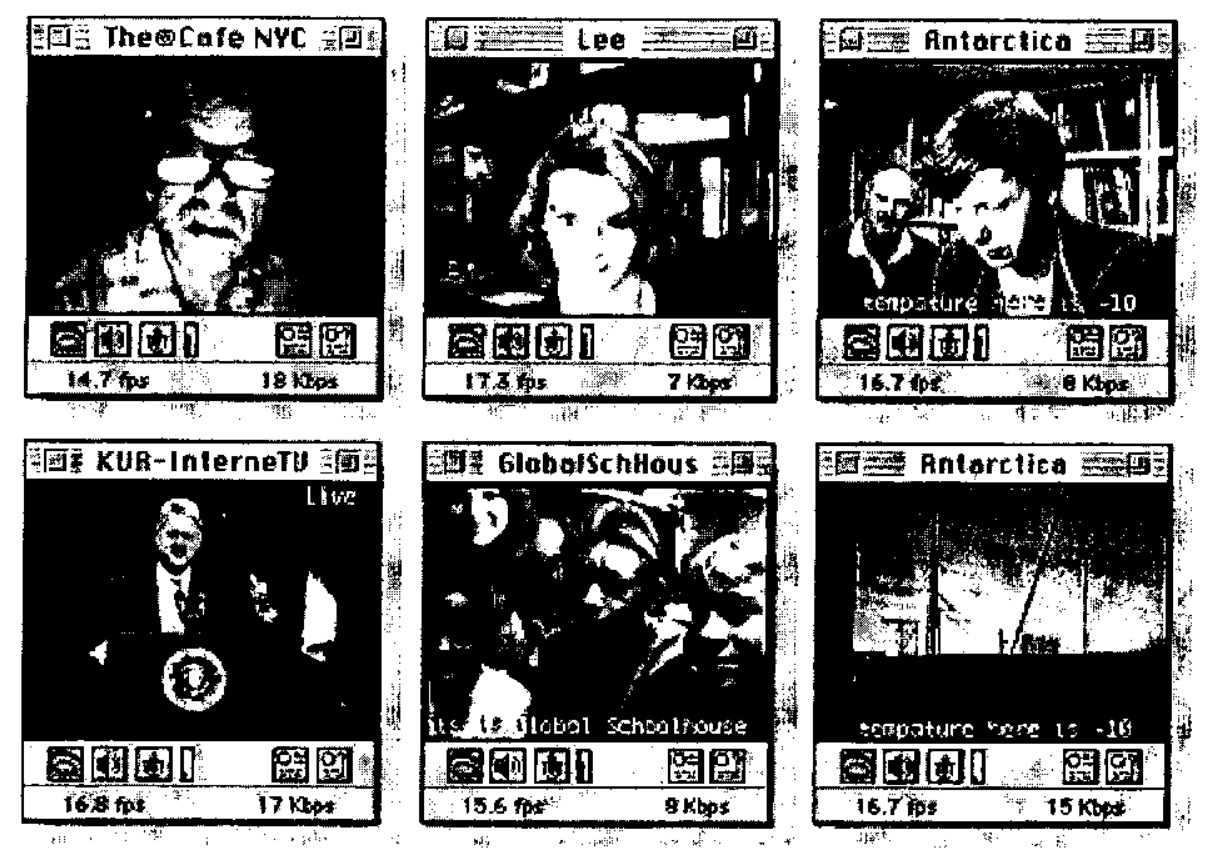

Figura 3.24 - Interface original do CuSeeMe (Dorcey, 1995). 


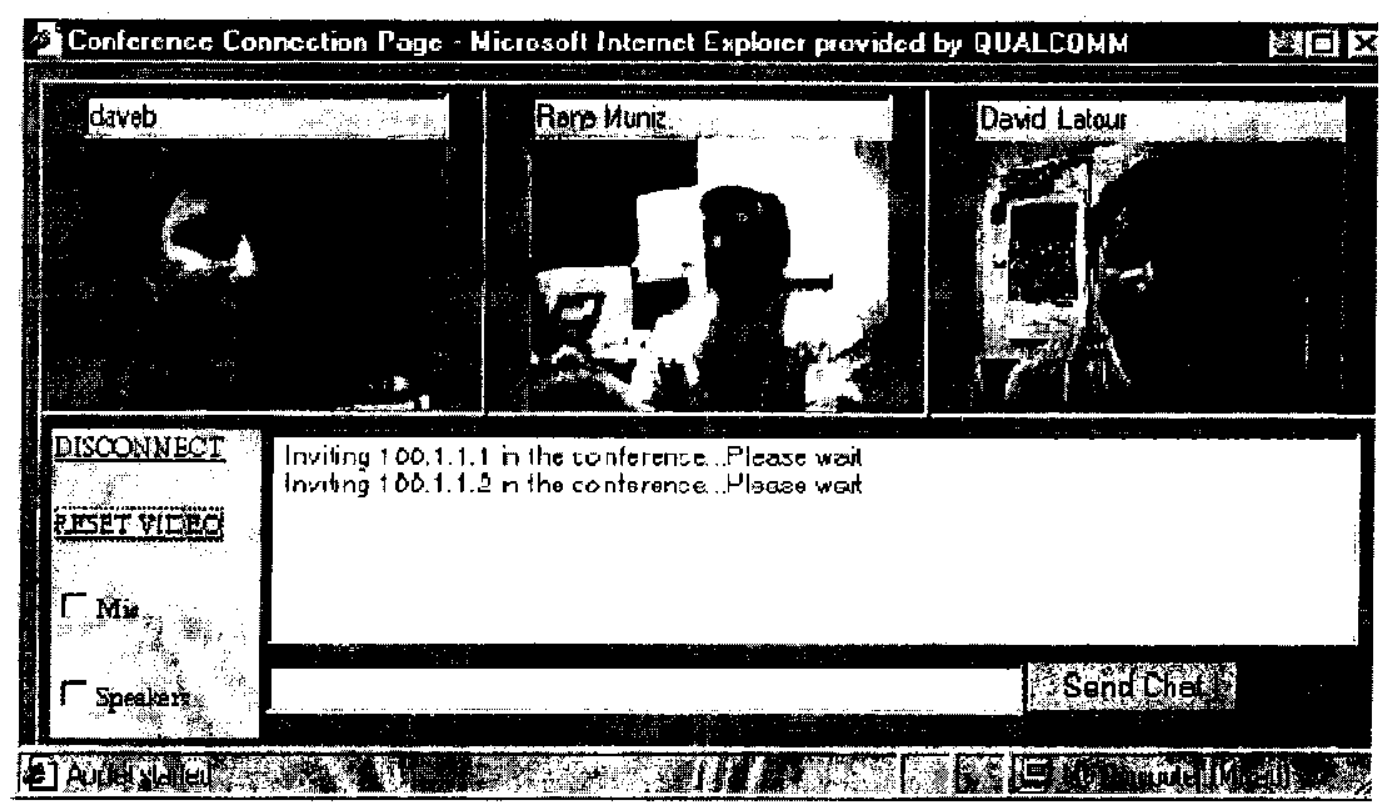

Figura 3.25 - A interface do CuSeeMe Web (http:/www.cuseeme.com/products).

\subsubsection{Microsoft NetMeeting}

O Microsoft NetMeeting (http://www.microsoft.com/windows/netmeeting/) é uma das ferramentas pioneiras de videoconferência, juntamente com o CuSeeMe descrito anteriormente. Sua primeira versão data de agosto de 1996, onde suportava somente conferências de áudio. Em suas versões mais recentes, o Microsoft NetMeeting possibilita a comunicação de áudio, vídeo, compartilhamento de documentos e aplicações, chat entre os participantes, utilização de um whiteboard (lousa eletrônica compartilhada), e transmissão de arquivos. Está de acordo com os principais protocolos padrões de transmissão e recepção dessas mídias, o que facilita a sua integração com várias outras aplicações de videoconferência existentes. Pelo fato de ser pioneiro nesta área, o NetMeeting foi, de fato, uma referência para outras aplicaçōes de videoconferência. A Figura 3.26 mostra a tela principal do Microsoft NetMeeting. 


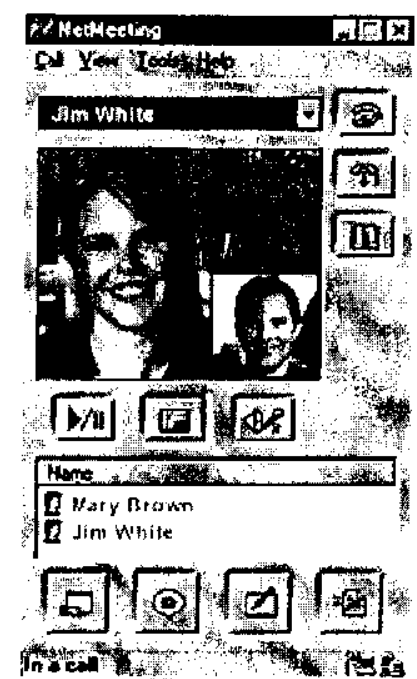

Figura 3.26 - Tela principal do Microsoft Netmeeting, um dos softwares pioneiros de conferência (http://www.microsoft.com/windows/netmeeting/).

\subsubsection{IVS}

O IVS (INRIA Videoconferencing System) foi um dos primeiros softwares de videoconferência para a Internet, tendo sua primeira versão lançada cm julho de 1992. Os codecs de compressão de dados de vídeo e áudio são por software, portanto, há uma configuração mínima de hardware necessário para que um usuário possa participar, normalmente uma câmera e um dispositivo de digitalização desta fonte de vídeo, além de um microfone.

Atualmente, o instituto INRIA (http://www-sop.inria.fr) está desenvolvendo duas novas ferramentas de vidcoconferência, são elas: Rendez-Vous (próxima geração do IVS) e o FreePhone. O IVS, em funcionamento, pode ser visto na Figura 3.27. 


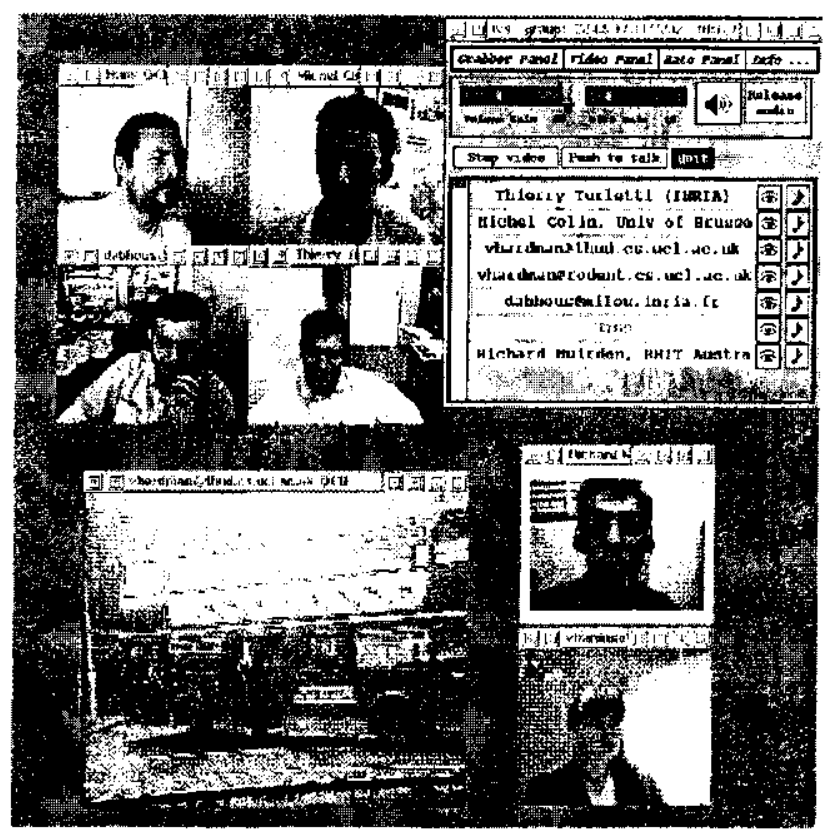

Figura 3.27 - A interface gráfica do IVS (INRIA Videoconferencing System) (http://wwwsop.inria.fr/rodeo/personnel/Thierry.Turletti/ivs.html).

\subsection{CONSIDERAÇÕES FINAIS}

Neste capítulo foram abordadas algumas ferramentas de suporte à decisão, salas eletrônicas e aplicações de videoconferência a fim de que a análise dessas aplicações, juntamente com todas suas características, pudesse ajudar no levantamento dos requisitos funcionais desejados ao eMeet/InCA.

Com relação às ferramentas de suporte à decisão, por exemplo, verificou-se que a inclusão de um mecanismo de votação poderia ajudar os participantes de uma reunião a chegar a um consenso para uma determinada divergência de opinião ou escolha. Os sistemas FORUM, TELEP e FLATLAND implementam tal característica. No entanto, não há possibilidades de resposta fora dos tradicionais "Sim" e "Não". Seria interessante, portanto, que o eMeet/InCA suportasse um meio termo ou uma justificativa para uma opção diferente do "Sim" e "Não" tradicionais. O TeamWorkstation também deixa clara a importância do compartilhamento de documentos para a tomada de decisões, sendo uma característica desejável no eMeet/InCA.

As salas eletrônicas são aplicações ligeiramente diferentes do foco da aplicação do eMeet/InCA, mas mesmo assim pode-se identificar funcionalidades importantes. No caso do 
Cornell Lecture Browser, o chaveamento automático do foco de vídeo, dentre as possíveis câmeras de captura de uma palestra, é uma característica interessante. No eMeet/InCA, as informações de áudio e vídeo devem ser capturadas durante toda a duração da reunião. A captura de todas essas streams de áudio e vídeo dos participantes, além de gerar um grande overhead de processamento, gera uma grande demanda de espaço de armazenamento. Assim, com base nas experiências bem sucedidas do Cornell Lecture Browser, principalmente em relação ao fato da satisfação do usuário final que verá a gravação da reunião, e visando a diminuição do processamento e espaço de armazenamento exigido, a escolha do armazenamento de uma única stream de vídeo foi adotada. No eMeet/InCA, a stream que é gravada é a stream do participante que está com a palavra em um determinado momento da reunião. Em relação ao áudio, a stream também é única e corresponde a mixagem de todas as streams de áudio dos participantes. Essa abordagem, além de melhorar a performance da aplicação, também permite que seja criado um único arquivo contendo as informações de áudio e vídeo que foram geradas durante a captura de uma reunião do $e M e e t / I n C A$.

Atualmente, as ferramentas mais utilizadas para o suporte a reuniões distribuídas são as ferramentas de videoconferência. Dentre elas foram citadas o TVS (TeleMidia Videoconferencing System), o CuSeeMe da CuSeeMe Networks, o Microsoft Netmeeting e o INRIA IVS. Todas essas ferramentas utilizam protocolos padrões para difusão de mídias de áudio e vídeo (H.323), compartilhamento de aplicações e dados (T.120), além de algoritmos padrões de compressão on-demmand, referentes a tais mídias. Esse enfoque, atualmente, é imprescindível em uma ferramenta de suporte a reuniões distribuídas e torna possível a existência de servidores de reuniões (como o CuSeeMe MeetingPoint da CuSeeMe Networks). Outra característica interessante que uma aplicação voltada a reuniões distribuídas pode oferecer a seus usuários ć a opção de utilização da comunicação Multicasting, existente na rede MBone (Multimedia Backbone); nesse caso a banda necessária a um servidor de reunião, para a manutenção do evento, seria sempre constante. Todas essas características são interessantes de serem suportadas pelo $\mathrm{eMeet/InCA}$ e a adoção de protocolos padrões de comunicações garantem a interoperabilidade do $e M e e t / \operatorname{InCA}$ com as demais aplicações apresentadas. Vale ressaltar porém, que o eMeet/InCA não se limita a ser uma aplicação de videoconferência, tendo 
características não encontradas em nenhuma outra ferramenta de videoconferência analisada, como é o caso da gravação da reuniāo e sua posterior visualização através do $e M e e t / S E R V E^{6}$.

O $e M e e t / I n C A$ foi concebido para atender as necessidades de uma reunião distribuída mas isso não impede que seja utilizado para reuniões presenciais onde os participantes se encontram em um mesmo ambiente físico. Assim, o eMeet/InCA teria a mesma funcionalidade apresentada pelo sistema PlexCenter, por exemplo.

\footnotetext{
${ }^{6}$ Trabalho de mestrado de Pedro Monteiro da Silva Eleutério (Eleutério \& Pimentel, 2001).
} 


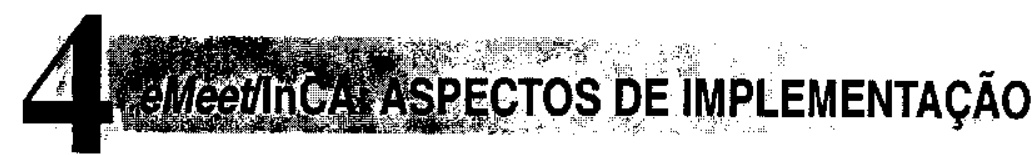

\subsection{CONSIDERAÇÕES INICIAIS}

Neste capítulo são destacadas as características ideais do $e M e e t / \operatorname{InCA}$, além de alguns pontos fundamentais utilizados para a modelagem da aplicação: linguagem de implementação, protocolo de transporte, difusão de dados pela rede e sincronização de mídias.

\subsection{CARACTERISTICAS IDEAIS DO eMeet/InCA}

Com o resultado do levantamento de requisitos realizado, conclui-se que as características ideais que o projeto $e M e e t / I n C A$ deveria apresentar incluem:

- suporte à recomendação ITU-T H.323, que garante uma aplicação totalmente compatível com os protocolos padrões de transmissão de dados e gerenciamento de sessão, além de ter a compatibilidade entre diferentes dispositivos e aplicações do mesmo gênero;

- transmissão de dados utilizando o protocolo multicast, com opção de transmissão unicast. Assim, sempre que possível, ter-se-ia uma racionalização da largura de banda exigida e o poder de processamento do servidor de reunião;

- portabilidade entre diversas plataformas computacionais, abrangendo-se assim, uma gama maior de usuários.

Estas características e os fatores que inviabilizaram sua total implementação na atual versāo do $e M e e t / \operatorname{InCA}$ são abordados nas seções a seguir.

\subsection{SUPORTE DA PLATAFORMA JAVA}

JAVA foi a linguagem escolhida para a implementação do eMeet/InCA. A decisão de se adotar JAVA foi bastante influenciada pelo fato de que grande parte do elass ter sido escrito nessa 
linguagem. Assim, é necessário manter o padrão de desenvolvimento da aplicação, uma vez que o eMeet irá ser estendido posteriormente por pessoas do ICMC ou da Georgia Tech.

A seguir são apresentadas as API's ${ }^{7}$ JMF - Java Media Framework e JTAPI - Java Telephony API, que se referem diretamente à criação de uma aplicação com as características do eMeet/InCA; a tecnologia JAVA Web Start, utilizada para a integração do sistema com a Web; e a criação da interface gráfica com o usuário através da utilização de uma ferramenta RAD (Rapid Application Development) da IBM, o IBM VisualAge for JAVA.

\subsubsection{A API JMF}

Nesta seção, serão introduzidos os conceitos da API JMF, as suas adequações ao projeto do eMeet/InCA bem como suas deficiências apresentadas durante a fase de desenvolvimento do sistema.

\subsubsection{Introdução a API JMF}

Java Media Framework, ou simplesmente JMF, é uma API (Application Programming Interface, ou Interface de Programação de Aplicação) da linguagem JAVA que tem por finalidade incorporar mídias temporais a aplicações e applets. Qualquer tipo de dado que tenha o seu valor modificado durante o decorrer do tempo é considerado como um tipo de mídia temporal. Uma fonte de áudio, sequiências MIDI, filmes c animações são os tipos mais comuns de mídias temporais.

Com a API JMF, pode-se fazer a captura de mídias de áudio e vídeo, processá-las (modificá-las de alguma forma ou simplesmente converter seu formato) e redirecionar a saída do processamento para um arquivo ou para uma transmissão pela rede, por exemplo. Esse modelo de processamento, concebido pcla API, é ilustrado na Figura 4.1.

\footnotetext{
${ }^{7}$ Application Program Interface's.
} 


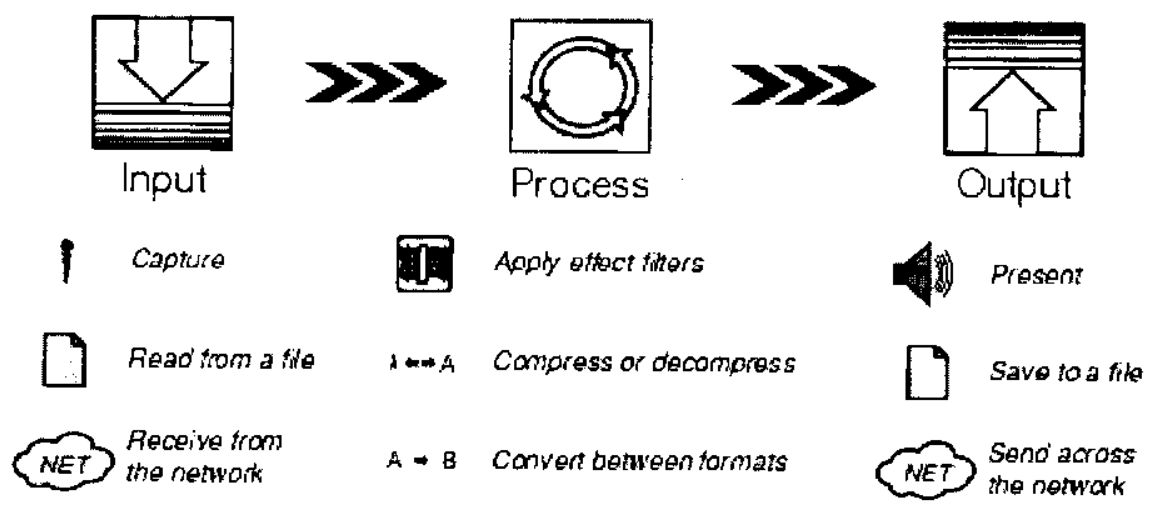

Figura 4.1 - Modelo de processamento de mídia adotado pela API JMF (Sun, 1999a).

Uma característica chave em mídias temporais é o fato de que requerem processamento e entrega da informação em um período de tempo curto. Uma vez que o fluxo de dados começa, há limites de tempos restritos (deadlines) que devem ser respeitados, tanto em termos de recebimento quanto de apresentação dos dados. Os tipos de mídias temporais que possuem esses tipos de requisitos para que possam produzir resultados aceitáveis, são freqüentemente referidos como streams.

Um exemplo comum é o de um filme. Se os dados não puderem ser entregues num período de tempo limite, pode haver pausas constantes e atrasos na reprodução. Por outro lado, se os dados não puderem ser recebidos e processados numa velocidade satisfatória, o filme poderá ser apresentado com pulos de cenas, pois vários quadros serão intencionalmente descartados para manter a taxa correta de exibição dos dados e manter o tempo exato de reprodução da mídia.

Na API JMF, o formato no qual um tipo de mídia de dado é armazenado, é referenciado como content type (ou tipo de conteúdo). QuickTime, MPEG, e WAV são todos exemplos de content types.

Uma stream de mídia são dados obtidos através de um arquivo local, de um endereço na rede, através da captura de dados de uma câmera de vídeo ou de um microfonc. Streams de mídia geralmente contêm múltiplos canais de dados chamados de tracks (trilhas). Por exemplo, um arquivo Quicktime pode conter tanto uma trilha de áudio como de vídeo. Streams de mídia que contêm múltiplas trilhas são chamadas de streams de mídias complexas ou multiplexadas. 
O tipo de uma trilha identifica o tipo de dado que ela contém, tal como áudio ou vídeo. $\mathrm{O}$ formato da trilha define como os dados de uma trilha estão estruturados. A Tabela 4.1 identifica os formatos mais comuns para vídeo, enquanto que a Tabela 4.2 apresenta os formatos mais comuns para áudio.

\begin{tabular}{|c|c|c|c|c|}
\hline Formato & Content Type & Qualidade & $\begin{array}{c}\text { Requerimentos de } \\
\text { CPU }\end{array}$ & $\begin{array}{c}\text { Requerimentos de } \\
\text { Banda de Rede }\end{array}$ \\
\hline Cinepak & AVI, QuickTime & Média & Baixos & Altos \\
\hline MPEG-1 & MPEG & Alta & Altos & Altos \\
\hline H.261 & AVI e RTP & Baixa & Médios & Médios \\
\hline H.263 & QuickTime, AVI e RTP & Média & Médios & Baixos \\
\hline JPEG & QuickTime, AVI e RTP & Alta & Altos & Altos \\
\hline Indeo & Quicktime e AVI & Média & Médios & Médios \\
\hline
\end{tabular}

Tabela 4.1 - Formatos mais comuns de vídeo (Sun, 1999a).

\begin{tabular}{|l|l|l|l|l|}
\hline \multicolumn{1}{|c|}{ Formato } & \multicolumn{1}{|c|}{ Content Type } & Qualidade & \multicolumn{1}{|c|}{$\begin{array}{c}\text { Requerimentos de } \\
\text { CPU }\end{array}$} & $\begin{array}{l}\text { Requerimentos de } \\
\text { Banda de Rede }\end{array}$ \\
\hline PCM & AVI, QuickTime e WAV & Alta & Baixos & Altos \\
\hline Um-Law & $\begin{array}{l}\text { AVI, QuickTime, WAV e } \\
\text { RTP }\end{array}$ & Baixa & Baixos & Altos \\
\hline ADPCM(DVI, IMA4) & $\begin{array}{l}\text { AVI, QuickTime, WAV e } \\
\text { RTP }\end{array}$ & Média & Médios & Médios \\
\hline MPEG-1 & MPEG & Alta & Altos & Altos \\
\hline MPEG Layer3 & MPEG & Alta & Altos & Médios \\
\hline GSM & WAV e RTP & Baixa & Baixos & Baixos \\
\hline G.723.1 & WAV e RTP & Média & Médios & Baixos \\
\hline
\end{tabular}

Tabela 4.2 - Formatos mais comuns de áudio (Sun, 1999a).

Alguns formatos foram desenvolvidos para aplicações e requisitos específicos. Formatos de alta qualidade com alta banda de rede são geralmente destinados a dispositivos de CD-ROM ou aplicações de armazenamento locais. H.261 e H.263 são geralmente utilizados para aplicações de videoconferência (no qual se enquadra o eMeet/InCA) e possuem uma otimização de compressão para vídeos com pouca mudança entre quadros (pouca movimentação). Similarmente, G.723 é tipicamente utilizado para produzir uma baixa taxa de bits de dados em aplicações de conversações que utilizam a rede de telefonia.

Para a transmissão remola (ou seja, através de uma rede de comunicação) de mídias que necessitam de transmissāo e/ou recepção rápidas, a API JMF utiliza o protocolo RTP (Real-Time Transport Protocol, ou Protocolo de Transporte em Tempo Real) (http://www.ietf.org/rfc/rfc1889.txt). O protocolo RTP foi desenvolvido para propiciar serviços 
de entrega de dados ponto a ponto com características de tempo real, ideais para mídias interativas de áudio c vídeo. Tipicamente, o protocolo RTP é executado sob o protocolo UDP ${ }^{8}$ (http://www.ietf.org/rfc/rfc768.txt), para fazer uso de seus serviços de multiplexação e controle de checksum. No entanto, RTP pode ser utilizado com outros protocolos de transporte de rede.

Apesar do protocolo RTP ter sido primariamente desenvolvido para satisfazer as necessidades de participantes de conferências multimídia (como é o caso do eMeet/InCA), ele não se limita a somente este tipo particular de aplicação. Armazenamento contínuo de dados, simulação interativa distribuída e aplicações de controle e medição podem também ser beneficiadas. A API JMF, em sua versão 2.1.1a (http://java.sun.com/products/java-media/jmf), suporta o protocolo RTP em vários formatos, como mostra a Tabela 4.3. Nessa tabela, $R$ denota que o formato pode ser decodificado e apresentado; $\mathrm{T}$ indica que mídias streams podem codificadas e transmitidas; * significa que JPEG/RTP pode ser transmitido somente em dimensões de vídeo que são múltiplas de 8 pixels; ** que H.263/RTP pode ser transmitido somente nos formatos SQCIF (128x96), QCIF (176x144) e CIF $(352 \times 288)$ e que ambos os formatos de payloads RPC 2190 (PT 34) e 2429 (payload dinâmico), são suportados; *** significa que vídeo MPEG/RTP pode ser somente transmitido pré-codificado com conteúdo MPEG.

\begin{tabular}{|l|c|c|c|c|}
\hline Tipo de Mídia & $\begin{array}{c}\text { Payload } \\
\text { RTP }\end{array}$ & $\begin{array}{c}\text { JMF 2.1.1 } \\
\text { Cross Plataform }\end{array}$ & $\begin{array}{c}\text { JMF 2.1.1 } \\
\text { Solaris }\end{array}$ & $\begin{array}{c}\text { JMF 2:1.1 } \\
\text { Windows }\end{array}$ \\
\hline Áudio: G.711 (U-law) 8 kHz & 0 & $\mathrm{R}, \mathrm{T}$ & $\mathrm{R}, \mathrm{T}$ & $\mathrm{R}, \mathrm{T}$ \\
\hline Áudio: GSM mono & 3 & $\mathrm{R}, \mathrm{T}$ & $\mathrm{R}, \mathrm{T}$ & $\mathrm{R}, \mathrm{T}$ \\
\hline Áudio: G.723 mono & 4 & $\mathrm{R}$ & $\mathrm{R}, \mathrm{T}$ & $\mathrm{R}, \mathrm{T}$ \\
\hline Áudio: 4-bit mono DVI $8 \mathrm{kHz}$ & 5 & $\mathrm{R}, \mathrm{T}$ & $\mathrm{R}, \mathrm{T}$ & $\mathrm{R}, \mathrm{T}$ \\
\hline Áudio: 4-bit mono DVI 11.025 kHz & 16 & $\mathrm{R}, \mathrm{T}$ & $\mathrm{R}, \mathrm{T}$ & $\mathrm{R}, \mathrm{T}$ \\
\hline Áudio: 4-bit mono DVI 22.05 kHz & 17 & $\mathrm{R}, \mathrm{T}$ & $\mathrm{R}, \mathrm{T}$ & $\mathrm{R}, \mathrm{T}$ \\
\hline Áudio: MPEG Layer I, II e III & 14 & $\mathrm{R}, \mathrm{T}$ & $\mathrm{R}, \mathrm{T}$ & $\mathrm{R}, \mathrm{T}$ \\
\hline Vídeo: JPEG (411, 422, 111) & 26 & $\mathrm{R}$ & $\mathrm{R}, \mathrm{T}$ & $\mathrm{R}, \mathrm{T}$ \\
\hline Vídeo: H.261 & 31 & - & $\mathrm{R}$ & $\mathrm{R}$ \\
\hline Vídeo: H.263 & 34 & Somente modo A & $\mathrm{R}, \mathrm{T}$ & $\mathrm{R}, \mathrm{T}$ \\
\hline Vídeo: MPEG-I & 32 & $\mathrm{~T}$ & $\mathrm{R}, \mathrm{T}$ & $\mathrm{R}, \mathrm{T}$ \\
\hline
\end{tabular}

Tabela 4.3 - Formatos suportados na API JMF utilizando o protocolo RTP (Sun, 2001a).

\footnotetext{
${ }^{8}$ User Datagram Protocol é um protocolo de transporte sem garantia de qualidade de serviço.
} 
A API JMF também suporta um grande número de dispositivos de captura. A Tabcla 4.4 mostra os dispositivos de captura suportados.

\begin{tabular}{|c|c|c|c|}
\hline Dispositivo de Captura & $\begin{array}{c}\text { JMF 2.1.1 } \\
\text { Cross Plataform }\end{array}$ & $\begin{array}{c}\text { JMF } 2.1 .1 \\
\text { Solaris }\end{array}$ & $\begin{array}{l}\text { JMF 2.1.1 } \\
\text { Windows }\end{array}$ \\
\hline JavaSound (16-bit, $44100,22050,11025 \mathrm{~Hz}, 8000 \mathrm{~Hz}$ linear) & - & $x$ & $\mathrm{X}$ \\
\hline Sun Video & - & $x$ & - \\
\hline Sun Video Plus & - & $x$ & - \\
\hline VFW & - & $=$ & $\mathrm{X}$ \\
\hline Intel Create \& Share & $=$ & - & Win $9 x$ \\
\hline Diamond Supra Video Kit Share & - & - & Win98 \\
\hline QuickCam VC (câmera) & - & - & WinNT \\
\hline e-cam (câmera) & - & - & WinNT, $9 x$ \\
\hline Winnoe Videum & - & $\therefore$ & WinNT, $9 x$ \\
\hline Creative Web Cam II & - & - & Win9x \\
\hline Miro Video DC30 & $\cdot$ & - & Win9x \\
\hline lomega Buz & $=$ & - & Win $9 x$ \\
\hline QuickCam Home USB (Camera) & - & - & Win98 \\
\hline Smart Video Recorder III & - & - & Win9x \\
\hline
\end{tabular}

Tabela 4.4 - Dispositivos de captura suportados pela API JMF 2.1.1a (Sun, 2001a).

A API JMF apresenta conceitos na qual toda sua arquitetura é baseada, entre eles : Data Source, Player e Processor.

Um Data Source é uma fonte de dados que encapsula streams de uma mídia. Um exemplo seria uma fita de vídeo para um videocassete. É a fita de vídeo que possui as informações, ou a fonte, das streams de áudio c vídeo de um filme.

Um Player é um dispositivo capaz de reproduzir dados que venham de uma fonte de dados, ou um Data Source. O videocasscte é um Player para uma fita de vídeo, sendo a fita de vídeo um Data Source. A Figura 4.2 ilustra uma abstração do modelo de arquitetura empregada na API JMF para um exemplo do nosso cotidiano.

Um Processor é um dispositivo capaz de processar dados que venham de uma fonte de dados (Data Source). Um transcodificador de sistema de vídeo NTSC para PAL é um Processor, pois ele processa a informação contida $\mathrm{cm}$ uma fita de vídeo NTSC (Data Source) e a transforma para que as nossas televisões possam apresentar o filme sem perda de cor, uma vez que o padrão adotado, aqui no Brasil, é o PAL. 


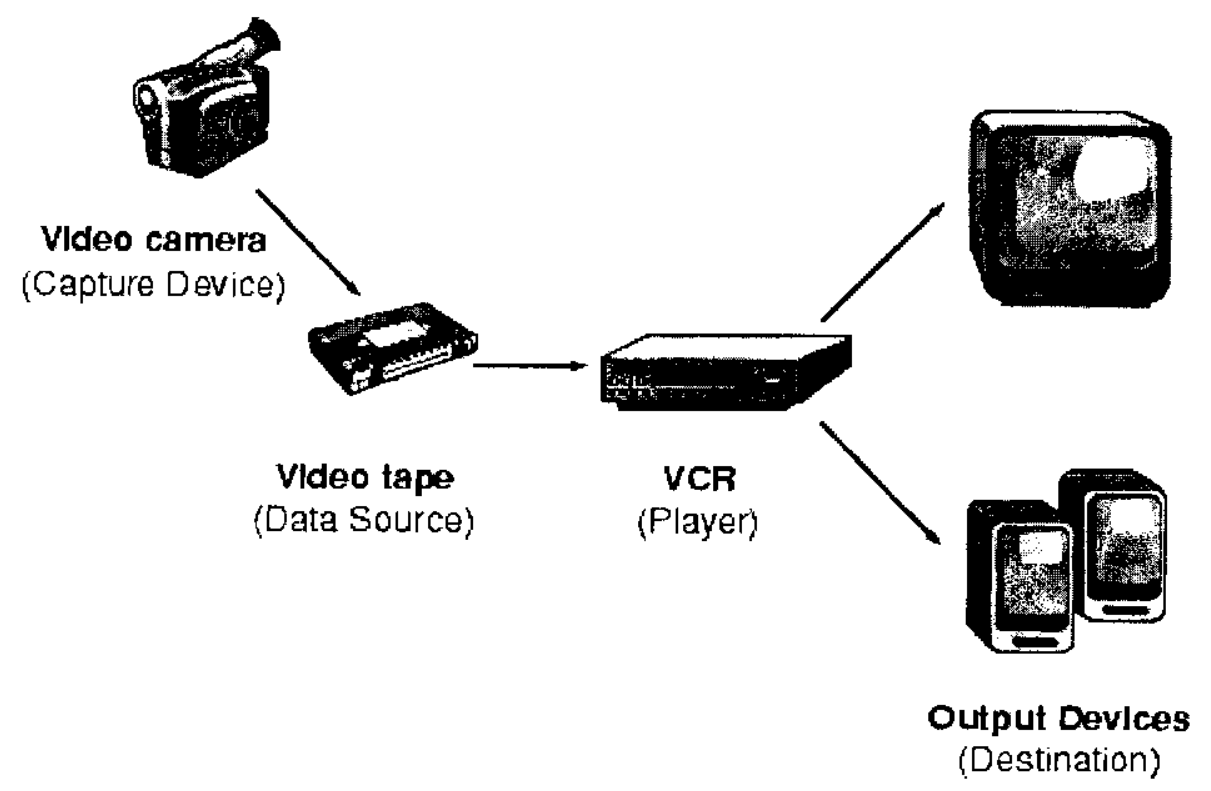

Figura 4.2 - Abstração real da arquitetura da API JMF (Sun, 1999a).

\subsubsection{2 eMeet/InCA e a API JMF}

No contexto da aplicação $e M e e t / I n C A$, A API JMF foi utilizada para a captura, apresentação e difusão pela rede das mídias de áudio e vídeo dos participantes de uma reunião.

A API JMF possui um serviço de registro próprio que funciona como uma base de dados para as aplicações que desejam consultar os dispositivos de captura $c$ apresentação de mídias, existentes na máquina local. A partir desta base de dados é que é feita a consulta dos dispositivos de captura e reprodução de mídias disponíveis para a utilização através da API. Portanto, antes que um dispositivo possa vir a ser efetivamente utilizado por uma aplicação, ele deve estar cadastrado no registro. A Figura 4.3 mostra o registro da API JMF 2.1.1a, de uma máquina que possui dispositivos de captura de áudio e vídeo cadastrados. 


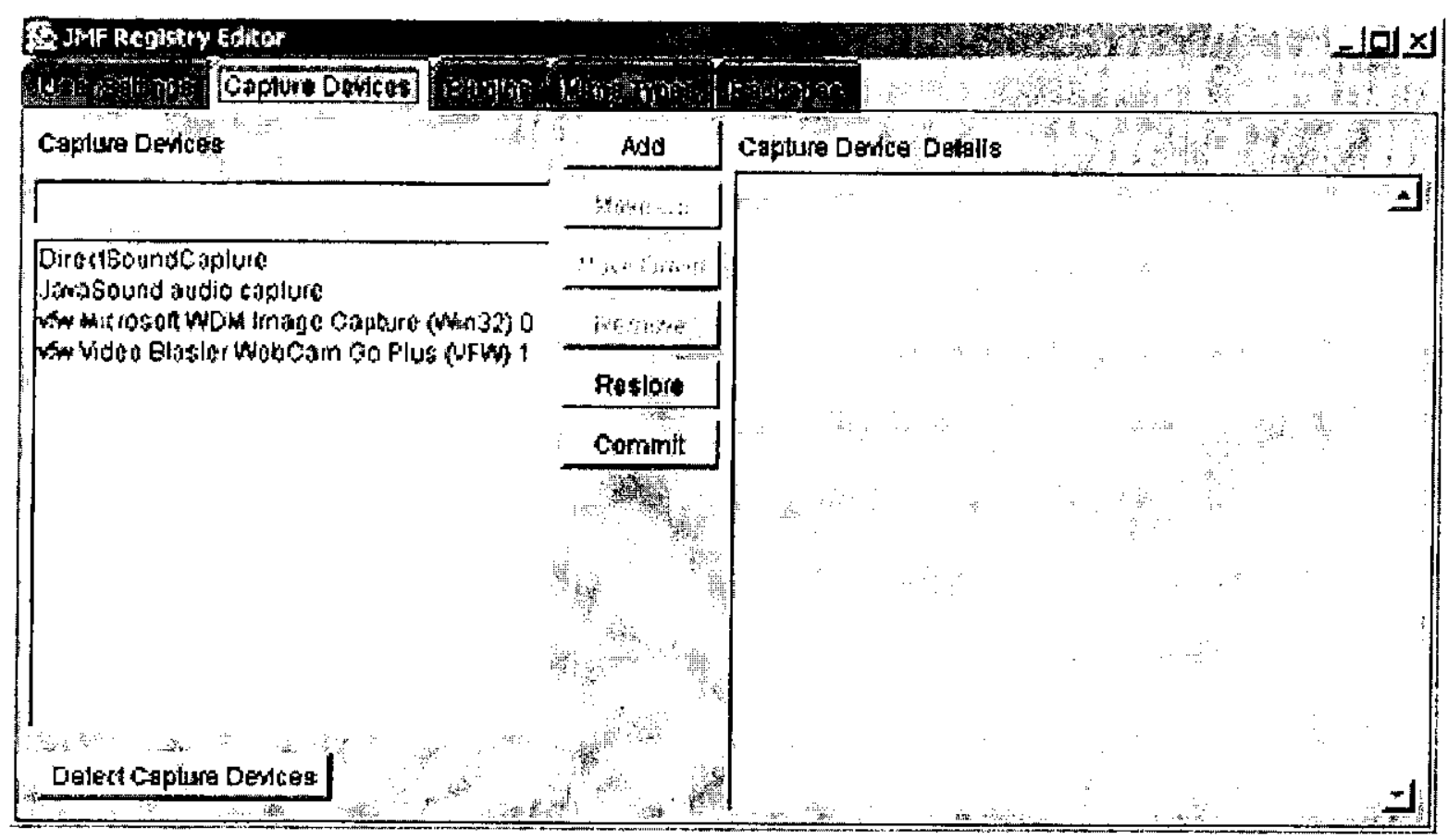

Figura 4.3 - Registro da API JMF 2.1.1a, contendo dispositivos de captura e apresentaçāo de áudio e vídeo cadastrados.

Caso a máquina possua recursos multimídia de captura e/ou apresentação que não estejam registrados, há a necessidade de se fazer uma busca no computador local para que eles sejam cadastrados. Isto é feito através da utilização de detecção automática do registro da API JMF, que é acionado através do pressionamento do botão "Detect Capture Devices", que pode ser visto na Figura 4.3. Uma vez que os dispositivos estão cadastrados no serviço de registro da API JMF, as aplicações podem facilmente acessá-los.

No $e$ Meet/lnCA, as mídias de áudio e vídeo de cada participante são capturadas através da API JMF e enviadas ao servidor de controle da reunião. O servidor é responsável pela difusão dessas mídias entre todos os outros participantes da reuniāo, além da gravação da reunião. A Figura 4.4 ilustra este processo. 


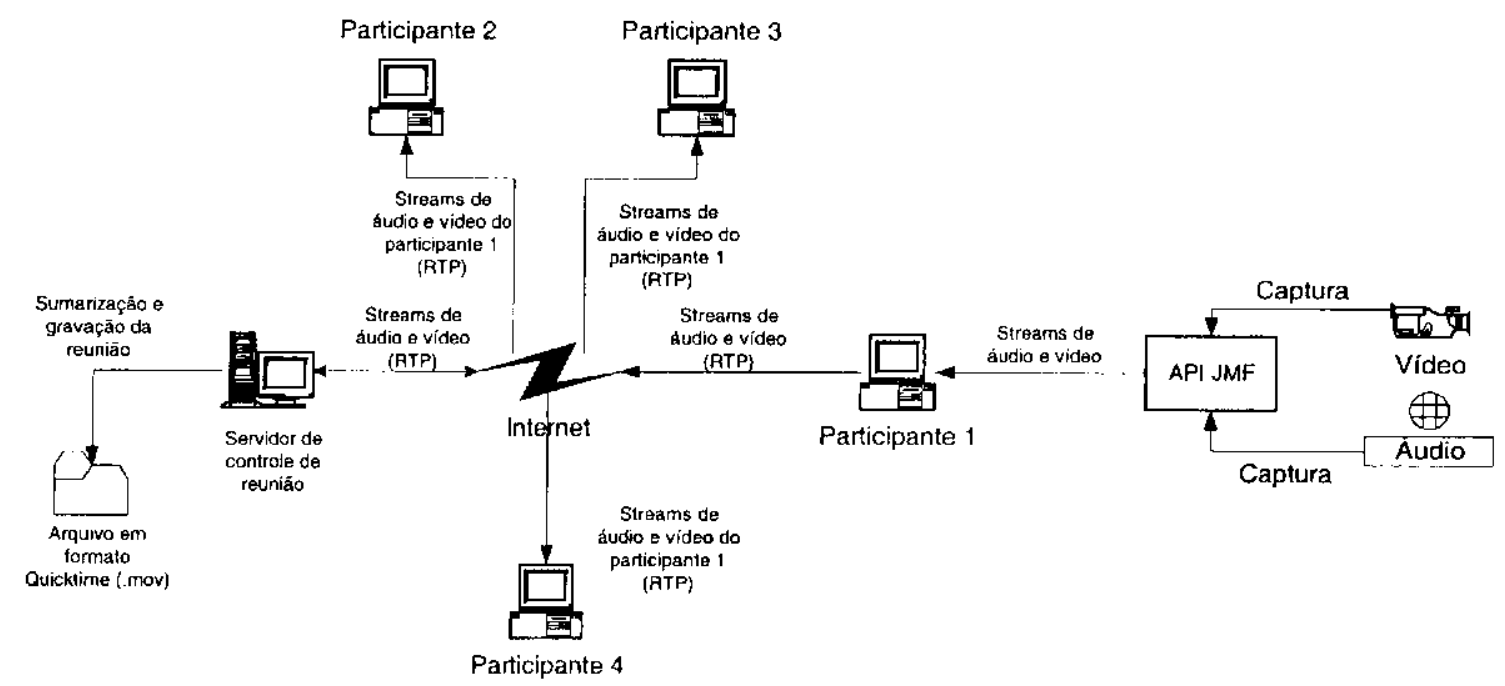

Figura 4.4 - Atribuiçōes do servidor controle de reunião da aplicação eMeet/nCA. O servidor de reunião controla a sumarização em tempo de execução da reuniāo, gravação e a difusão das mídias de áudio e vídeo de um participante para todos os outros participantes. No caso exemplificado, do Participante 1 para os Participantes 2,3 e 4.

O servidor de reunião é um daemon (intitulado eMeetd) que é executado em uma máquina específica para o gerenciamento de reuniões. O eMeetd espera requisiçōes de cadastramento de participantes de uma reunião, através do software cliente do eMeet/InCA. Um participante, uma vez cadastrado, envia suas mídias de áudio e vídeo para a difusão entre os outros clientes. A difusão é feita através da utilização do protocolo RTP, como pode ser notado na Figura 4.4.

O processo de gravação da reunião, na realidade, é um processo de sumarização em tempo de execução da mesma. O resultado final desta sumarização é um arquivo no formato Quicktime (.mov) com informações de áudio e vídeo de todos os participantes. A informação de áudio é a mixagem de todas as streams de áudio dos participantes da reunião e o vídeo é o vídeo da pessoa que está falando em um determinado momento, ou seja, presume-se que no decorrer da reunião haja uma conversação organizada na qual uma pessoa fala por vez. Caso duas ou mais pessoas falem ao mesmo tempo, o enfoque do vídeo fica centralizado na pessoa que estava falando anteriormente, a menos que esta esteja sem falar há mais de 2,5 segundos. Caso isto ocorra, uma outra pessoa é eleita para o foco do vídeo que somente será trocado se ela permanecer em silêncio por mais de 2,5 segundos. Este tipo de detecção é comumente conhecido na literatura como Floor-Control (Kausar \& Crowcroft, 1998). A Figura 4.5 ilustra o mecanismo de sumarização em tempo de execução adotado no eMeet/InCA. 


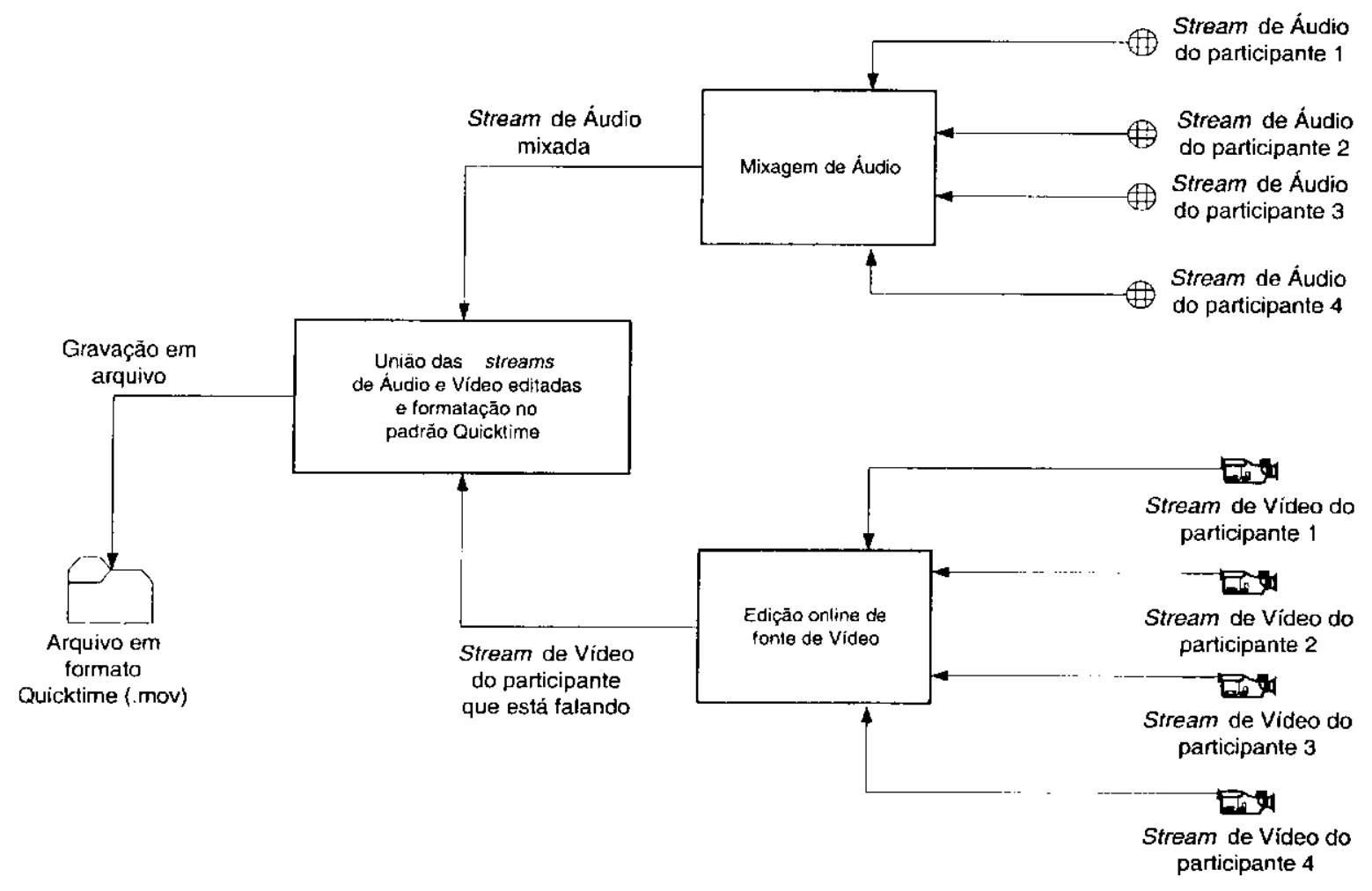

Figura 4.5 - Algoritmo de sumarização de uma reunião, empregado na aplicação eMeet/InCA.

A Figura 4.4 ilustra o processo de captura e transmissão das mídias de áudio e vídeo de um participante (Participante 1) até o servidor e do servidor aos outros participantes. Porém, este também tem que receber as mídias dos outros participantes, o que é ilustrado na Figura 4.6. 


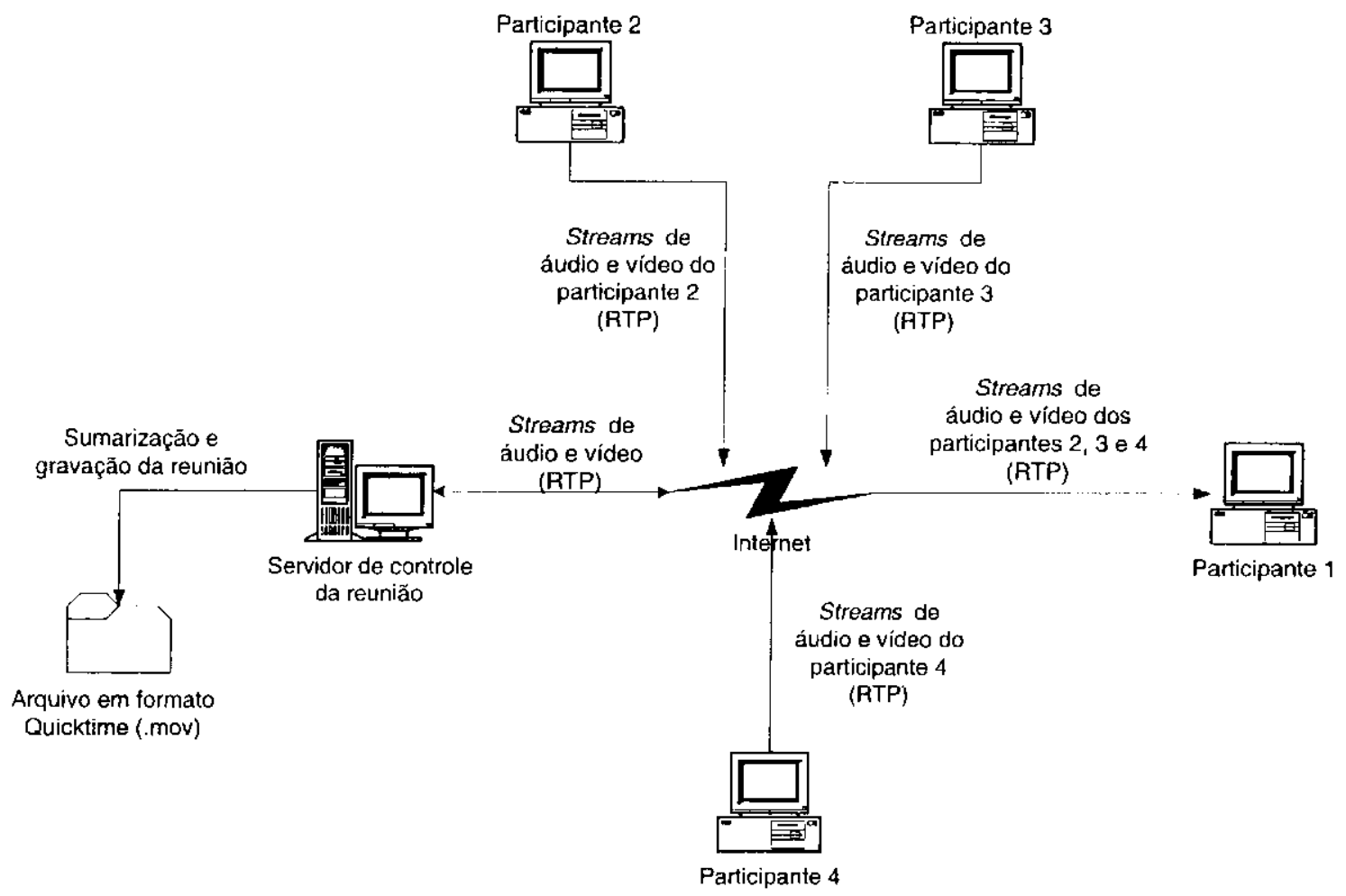

Figura 4.6 - Participante 1 recebendo as mídias de áudio e vídeo de todos os outros participantes da reuniāo (Participantes 2, 3 e 4).

Vale ressaltar que no eMeet/InCA todas as transmissões das mídias de áudio e vídeo dos participantes são feitas utilizando-se o protocolo de transporte RTP e este deve estar habilitado para o uso na API JMF. Normalmente, o suporte ao protocolo RTP já vem configurado na API, mas caso suspeite-se de que o protocolo não está sendo suportado, haverá a necessidade de verificar se a API JMF foi customizada, com o auxílio do JMF Customizer, e verificar se o protocolo realmente está sendo suportado. O JMF Customizer pode selecionar as funcionalidades (classes JAVA) que se deseja utilizar, fazendo com que o seu sistema possa ficar muito mais enxuto para uma determinada aplicação. A Figura 4.7 mostra a tela de configuraçāo do $J M F$ Customizer que seleciona ou nāo o suporte ao protocolo RTP. 


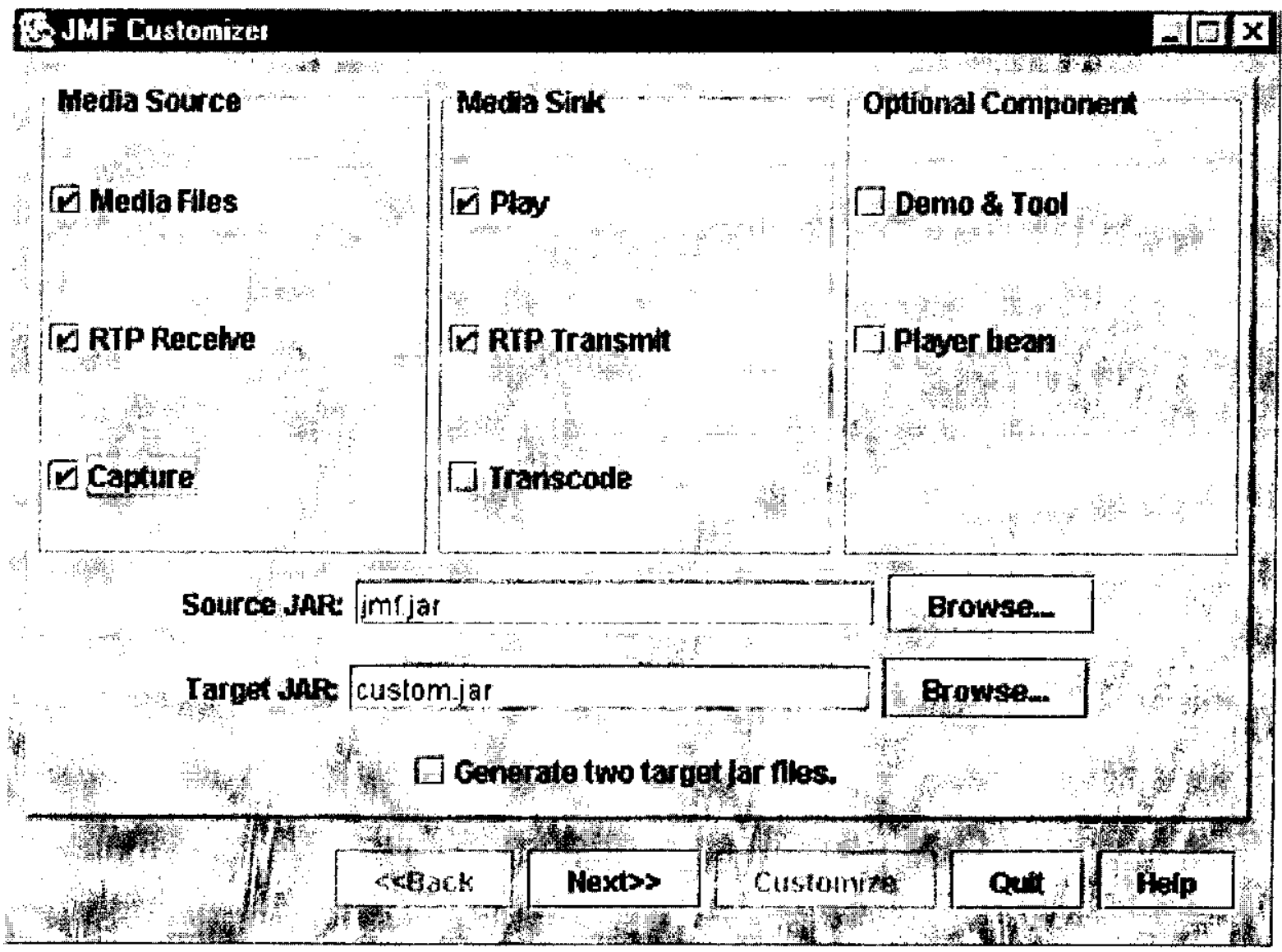

Figura 4.7 - JMF Customizer, aplicativo da API JMF para a configuraçāo dos recursos a serem suportados pela API. Recebimento e transmissão RTP estāo selecionados nesta configuração.

\subsubsection{Limitações da API JMF}

Durante a fase de desenvolvimento do projeto eMeet/InCA, a API JMF apresentou deficiências e bugs que se espera sejam solucionados nas próximas versões da API. A mixagem de várias streams de áudio é uma delas; atualmente, a API não suporta mixagem de várias streams de áudio para que se possa conseguir uma única stream final (isso é, stream que seja a somatória de todas as informações de áudio). Numa API destinada a trabalhar com várias mídias de informações, dentre elas a de áudio, isto é básico e fundamental. A API consegue somente fazer a multiplexação de streams de áudio, para que sejam demultiplexadas pelo receptor. Isto dá a impressāo, por parte do receptor, de que ele está recebendo somente uma stream. No entanto, esta stream deve ser demultiplexada para que se possa resgatar e processar corretamente as informações de áudio. No projeto descrito aqui, há a necessidade de uma mixagem das fontes (streams) de áudio para que o espaço de armazenamento de disco, exigido para a gravação da 
reunião, seja reduzido e a produção de um arquivo de vídeo no formato Quicktime, que contém a gravação da reunião, seja possível. Portanto, foi implementada uma classe (eMeetdDataSource) que faz a mixagem de várias fontes de áudio, em uma única stream. Essa tarefa não se mostrou trivial dada a dificuldade de extensão da API JMF para finalidades que ainda não tenham sido concebidas pelo modelo de implementação da API.

Outra deficiência apresentada foi quanto ao suporte ao protocolo RTP. Em máquinas rodando o sistema operacional Linux (RedHat 7.I) nem o recebimento e nem a transmissão de streams RTP foi possível (implicando que o servidor de reuniões do $e M e e t / I n C A$ não pode rodar em uma máquina Linux, pelo menos no momento em que este texto está sendo escrito). Neste caso, o problema poder ser a própria implementação da API no Linux, visto que a implementação não é de responsabilidade da Sun e sim de uma outra empresa, a Blackdown (http://www.blackdown.org). Já em máquinas rodando o sistema operacional Windows o recebimento de uma stream RTP fica restrito à aplicação dessa stream a apenas uma finalidade, ou seja, caso haja a necessidade de reproduzir uma stream de áudio, recebida pela rede através do protocolo RTP, e ao mesmo tempo gravá-la em arquivo, a API não fará nenhuma dessas duas tarefas. $O$ procedimento indicado pelo manual de referência da API JMF (http:/java.sun.com/products/java-media/jmf/2.1.1/guide) é o de a partir da stream RTP recebida, extrair o seu Data Source e, com ele, criar um novo Data Source que possa vir a ser clonado. Isto é possível através da chamada a um método estático da API (RTPManager.createCloneableDataSource()). Tendo-se criado um Data Source que pode ser clonado (Cloneable Data Source), para cada tarefa que se quer realizar com os dados encapsulados pelo Data Source, deve-se criar um clone. Esse clone é criado quando chamamos o método clone(), do Data Source que pode ser clonado, e é ele que será utilizado como Data Source para a realização das tarefas. Esse procedimento é ilustrado na Figura 4.8. 


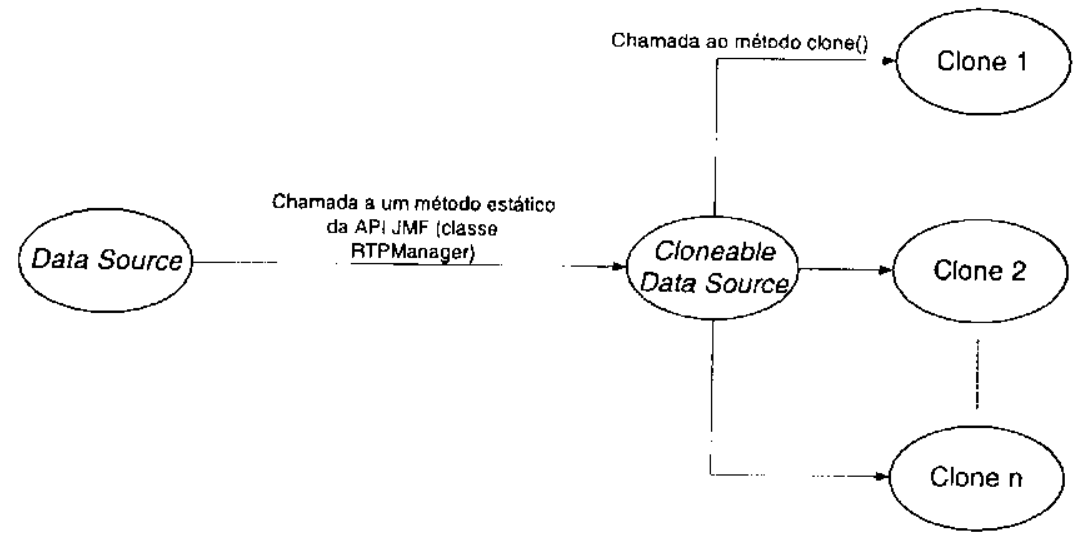

Figura 4.8 - Procedimento indicado pelo manual de referência da API JMF 2.1.1a (http://java.sun.com/products/java-media//mf/2.1.1/guide) para que, a partir de um Data Source consiga-se empregá-lo paralelamente a múltiplas tarefas.

Apesar desse ser o procedimento indicado pela API JMF, quando se extrai um Data Source de uma stream RTP as chamadas de criação de um novo Data Source clonável e de criação de clones não funcionam como esperado, apesar de não indicarem ocorrência de erro. Isto caracteriza um bug de implementação no projeto da API JMF. A solução encontrada para a aplicação eMeet/InCA (que necessita receber a stream de áudio de um participante e, ao mesmo tempo, enviá-la para os outros participantes além de processá-la para que haja a mixagem de áudio para a geração do arquivo de gravação da reunião), foi o redirecionamento das streams recebidas para portas locais da própria máquina. Essa solução funcionou perfeitamente. Assim, para cada tarefa, uma porta foi alocada na máquina. Entretanto, essa solução faz com que o servidor fique com um conjunto de portas alocadas muito maior do que o necessário teoricamente mas foi a única solução encontrada até o presente momento. A Figura 4.9 ilustra este procedimento alternativo que foi empregado no $e M e e t / I n C A$. 


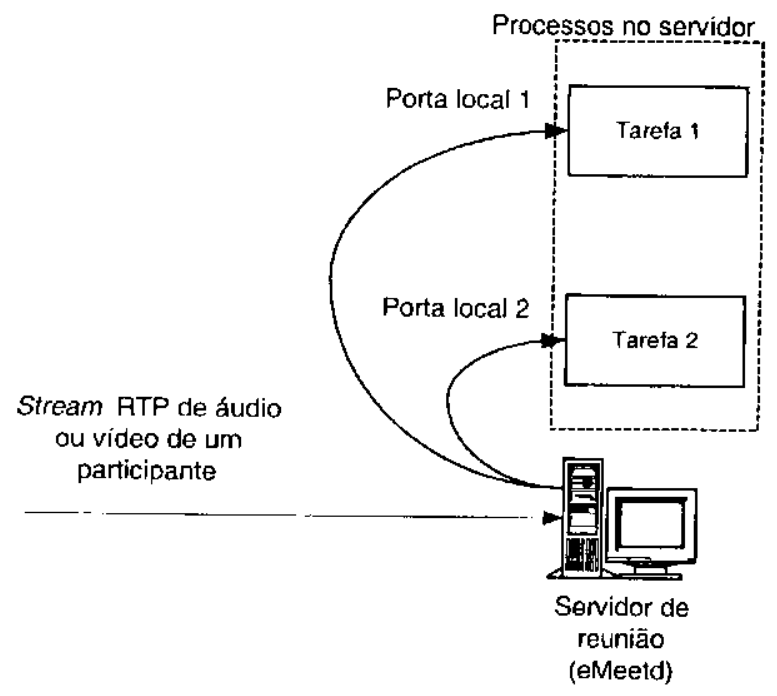

Figura 4.9 - Abordagem alternativa para solucionar uma das deficiências da API JMF, a recepção e tratamento múltiplos de uma stream RTP.

Deficiências como essas inviabilizaram a utilização no $e M e e t / I n C A$ de uma implementação da recomendação H.323, o J323 da IBM. A recomendação H.323 é um esforço de padronização dos formatos de áudio, vídeo, texto, compartilhamento de dados e controle de sessão utilizados em uma tele ou videoconferência que utiliza redes de computadores como meio de comunicação. Isso será explicado com mais detalhes na seção 4.4.4.2.

\subsubsection{A API JTAPI}

Nesta seção será abordada mais uma API da linguagem JAVA, a API JTAPI. Ela foi relevante ao projeto de análise e desenvolvimento do eMeet/InCA. É dada uma visão geral da API e são discutidas suas características relevantes ao projeto.

\subsubsection{Visão geral da API JTAPI}

A API JTAPI (Java Telephony API) é uma interface de programação portável e orientada a objeto, desenvolvida para aplicações computacionais de telefonia que utilizam a linguagem JAVA. A API é um conjunto de classes e interfaces que constituem uma extensão opcional do pacote javax.* de JAVA. JTAPI é essencialmente uma interface entre aplicaçõcs de telefonia computacionais em JAVA e telefones ou implementações de sistemas de telefonia. JTAPI pode ser utilizada em diversos tipos de aplicações, desde a implementação de uma aplicação de call center até o desenvolvimento de páginas web. 
JTAPI, na realidade, é um conjunto de várias API's e sua arquitetura é ilustrada na Figura 4.10. O núcleo da API provê um modelo básico com características rudimentares de telefonia, como estabelecer chamadas telefônicas e responder a uma chamada. O núcleo da API é rodeado por API's de extensões padrões que provêm funcionalidades para domínios específicos de telefonia, tais como call centers e acesso a streams de mídias.

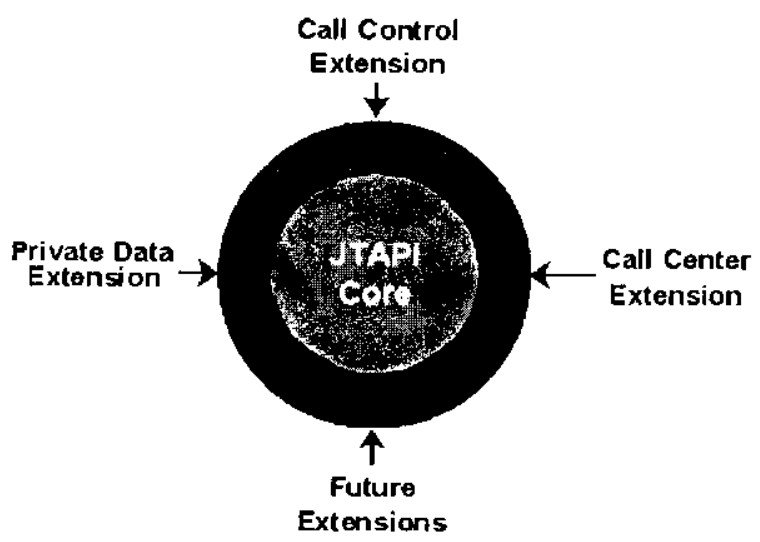

Figura 4.10 - Arquitetura da API JTAPI (Sun, 1999b).

Aplicações escritas utilizando a API JTAPI são portáveis entre vários tipos de plataformas computacionais e sistemas telefônicos. Implementações da JTAPI estarão disponíveis para plataformas de integração de sistemas telefônicos e computacionais, como a implementação SunXTL (da Sun Microsystems), a implementação TAPI (da Intel), a TSAPI (da Lucent) e o IBM CallPath. Outros fabricantes independentes, também podem escolher suportar a implementação JTAPI em cima de suas próprias plataformas de hardware.

A Figura 4.11 destaca como a API JTAPI se enquadra na comunicação entre uma aplicação ou applet e a máquina virtual e os dispositivos telefônicos que um sistema computacional possa ter. 


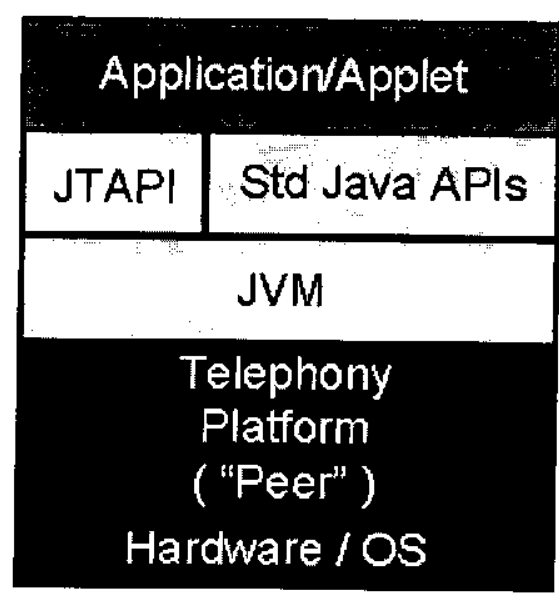

Figura 4.11 - Interação entre a API JTAPI, uma aplicação ou applet, a máquina virtual e os dispositivos telefônicos que a máquina possa ter (Sun, 1999b).

Como se pode notar pela Figura 4.11, a API JTAPI atua em paralelo a qualquer outra API padrão de JAVA, executando sobre a máquina virtual e fazendo uma interface entre a aplicação ou applet e os dispositivos de hardware telefônicos de um sistema computacional.

\subsubsection{2 eMeet/InCA e a API JTAPI}

A aplicação $e M e e t / I n C A$ é inerentemente uma aplicação que tem por base os princípios de uma tele ou videoconferência. Portanto, apesar de ter sido idealizada para atuar primariamente com dispositivos computacionais isto não significa que não seja desejável ampliar os dispositivos capazes de participar de uma reunião. Assim sendo, com a adoção e utilização da API JTAPI, o sistema eMeet/InCA pode abranger dispositivos telefônicos ou PDA's (Personal Digital Assistants).

A utilização da API JTAPI no eMeet/InCA se daria através da utilização da implementação da IBM da recomendação H.323 (destinada a padronizar os protocolos de comunicação em tcle ou videoconferências para dispositivos computacionais), o J323. Essa implementação utiliza como camada mais inferior de comunicação a API JTAPI.

No projeto atual não foi possível a utilização do J323 (ver seção 5.3.4.2) o que implica que a API JTAPI também não foi utilizada. No entanto, a sua utilização pode ser futuramente um agregado a mais ao projeto eMeet/InCA. 


\subsubsection{JAVA Web Start e a Integração do Sistema com a Web}

JAVA Web Start é uma nova tecnologia de implementação de aplicações a qual possibilita que aplicações JAVA sejam carregadas a partir de um link em uma página web.

Antes da existência da tecnologia JAVA Web Start qualquer aplicação ou applet que necessitasse de permissões extras para executar em uma máquina remota, além daquelas permissões que o sandbox do JAVA permite, era necessário que o código passasse por todo um processo complexo de autenticação e validação de código. Além disso, os processos de autenticação divergiam entre navegadores diferentes, cada um tendo o seu próprio critério de autenticaçāo (Microsoft Authenticode para o Internet Explorer, Netscape Object Sign para o Netscape e o sistema de autenticação do JDK 1.2 para o HotJava, são exemplos disto). Com JAVA Web Start pode-se carregar e iniciar aplicações sem a necessidade de se passar por todo esse processo, bastando apenas que a máquina cliente possua o JAVA Web Start instalado.

JAVA Web Start inclui os critérios de segurança de uma plataforma JAVA 1.2 (também conhecido como JAVA 2), portanto a integridade dos dados e arquivos não são comprometidos, além de se poder utilizar a tecnologia JAVA 2 em qualquer navegador web.

Quando a aplicação desejada não estiver presente no computador o JAVA Web Start automaticamente faz o download de todos os arquivos necessários. Esses arquivos são colocados no cache local da máquina para que a aplicação possa vir a ser executada novamente a qualquer momento (por exemplo através de um ícone no desktop ou de um link no navegador). Não importa qual o método que se utilize para iniciar a aplicação, pois a versão mais recente é sempre apresentada.

Como a tecnologia JAVA Web Start é independente de qualquer navegador pode-se encerrar a execução do navegador ou navegar para uma outra página e, mesmo assim, continuar usando a aplicação. As aplicações implementadas com o JAVA Web Start não precisam de uma interface de um navegador para operar.

A Figura 4.12 mostra a arquitetura da tecnologia JAVA Web Start. 


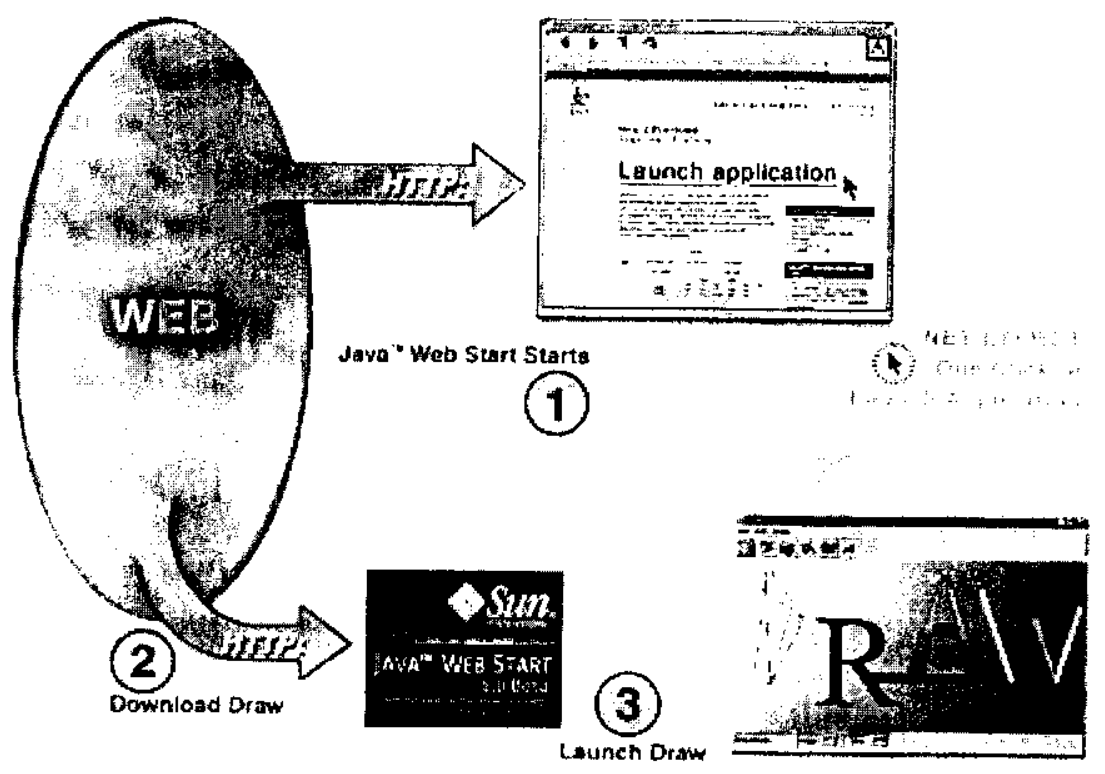

Figura 4.12 - Arquitetura da tecnologia JAVA Web Start (Sun, 2001b).

Na Figura 4.12 a seta localizada mais à direita ("NET EFFECT") mostra a experiência por parte do usuário que através de uma navegação inicia uma aplicação completa em JAVA, a qual pode nunca ter sido executada antes na máquina. O que está acontecendo por trás é o que as outras setas $(1,2$ e 3$)$ estão indicando :

- Quando o usuário clica em um link de download, o link instrui o navegador a invocar a tecnologia Web Start. O JAVA Web Start apresenta então uma tela inicial (seta (1));

- O JAVA Web Start procura na Web e tenta determinar se todos os recursos necessários para a execução da aplicação estão presentes. Se não, ou se eles não forem os mais recentes, ele automaticamente os carrega de uma forma totalmente transparente ao usuário (seta (2));

- Finalmente, a aplicação é executada (seta (3)).

\subsubsection{1 eMeet/InCA e JAVA Web Start}

Como a autenticação dos usuários que irão participar de uma reunião é feita através das páginas na Web do eMeet/SERVE, há então a necessidade de se iniciar a aplicação eMeet/InCA na máquina do participante. Isto é feito com o auxílio da tecnologia JAVA Web Start, tornando todo 
o processo transparente ao usuário. A Figura 4.13 mostra a tela inicial do eMeet/SERVE, a qual tem no seu canto inferior esquerdo um sistema de autenticação dos usuários da aplicação eMeet e que é baseado na entrada de um login e uma senha previamente cadastrados. Além da autenticação c visualização das informações capturadas pelo eMeet/InCA, o eMeet/SERVE também possui um módulo de criação e agendamento de reuniões (Eleutério, 2002).

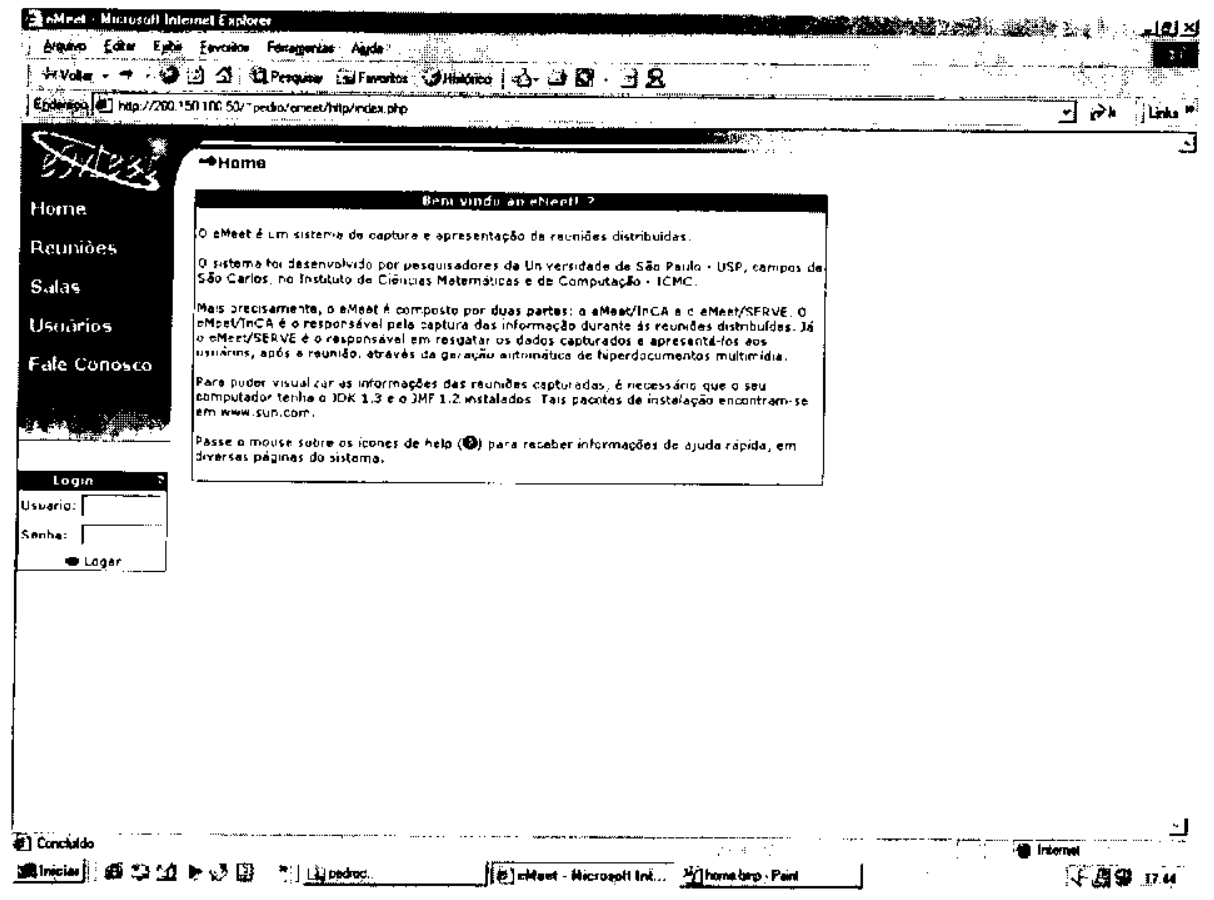

Figura 4.13 - Tela inicial do eMeet/SERVE (Eleutério, 2002).

\subsubsection{Interface Gráfica com o usuário}

Uma vez que para se chegar a uma interface gráfica adequada, em qualquer projeto de desenvolvimento de software, há a necessidade de se avaliar a funcionalidade da mesma e, geralmente, necessita-se construir várias versões, optou-se por adotar uma ferramenta de desenvolvimento RAD (Rapid Application Development), diminuindo assim, o tempo de desenvolvimento da interface.

No mercado existem algumas ferramentas desenvolvidas para JAVA, dentre elas pode-se destacar: Forte for JAVA, Symantech VisualCafe, J++ e IBM VisualAge for JAVA. Esta última foi a ferramenta escolhida para tal tarefa, simplesmente pelo fato do autor ter afinidade com a mesma (de utilizações anteriores a este projeto). 
No IBM VisualAge for JAVA pôde-se criar a interface gráfica de uma forma rápida e eficaz, proporcionando um ambiente de desenvolvimento WYSIWYG (What You See Is What You Get). A Figura 4.14, mostra o ambiente integrado de desenvolvimento (IDE - Integrated Development Environment) do IBM VisualAge for JAVA, e a interface principal do eMeet/InCA com o usuário.

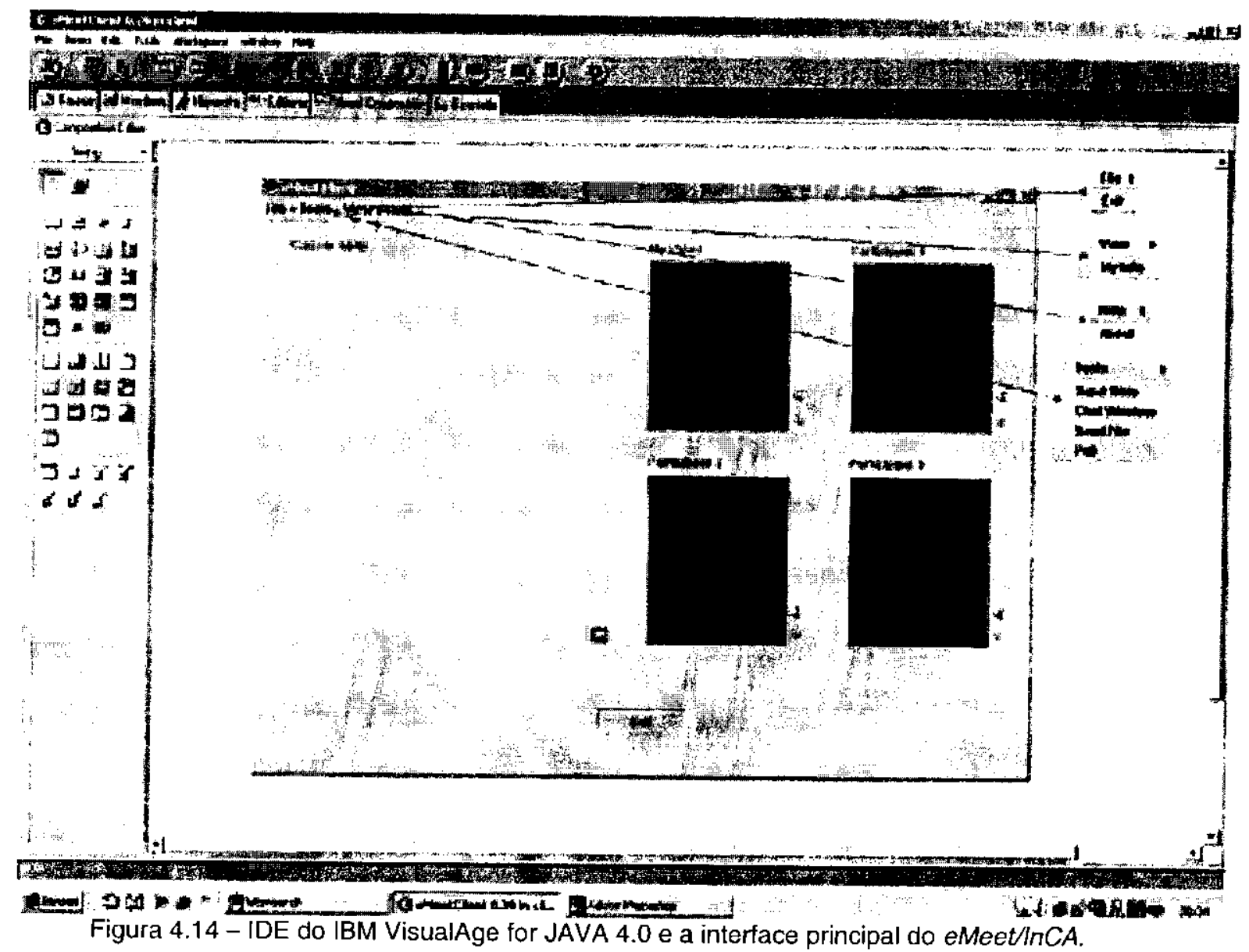

O IBM VisualAge for JAVA foi também utilizado para criar grande parte do código requerido para a interação com o usuário. Assim, todos os eventos referentes à interface gráfica tais como cliques do mouse ou pressionamento de teclas puderam ser tratados de forma rápida e eficaz. Uma desvantagem disso foi os vários métodos criados no código fonte das classes, o que foi compensado pelo tempo economizado para a criação do código manualmente. 


\subsection{OS PROTOCOLOS PADRÕES DE COMUNICAÇÃO}

Uma das características fundamentais na construção de uma aplicação como o eMeet/InCA é a adoção de protocolos padrões de comunicação. Assim, é possível a interoperabilidade do sistema com outras ferramentas similares existentes ou que venham ainda a ser criadas. Esse aspecto foi levado em consideração no desenvolvimento da aplicação e, nesta seção, são discutidas algumas alternativas encontradas (recomendação H.323 (IEC, 1999) e o SIP - Session Initiation Protocol (http://www.ietf.org/rfc/rfc2543.txt)) e as decisões de implementação tomadas.

\subsubsection{O padrão $\mathrm{H} .323$}

H.323 (IEC, 1999) é um padrão que especifica os componentes, protocolos e procedimentos que provêm serviços de comunicação em tempo real (áudio, vídeo e comunicação de dados), sobre redes por pacote, incluindo redes baseadas no protocolo de internet (IP). H.323 é parte da família de recomendações ITU-T (um dos setores de padronização da International Telecommunication Union) chamada H.32x, que provê serviços de comunicação multimídia sobre uma variedade de redes.

O H.323 é um padrão para a transmissão em tempo real de áudio, vídeo e comunicação de dados sobre uma rede baseada em pacotes. Ele especifica os componentes, protocolos e procedimentos que provêm uma comunicação multimídia sobre redes baseadas em pacotes, como é ilustrado na Figura 4.15.

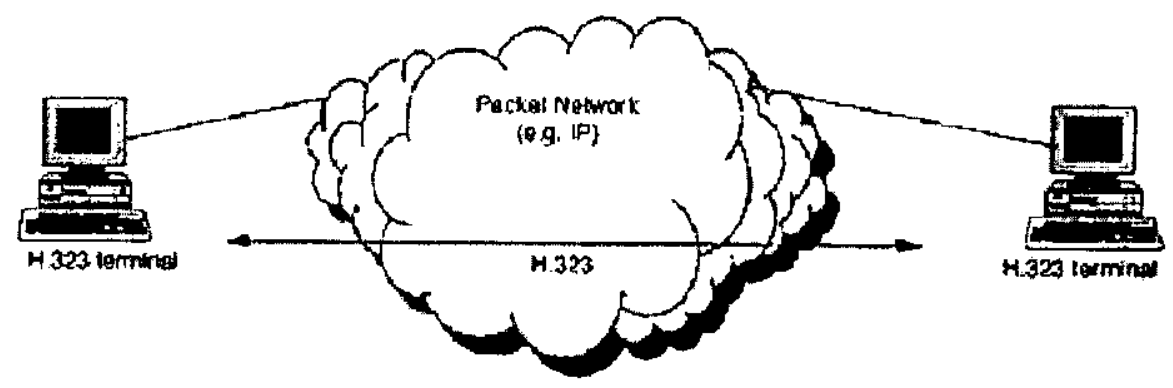

Figura 4.15 - Terminais H.323 em uma rede por pacotes (IEC, 1999).

Redes baseadas em pacote incluem redes que utilizam a tecnologia IP (incluindo a Internet), redes IPX (Internet Packet eXchange), que podem abranger LANs (Local Area Networks), Ens (Enterprise Networks), MANs (Metropolitan Área Networks) e WANs (Wide Area Networks). O 
H.323 pode ser empregado $\mathrm{cm}$ uma variedade de mecanismos: somente áudio (telefonia IP), áudio e vídeo (videotelefonia), áudio e dados com áudio, vídeo e dados (eMeet/InCA, por exemplo). H.323 pode ser utilizado também em comunicações multimídia multiponto.

\subsubsection{Versões do H.323}

A primeira versão do padrão $H .323$ especificado pelo grupo de estudo 16 do ITU-T refere-se a sistemas telefônicos visuais e equipamentos para LANs que não tenham garantia de qualidade de serviço (QoS). Essa versão, em outubro de 1996, foi oficializada e era muito fortemente direcionada a comunicações multimídia em LANs.

Com o advento da tecnologia de voz sobre IP (VoIP) e suas aplicações, foi necessária a reformulação da recomendação H.323, pois a ausência de um padrão para voz sobre IP resultou em produtos que eram incompatíveis entre si. A tecnologia de voz sobre IP exigia novos requisitos, tais como: prover a comunicação entre um computador e um telefone convencional através da rede de telefonia (SCN, Switched Circuit Network). A segunda versão do H.323 oficializada em janeiro de 1998 atende a tais requisitos.

A versão 3 do H.323 traz novas características como o suporte à transmissão e recepção de fax e mecanismos de conexão rápida.

\subsubsection{H.323 e sua relação com outros padrões da família H.32x}

O H.323 é um padrão que faz parte de uma família, a H.32x, especificada pela ITU-T. As outras recomendações da família especificam scrviços multimídia em diferentes tipos de redes:

- H.324 sobre SCN (a rede pública de telefonia);

- H.320 sobre ISDN (Integrated Services Digital Networks);

- H.321 e H.310 sobre ISDN de banda larga (B-ISDN);

- H.322 sobre LANs que tenham garantia de qualidade de serviço (QoS).

Um dos principais objetivos no desenvolvimento do padrão H.323 foi a interoperabilidade com outras redes de serviço multimídia. Isto é conseguido através dos Gateways, que são 
dispositivos responsáveis pela tradução, de uma rede para a outra, dos sinais necessários para a interoperabilidade (IEC, 1999).

\subsubsection{Protocolos especificados pelo H.323}

H.323 é independente da rede de pacotes e protocolos de transporte na qual ele é executado, portanto, nenhum dos dois é mencionado. Os protocolos especificados pelo H.323 são:

- Codificadores de áudio (áudio CODECs);

- Codificadores de vídeo (vídeo CODECs);

- H.225 registro, admissão e status;

- H.225 sinalização de chamada;

- H.245 sinalização de controle;

- Protocolo de transporte em tempo real (RTP);

- Protocolo de controle de transporte em tempo real (RTCP).

A Figura 4.16, mostra a pilha de protocolos de um terminal H.323.

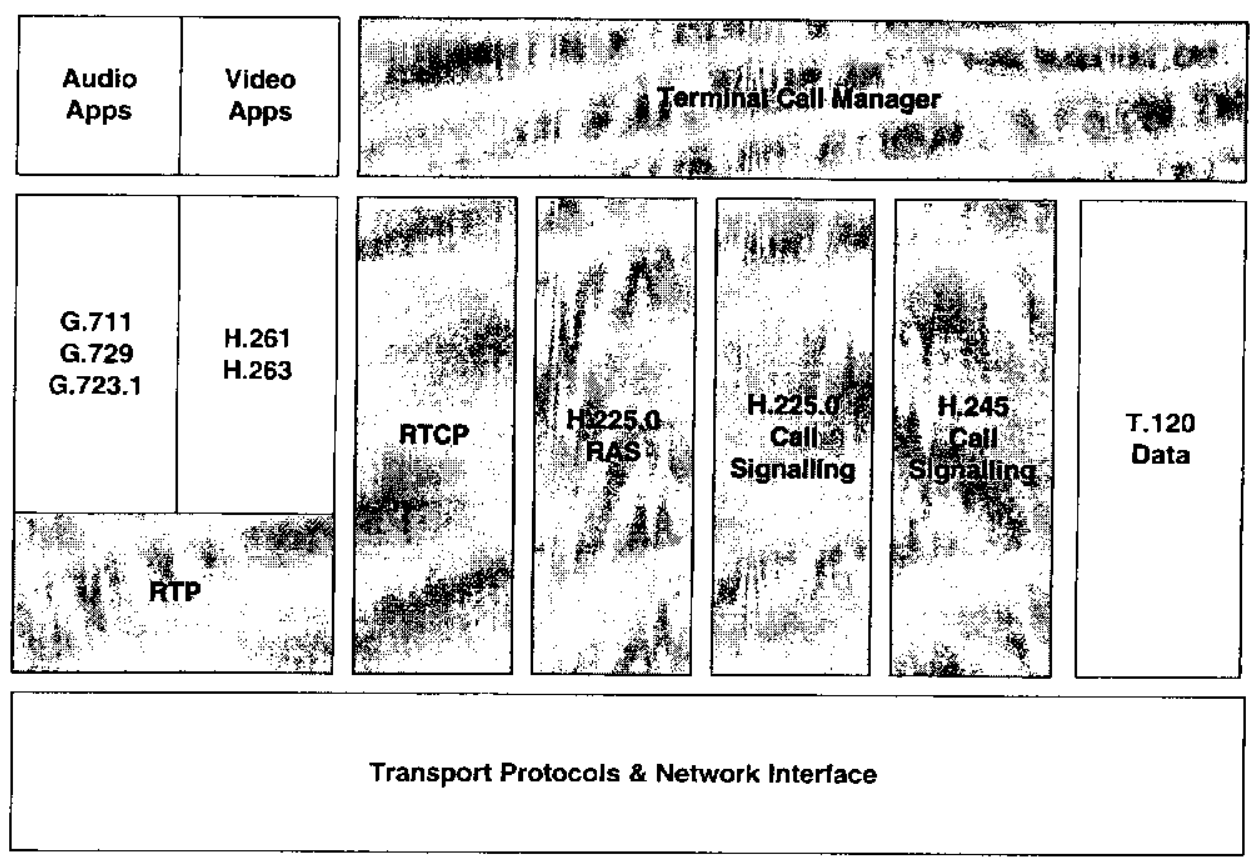

Figura 4.16 - Pilha de protocolos de um terminal H.323 (IEC, 1999). 


\subsubsection{1 Áudio CODEC}

Um codificador-decodificador de áudio ( $C O D E C$ de áudio) é responsável pela codificação do sinal de áudio de um microfone de um terminal H.323 e pela decodificação no terminal H.323 de recepção. Como áudio é o serviço mínimo provido pelo padrão H.323, todos os terminais H.323 têm que possuir pelo menos um CODEC de áudio, o ITU-T G.711 (recomendação de codificação de áudio a $64 \mathrm{kbps}$ ). Outras recomendações de áudio podem ser suportadas, tais como: G.722 (64, 56 e 48 kbps), G.723.1 (5.3 e 6.3 kbps), G.728 (16 kbps) e G.729 (8 kbps).

\subsubsection{Vídeo CODEC}

O CODEC de vídeo é responsável pela codificação de vídeo de uma câmera para a transmissão de um terminal H.323 e pela decodificação no terminal H.323 destino, para que o vídeo possa ser apresentado ao usuário remoto. Como o suporte ao vídeo é opcional no H.323, o suporte a um CODEC de vídeo também é opcional. No entanto, qualquer terminal H.323 que tenha suporte a comunicação por vídeo deve suportar, ao menos, a recomendação ITU-T H.261.

\subsubsection{H.225 registro, admissão e status}

Registro, admissão e status (RAS) é o protocolo entre dispositivos endpoint (terminais e gateways) e gatekeepers (dispositivos que centralizam todas as chamadas em uma rede H.323). O RAS é utilizado para gerenciar o registro, controle de admissão, mudanças de largura de banda, status e saída entre dispositivos endpoint e gatekeepers. Um canal RAS é usado para a troca de mensagens, sendo aberto entre dispositivos endpoint e gatekeepers antes da abertura de qualquer outro canal de comunicação.

\subsubsection{H.225 sinalização de chamada}

O protocolo H.225 de sinalização de chamada é utilizado para se estabelecer a conexão entre dois dispositivos terminais H.323. Essa conexão é estabelecida através da troca de mensagens no canal de sinalização de chamada. O canal de sinalização de chamada é aberto entre dois dispositivos terminais H.323 ou entre um endpoint e um gatekeeper. 


\subsubsection{H.245 sinalização de controle}

O protocolo de controle H.245 é utilizado entre dois dispositivos terminais H.323 para a troca de mensagens de controle. As mensagens de controle referem-se a:

- troca de capabilidades;

- abertura e fechamento de canais lógicos utilizados para o transporte de streams de dados;

- mensagens de controle de fluxo;

- comandos genéricos e indicações.

\subsubsection{Protocolo de transporte em tempo real (RTP)}

O protocolo de transporte em tempo real (RTP) é responsável pela entrega ponto a ponto de serviços de áudio e vídeo, de mancira rápida e eficiente. Enquanto o H.323 é utilizado para o transporte de dados sobre redes baseadas na tecnologia IP, RTP é normalmente utilizado para o transporte de dados via UDP (User Datagram Protocol). RTP, em conjunto com UDP, provê funcionalidades de um protocolo de transporte. No entanto, RTP pode ser utilizado em conjunto com outros protocolos, além do UDP.

\subsubsection{Protocolo de controle de transporte em tempo real (RTCP)}

O protocolo de controle de transporte em tempo real (RTCP) é o protocolo que provê serviços de controle a uma transmissāo RTP. A sua principal função é dar uma resposta sobre a qualidade de distribuição de dados que está sendo feita.

\subsubsection{Implementações existentes do padrão H.323}

Existem, atualmente, algumas implementações de APIs da recomendação ITU-T H.323. A maioria corresponde a implementações proprietárias, geralmente baseadas na linguagem C. As principais API's encontradas são destacadas a seguir: 
- OpenH323: projeto iniciado por uma empresa australiana, a Equivalence Pty Ltd. É um projeto colaborativo baseado na implementação da recomendação H.323 na linguagem C (Equivalence, 2002);

- RADVision H.323 Toolkit: é um toolkit de desenvolvimento implementado na linguagem $\mathrm{C}$ para a implementação de aplicações que necessitem suportar a recomendação $H .323$, contando com todas as exigências mínimas impostas pela recomendação (RADVision, 2001);

- CoH.323: é um kit de desenvolvimento de software da Altium Technologies implementado na linguagem $\mathrm{C}$ e que consiste na implementação da pilha de protocolos H.323 e documentos relacionados, possibilitando a utilização do protocolo de transporte RTP em conjunto com RTCP (Altium, 2001);

- Horizon H.323: implementação ANSI-C do padrão ITU-T H.323 que executa em Windows, Linux e telefones com suporte a vídeo, da Lucent. A empresa responsável pelo projeto é a Horizon Companies Inc. (Horizon, 2001);

- J323: implementação JAVA da IBM para suportar o H.323. Utiliza como base a API de telefonia do JAVA (JTAPI) e, para a apresentação das streams de mídia, o JMF (Java Media Framework) (IBM, 2001).

Como a aplicação eMeet/InCA foi desenvolvida em JAVA, a API mais adequada seria a J323, da IBM. No entanto, essa API não foi utilizada no projeto pois possuía muitas limitações, conforme detalhado na Seção 4.4.4.2. Atualmente, está sendo desenvolvida, pela Sun, uma API JAVA para redes integradas, a JAIN (Java API for Integrated Networks). Uma das requisições de especificação existente é a JAIN H.323, solicitada pela empresa RADVision. Esta requisição é um esforço de padronização de uma API de suporte ao protocolo H.323. Esse esforço deve ser acompanhado com atenção, mesmo ainda estando em fase inicial de desenvolvimento. 


\subsubsection{O eMeet/InCA como um terminal $\mathrm{H} .323$}

Caso o eMeet/InCA implementasse a recomendação H.323, por exemplo através da API J323, teria características que o faria compatível com muitas aplicações de tele ou videoconferência existentes atualmente (como, por exemplo, o Microsoft Netmeeting). As características que o $e M e e t / I n C A$ suportaria e as limitações da API $\mathbf{J} 323$, que indisponibilizaram a sua utilização no projeto, inviabilizando o suporte ao H.323, são abordadas a seguir.

\subsubsection{As características de um terminal H.323}

As características que devem ser suportadas por um terminal H.323 são:

- suporte a H.245 para a troca de recursos (capabilities) de terminais e criação de canais de mídia;

- suporte a H.245 para sinalização de chamada e seu estabelecimento;

- suporte a RAS para o registro e outros controles de admissão com um gatekeeper;

- seqüenciação de pacotes de áudio e vídeo para RTP/RTCP.

Os terminais H.323 têm que suportar o CODEC G.711 para áudio. Como componentes opcionais temos: CODECS de vídeo, protocolo de compartilhamento de dados (T.120) e recursos (capabilities) de MCU (Multipoint Control Units).

\subsubsection{A API J323 e suas limitações}

O J323 (implementação da recomendação H.323, em JAVA, pela IBM) utiliza como API's de suporte as API's JMF e JTAPI. Ambas contribuem para que o desenvolvimento do J323 não seja uma tarefa trivial.

O JMF, mesmo na sua última versão 2.1.1a, possui muitas limitações quanto ao suporte a aplicações voltadas à telefonia IP. A versão atual do J323 consegue, de modo limitado, utilizar a API JMF para o suporte a uma única chamada ponto a ponto. Conferências multiponto, como é o caso do projeto $e M e e t / I n C A$, não podem ser implementadas atualmente. Existe uma lista de erros identificados pela IBM que foram reportadas ao grupo de desenvolvimento da Sun (IBM, 2000). Há um esforço conjunto da IBM e da Sun para que todas as deficiências encontradas sejam solucionadas para a próxima versão da API. 
A API JTAPI teve grandes modificações tanto em termos de conceitos como de implementação na evolução de sua versão 1.2 para a 1.3, no final de julho de 1999. Muitos métodos foram abandonados e muitas classes foram remodeladas. Assim, o impacto perante a implementação do J323, que é baseado na JTAPI 1.2, foi muito grande. A API J323 terá que ser totalmente reformulada e grande parte do seu código alterado.

Todos esses fatores fizeram com que durante o processo de criação da versão atual do eMeet/InCA a possível adoção da API $\mathrm{J} 323$ fosse abandonada.

\subsubsection{O protocolo SIP}

O SIP (Session Initiation Protocol, ou Protocolo de Iniciação de Sessão) era outra alternativa de utilização para o controle e gerenciamento do eMeet/InCA. O SIP é um protocolo de sinalização de controle para a criação, modificação e término de sessões com um ou mais participantes. Essas sessões incluem conferências multimídia pela Internet (como é o caso do eMeet/InCA), chamadas de telefones pela Internet e distribuição multimídia. Membros em uma sessão podem comunicar-se via difusāo multicast ou através de várias comunicações unicast ou uma combinação de ambos.

O SIP permite que em uma sessão seus participantes concordem com um conjunto compatível de tipos de mídia. SIP também não é atrelado a um protocolo de controle de conferência particular e foi desenvolvido para ser independente das camadas mais baixas de protocolo de transporte, podendo ser estendido com capacidades adicionais.

Uma das desvantagens do SIP durante a fase de implementação do $e M e e t / \ln C A$ foi a inexistência da garantia de que o SIP pudesse se tornar um protocolo padrão a todas as aplicações de tele ou videoconferência para dispositivos que rodem em uma rede de pacotes. Com isso, a grande vantagem que se tinha quando se desejava adotar a recomendação H.323, que era justamente a padronização $\mathrm{c}$ interoperabilidade de dispositivos, também não estava prescnte no SIP. Hoje, apesar do SIP estar ainda evoluindo e se tornando mais popular, ainda não é uma garantia de que se torne um padrão a ser seguido. 


\subsection{6 eMeet/lnCA e a escolha dos protocolos de comunicação}

O eMeet/InCA deveria suportar o protocolo ITU-T H.323 para que pudesse se tornar uma aplicaçăo realmente padronizada e intercambiável com demais aplicações do gênero. Isso seria alcançado com a adoção da API J323 da IBM na construção da aplicação. Porém, devido às deficiências encontradas e comentadas na seção 4.4.4.2 a API J323 não foi utilizada. Outra opção era a utilização do protocolo de sinalização SIP (ver seção 4.4.5) mas, como não era uma alternativa padronizada ou adotada em várias aplicações similares, a sua utilização também não foi empregada. A melhor alternativa encontrada foi a criação de um mecanismo próprio de controle e gerenciamento, tanto em termos de sessão como em termos de controle de mídias, para facilitar e agilizar o desenvolvimento da aplicação, uma vez que a interoperabilidade entre sistemas não poderia ser alcançada na versão atual. No entanto, durante o processo de desenvolvimento da versão atual do $e M e e t / I n C A$ foram tomados cuidados para facilitar a futura padronização da aplicação.

\subsection{TRANSMISSÃO DE DADOS}

O tipo de difusão de dados a ser adotado no eMeet/InCA também foi um aspecto de implementação analisado. Numa comunicação entre dois ou mais computadores existem, basicamente, três formas de difusão de dados: unicast, multicast e broadcast. Essas três formas de transmissão são analisadas a seguir juntamente com a escolha adotada para a implementação do $e$ Meet/InCA.

\subsubsection{Transmissāo Unicast}

A difusão unicast é o tipo de difusão de dados que é comumente utilizada na Internet, ou seja, há uma fonte que envia dados (servidor) e uma que recebe estes dados (cliente). O serviço unicast é uma característica básica provida pelo protocolo de Internet, o protocolo IP.

A desvantagem associada à transmissão unicast em uma aplicação como o eMeet/InCA é o fato de que todas as streams a serem enviadas, do servidor para os participantes, serão enviadas uma a uma para cada participante. Portanto, se a informação a ser enviada for a mesma para os participantes, há a necessidade de se criar várias streams idênticas de dados. Isto faz com que a 
banda de rede necessária seja elevada, além de exigir um poder maior de processamento do servidor. A Figura 4.17 ilustra esse caso em particular no qual as streams de dados (áudio e vídeo) do Participante 1 têm que ser replicadas para cada transmissão para os outros participantes, demandando uma maior largura de banda para o servidor além de um processamento maior.

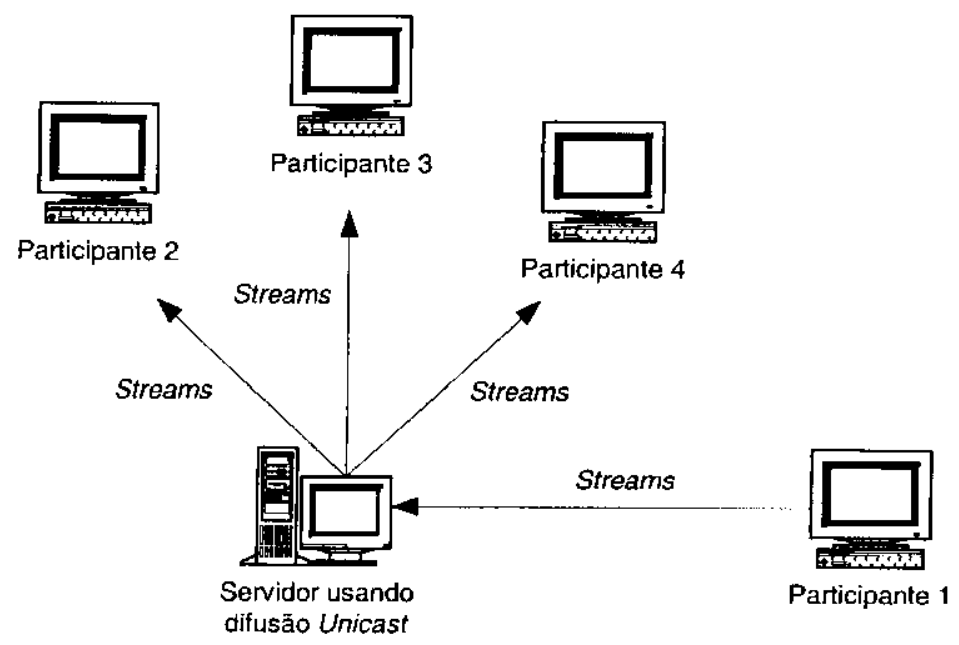

Figura 4.17 - Transmissão de dados Unicast.

\subsubsection{Transmissão Multicast}

O princípio da transmissão multicast é o envio de dados de uma fonte para múltiplos destinatários. Esses múltiplos destinatários sāo reunidos em grupos chamados grupos multicast. Multicast é um serviço de comunicação ponto a multiponto que replica um pacote de dados somente quando ele atinge uma bifurcação. O pacote deve ser recebido simultaneamente pelos participantes de um grupo com o menor número de replicações e na menor rota para cada destino de um grupo.

A transmissão multicast é o tipo de transmissão ideal para aplicações como o eMeet/InCA, pois a banda requerida pelo servidor, bem como o processamento exigido, é sempre constante uma vez que a sub-rede é que se encarrega da distribuição dos dados para os múltiplos destinatários, todos associados a um mesmo grupo. A Figura 4.18 ilustra a utilização desse tipo de transmissão associada à aplicação $e M e e t / \ln C A$ no qual o Participante 1 envia as streams de dados (áudio e vídeo) ao servidor que, por sua vez, reenvia-as para múltiplos destinatários (os 
outros participantes). Os pacotes de dados são replicados pela sub-rede à medida que seja necessário tal procedimento.

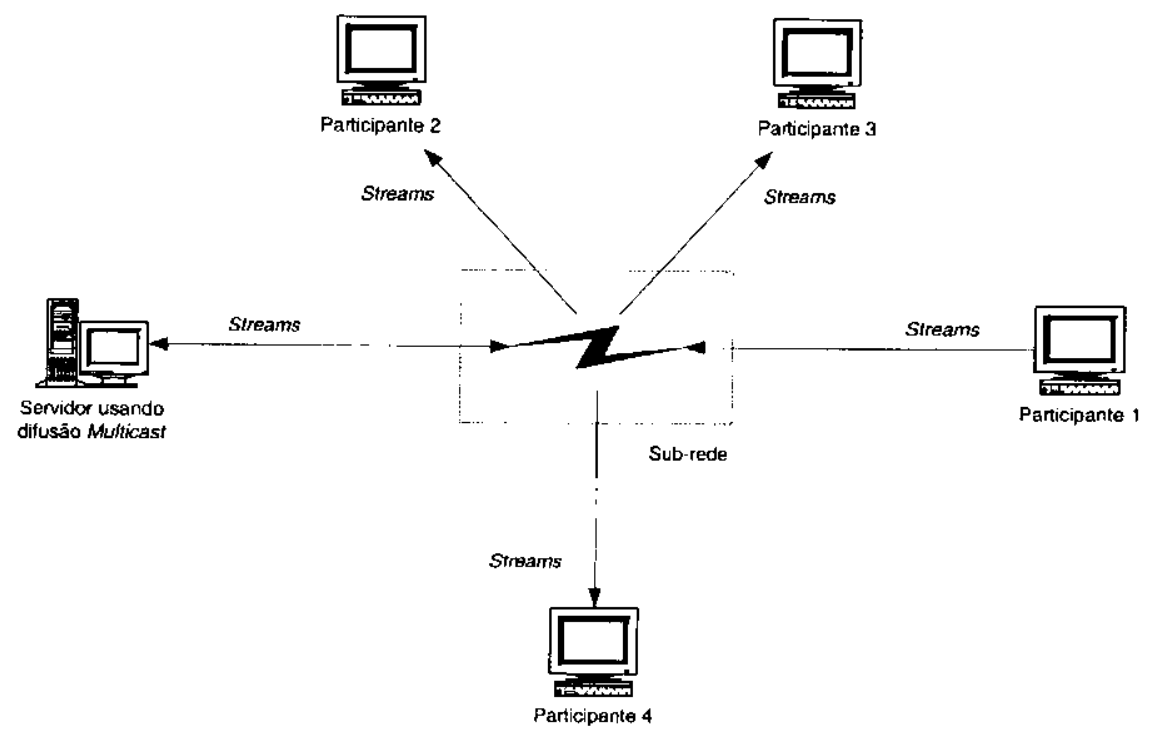

Figura 4.18 - Transmissāo Multicast.

\subsubsection{Transmissão Broadcast}

A transmissão broadcast é uma transmissão de dados de uma fonte a todos os outros destinatários conectados. Broadcast é diferente de multicast porque multicast é uma transmissão seletiva e broadcast não. Um exemplo de transmissão broadcast é a transmissão de uma rádio que atinge todos os aparelhos receptores daquela região em que a rádio atua. A Figura 4.19 ilustra esse tipo de difusão no qual o Participante 1 envia suas streams de dados (áudio e vídeo) para o servidor $e M e e t / I n C A$. Este, por sua vez, retransmite as streams recebidas para todos os participantes da reunião, ou seja, os Participantes 2,3,4 e também o Participante l porque ele também está conectado com o servidor (responsável pela distribuição dos dados). 


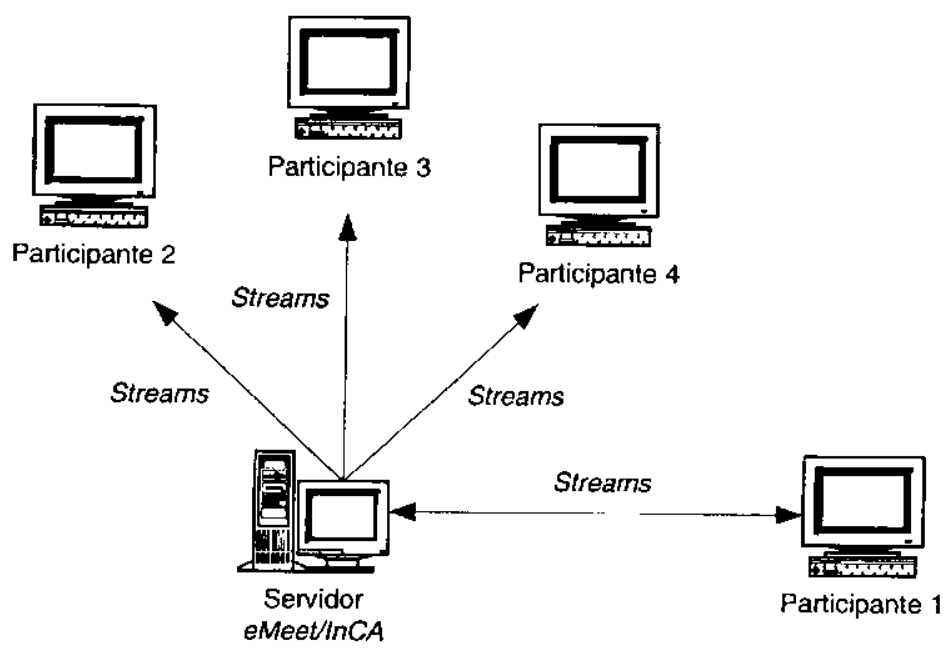

Figura 4.19 - Transmissāo Broadcast.

\subsubsection{Transmissão empregada no eMeet/InCA}

Numa aplicação como o eMeet/InCA, uma pequena janela de vídeo com proporções de $160 \times 120$ pixels e 15 quadros por segundo demanda uma banda de rede na ordem de $100 \mathrm{Kbps}$. Caso se queira uma transmissão de ótima qualidade (tela cheia, por exemplo), a banda passante pode chegar até $600 \mathrm{Kbps}$. Isso pode ser muito prejudicial à transmissão dos dados em uma rede de baixa velocidade com grande fluxo de dados ou com usuários utilizando conexões dial-up. Caso a comunicação entre os participantes seja muito lenta nada se pode fazer e, muito provavelmente, isto levará à frustração do participante. Assim sendo, o tipo de transmissão de dados ideal para uma aplicaçāo como o eMeet/InCA é, sem dúvida, a transmissão multicast. Com ela, a banda de rede necessária para a difusão das streams de um participante a todos os outros fica minimizada.

Atualmente, a grande desvantagem da utilização da tecnologia de transmissão multicast, $\mathrm{e}$ que foi o fator pelo qual esse tipo de transmissão não foi empregado no eMeet/InCA, é o fato de que o protocolo multicast é suportado somente por alguns poucos computadores da sub-rede. Um roteador de um provedor de serviços de internet (um ISP, Internet Service Provider) comum, em geral, não suporta a transmissão multicast se não possuir um mrouter (roteador capaz de entender o protocolo multicast), o que diminui muito o grau de abrangência da aplicação. Além do mais, serviços de alta velocidade no Brasil não suportam atualmente o protocolo multicast.

Com base nesses aspectos, a tecnologia de difusão empregada na construção do eMeet/InCA foi a tecnologia padrāo, a difusão unicast. Porém, como a transmissão das mídias é 
feita por RTP, utilizando-se a API JMF, fica muito fácil estender a aplicação para suportar a transmissão multicast, mudando-se somente a lógica de controle de gerenciamento de sessāo do sistema. À medida que o protocolo multicast tenha um suporte maior, esta é uma evolução lógica da implementação atual.

\subsection{SINCRONIZAÇÃO INTERMÍDIA}

A maior dificuldade no desenvolvimento de projetos como o eMeet/InCA está justamente na sincronização e no armazenamento de todas as streams (áudio, vídeo, texto, etc.) de dados geradas por todos os participantes de uma sessão. (Mukhopadhyay \& Smith, 1999) mostram soluções de sincronização de mídias em pares, classificando o problema de sincronização de mídias em três categorias básica: sincronização temporizada/temporizada (entre duas mídias que podem conter sua própria sincronização cada), temporizada/não-temporizada (somente uma das mídias é sincronizada) e não-temporizada/não-temporizada (nenhuma das mídias possui sincronização). Mukhopadhyay \& Smith ainda apontam, uma vez sincronizadas as mídias em pares, como organizar uma sincronia geral para todas as mídias. Esta abordagem parece ser ótima para poucas mídias, mas uma vez que se tenham várias fontes de dados, o erro de sincronização de cada par é somado e o erro de sincronia do sistema será a soma de todos os erros dos pares. (Hürst \& Müller, 1999) sugerem uma outra opção: escolhe-se uma mídia mestra (geralmente áudio) à qual possam ser associadas timestamps e todas as outras mídias são relacionadas com a sua temporização. Durante a reprodução, a mídia mestra servirá como base de sincronia para as demais, podendo a reprodução de todas as outras mídias parar caso haja interrupçāo da mídia mestra durante sua transmissão. Isto é visível na prática já que, por exemplo, durante uma transmissão ao vivo de um evento, é muito menos sensível a perda da imagem do que do som. Muitas vezes, a perda do som faz com que a informação de vídeo seja desmotivante ou até mesmo inútil. Várias pesquisas demonstram que a qualidade do áudio é fundamental para que o participante se sinta motivado, mostrando assim, ainda mais, a tendência de que a escolha do áudio como mídia mestre é a melhor opção.

Na implementação do $e M e e t / I n C A$, as mídias de áudio e vídeo de cada participante são sincronizadas, com o auxílio da API JMF (que provê esse tipo de funcionalidade), e os timestamps para o armazenamento de outras mídias (como texto, por exemplo) são criados com base no tempo do servidor de reunião do eMeet/InCA. Este modelo se mostrou eficaz no 
contexto de implementação da aplicação, que atualmente conta com quatro participantes simultâneos, não tendo grandes problemas com a sincronização das mídias capturadas. Na reprodução, porém, é aconselhável que a mídia de referência seja o áudio.

\subsection{CARACTERÍSTICAS IMPLEMENTADAS NO eMeet/InCA}

As características implementadas na atual versão do $e M e e t / I n C A$ são :

- suporte à reunião distribuída com áudio, vídeo, lousa eletrônica e chat, suportando um número máximo de 4 participantes (limitação imposta na parte gráfica do software cliente, não no servidor);

- sumarização em tempo de execução e gravação da reunião em um arquivo no formato Quicktime (.mov);

- sistema interno de controle e gerenciamento de sessão, controle dos usuários e difusão das streams de dados entre os participantes;

- integração total do eMeet/InCA com a autenticação de usuários pela $W e b$, através da utilização da tecnologia JAVA Web Start;

- transmissão e recebimento das mídias de áudio e vídeo, dos participantes, em tempo real, com o auxílio da API JMF e o seu suporte a RTP/RTCP;

- transmissão unicast das streams de áudio e vídeo de cada participante (visando a utilização do sistema em conexões comuns via Internet, como em ISPs - Internet Service Providers), com possível extensão para o protocolo multicast;

- escrito utilizando-se das vantagens do paradigma de programação orientado a objetos, facilitando o reuso e extensão do código;

- como o eMeet/InCA foi desenvolvido inteiramente na linguagem JAVA, a aplicação consegue ter uma multiplataformidade, abrangendo vários sistemas operacionais e hardwares diferentes.

Como se pode notar, pela seção 4.2 , as características que faltam no $e M e e t / \operatorname{lnCA}$ real são: a conformidade com a recomendação ITU-T H.323 e a implementação da difusão multicast para as streams de dados. A conformidade com a recomendação ITU-T H.323 pode ser conseguida com a utilização da API J323 à medida que ela venha a evoluir, assim como as APIs JTAPI e JMF, pois elas são a base da J323. Já a implementação da transmissão multicast para as streams 
de dados pode ser conseguida (à medida que o suporte a difusão multicast cresça nos roteadores da Internet) de forma não muito traumática, através da modificação do sistema interno de controle de gerenciamento da aplicação. Caso utilize-se o protocolo de controle H.245, previsto pela recomendação ITU-T H.323 e implementado na API J323, essa tarefa fica sendo ainda mais fácil.

\subsection{CONSIDERAÇÕES FINAIS}

Neste capítulo foram abordadas características fundamentais para a implementação do eMeet/InCA, tais como: linguagem de implementação, protocolo de transporte, difusão de dados pela rede e sincronização de mídias. Foram apresentadas soluções adequadas e padronizadas para a criação de uma ferramenta do gênero do eMeet/InCA, as quais foram utilizadas no desenvolvimento da aplicação, fazendo com que grandes dificuldades aparecessem. Devido a essas dificuldades o $e M e e t / I n C A$ implementado não possui as características ideais apresentadas na seção 4.2. A implementação atual conta com as características descritas na seção 4.7 além de ter sido construída prevendo futuras atualizações a fim de que as características ideais possam vir a ser suportadas futuramente. 


\subsection{CONSIDERAÇÕES INICIAIS}

Neste capítulo são abordadas características da arquitetura do eMeet/InCA, a começar pela arquitetura ideal desejada e que não pôde ser alcançada pelos motivos descritos no Capítulo 4; a arquitetura real e implementada na atual versão do $e$ Meet/InCA; o diagrama de classes do servidor e do cliente; as interfaces gráficas dos usuários da aplicação e os módulos $x I n C A$ integrados ao cliente $e$ Meet/InCA.

\subsection{MODELO LÓGICO IDEAL}

Conforme toda a análise descrita no Capítulo 4, o eMeet//nCA deveria suportar a recomendação ITU-T H.323, possivelmente através da utilização da API J323 da IBM, a fim ser uma aplicação de acordo com os protocolos padrões de transmissão de dados e de controle de sessão. Portanto, é possível delinear um modelo lógico da estrutura de funcionamento ideal do eMeet/InCA, mostrado na Figura 5.1.

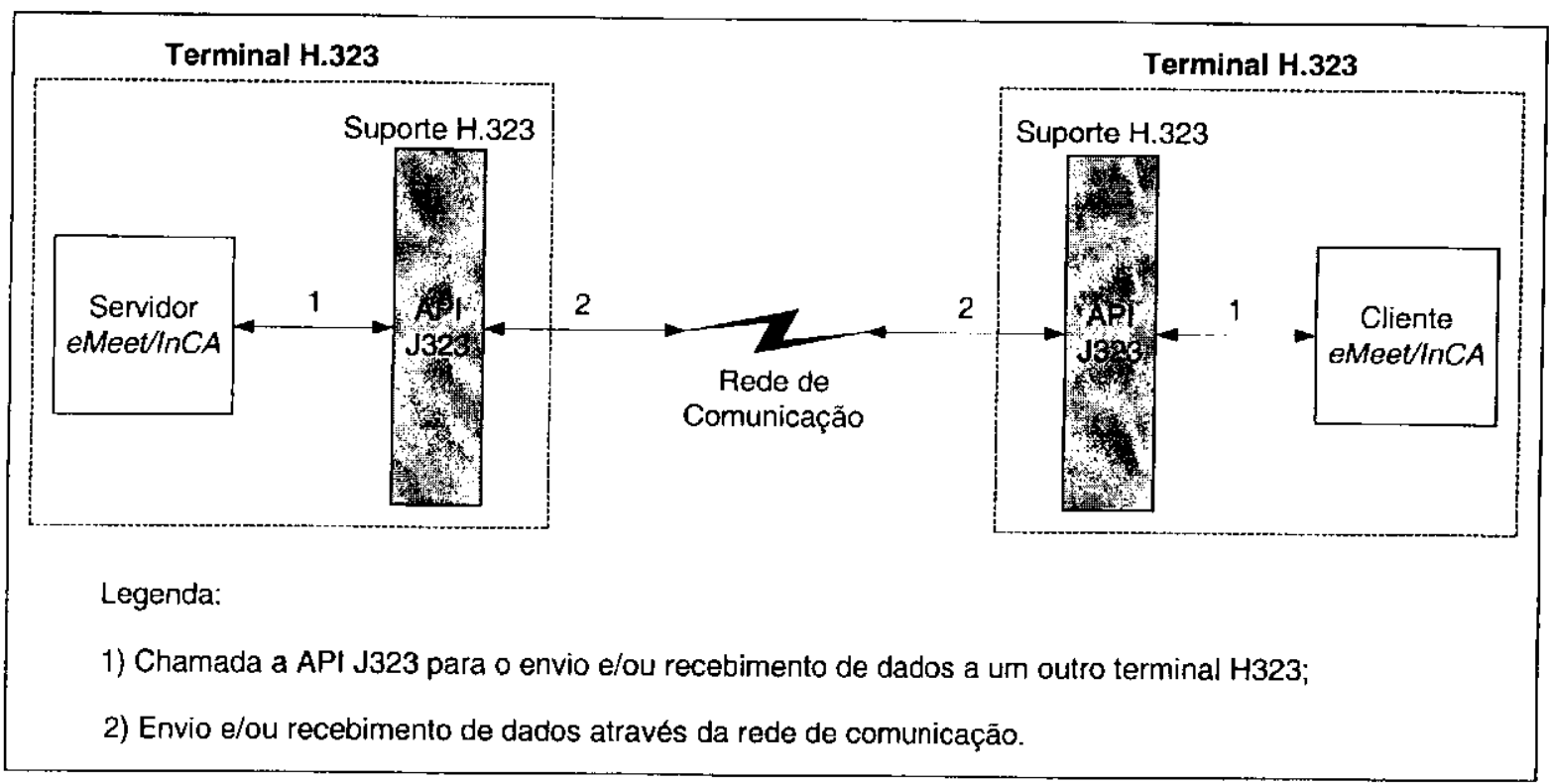

Figura 5.1 - Modelo lógico ideal de implementação do eMeet/inCA. 
Pode-se notar pela Figura 5.1 que a comunicação entre um cliente $e M e e t / I n C A$ (que representa um participante de uma reunião) e o servidor é feita utilizando-se a API J323 que fornece o suporte à recomendação H.323. Portanto, de um ponto de vista mais genérico, a comunicação do cliente ao servidor é uma comunicação de terminais H.323. Essa estrutura garante a interoperabilidade entre a aplicação $e M e e t / \operatorname{InCA}$ e qualquer outro dispositivo de comunicação que seja um terminal H.323. O controle de sessão, compartilhamento de dados e o envio e recebimento de streams de áudio e vídeo ficam encapsulados através da API J323.

\subsection{MODELO LÓGICO IMPLEMENTADO}

No Capítulo 4 foram destacados vários problemas encontrados durante a fase de implementação do projeto e que inviabilizaram a implementação do modelo lógico ideal, descrito na seção anterior, na atual versão do eMeet/InCA. A impossibilidade de se utilizar a API J323 foi o que provocou a maior mudança na concepção do modelo lógico funcional do eMeet/InCA, fazendo com que houvesse a necessidade de se incorporar um mecanismo de controle de sessão e envio de dados das informações de áudio e vídeo de cada participante. O modelo lógico implementado na atual versão do eMeet/InCA é mostrado na Figura 5.2.

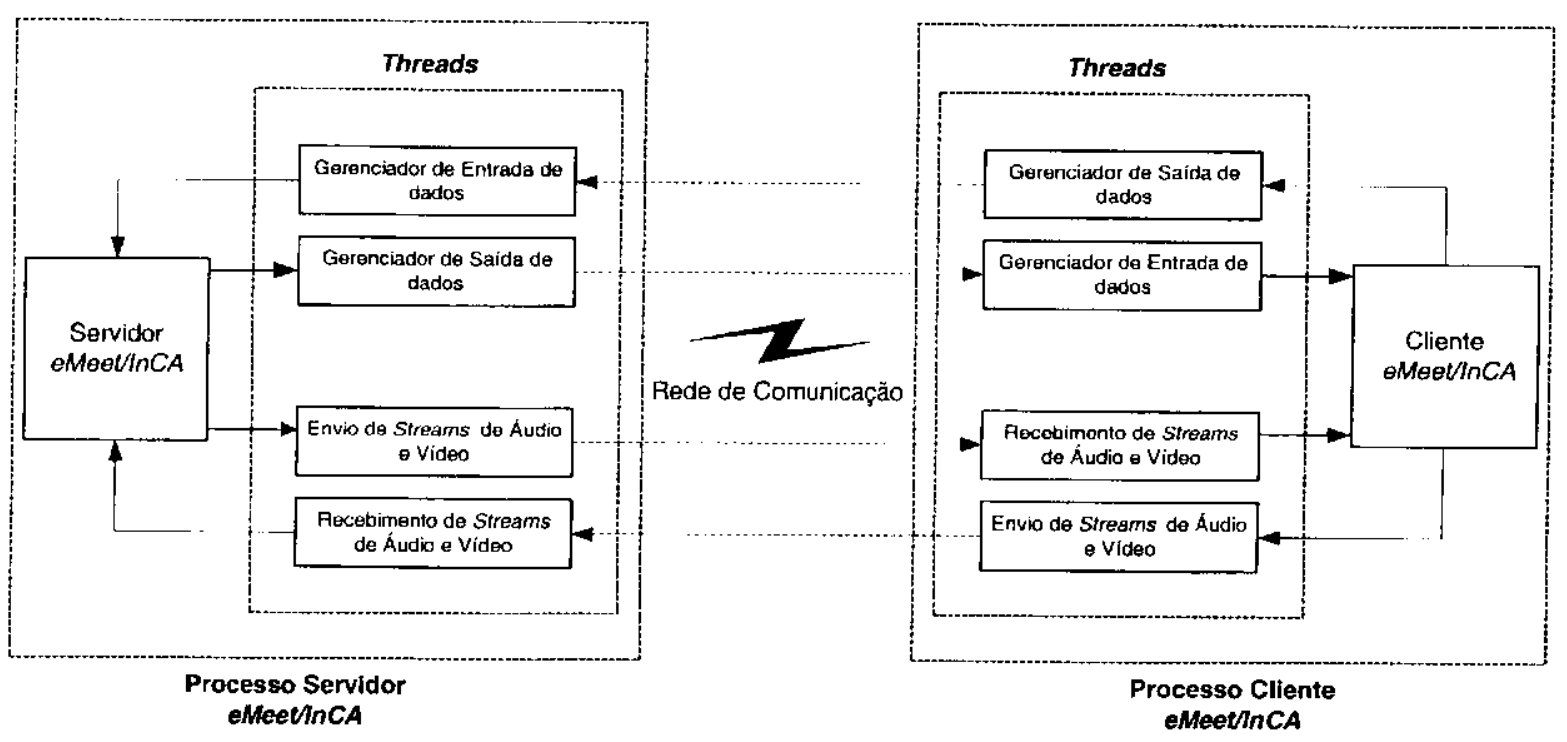

Figura 5.2 - Modelo lógico implementado no eMeet/InCA. 
Observando-se a Figura 5.2 nota-se a existência de gerenciadores de entrada e saída de dados, tanto por parte do servidor quanto por parte do cliente. Eles correspondem ao arranjo lógico destinado a prover uma comunicação de entrada e saída bidirecional, responsável pela troca de informações de controle entre o servidor e o cliente. É por meio dessa comunicaçāo que, por exemplo, um participante sabe da existência ou não de outros participantes, mantendo-se assim, a consistência da reunião. Os gerenciadores de entrada e saída foram implementados como threads, a fim de se obter uma melhor performance e uma estrutura de comunicação nāo bloqueante (sem a necessidade de pooling). As atualizações das informações são feitas a partir de chamadas a métodos dos objetos que instanciaram os gerenciadores, ou seja, se uma informação de controle é enviada do servidor a um determinado cliente (uma informação de chegada de um novo participante, por exemplo), o gerenciador de entrada de dados do cliente chamará um método do cliente a fím de que a atualização possa ser refletida na visão do participante. Analogamente, o processo é o mesmo para o envio e atualização de uma informação de um participante ao servidor $e M e e t / I n C A$.

Pode-se notar também na Figura 5.2 a existência de threads destinadas ao envio e recebimento de streams de áudio e vídeo do cliente ao servidor e vice-versa. Essas threads possibilitam a consistência no recebimento das informações de áudio e vídeos dos participantes de uma sessão do eMeet/lnCA.

Os gerenciadores de dados de entrada c saída, os métodos de atualização das informações de controle, existentes tanto no servidor quanto no cliente, juntamente com as threads de envio e recebimento das streams de áudio e vídeo dos participantes, formam a estrutura lógica desenvolvida para prover as funcionalidades da API J323 que seriam utilizadas. Assim, a partir do momento em que a API J323 chegar a uma maior maturidade, juntamente com as APIs JMF e JTAPI (nas quais a API J323 é baseada), essa estrutura lógica poderá ser substituída. A Figura 5.3 mostra o impacto de tal modificação na versão atual do eMeet/InCA, onde os blocos sombreados serão substituídos por funcionalidades da API J323, juntamente com as interfaces de chamadas a esses blocos tanto por parte do cliente quanto por parte do servidor eMeet/InCA. 


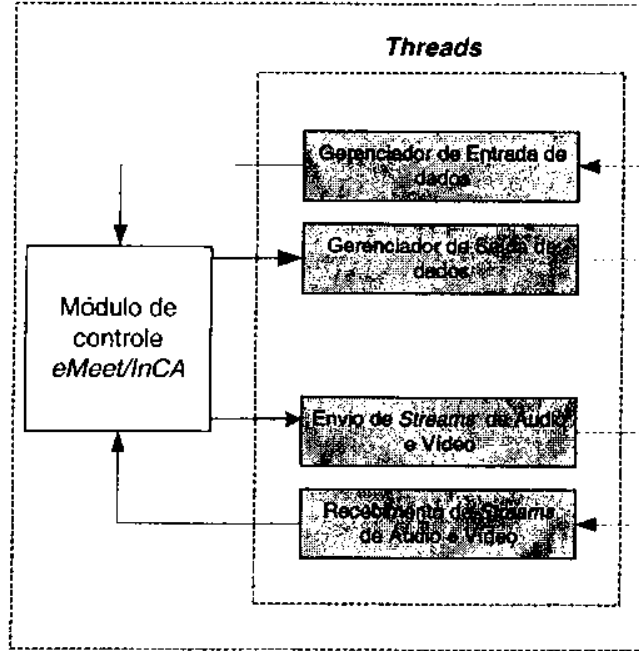

Servidor eMeet/nCA

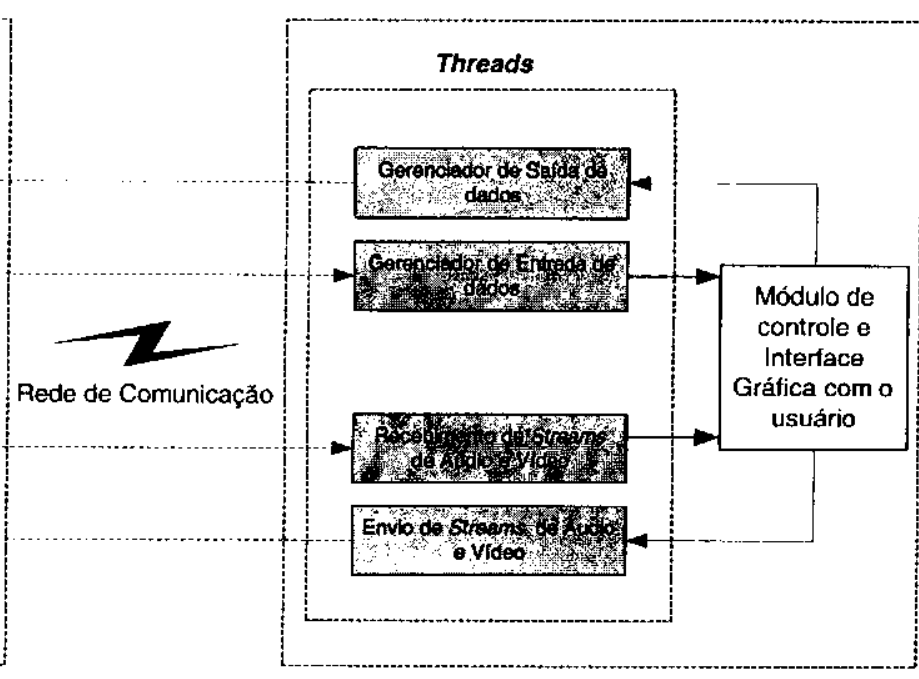

Cliente eMeet/inCA

Figura 5.3 - Impacto causado por uma possivel utilização da API J323 na versão atual do eMeet/InCA. Os blocos sombreados deverão ser substituídos por chamadas a API, juntamente com a interface de chamada aos blocos, que estão contidas tanto no servidor quanto no cliente eMeet/InCA.

\subsection{DIAGRAMA DE CLASSES DO eMeet/InCA}

Nesta seção será abordada a estrutura de classes do eMeet/InCA que é, na realidade, uma implementação do modelo estrutural lógico apresentado na seção anterior. Nas seções subsequientes serão mostradas as classes implementadas no servidor $e M e e t / h C A$, no cliente e, por último, o cenário completo da aplicação. Nesses diagramas foram excluídas classes periféricas que lidam com a interface gráfica com o usuário (tais como apresentação de mensagens e erros), por não influenciarem diretamente na estrutura lógica do eMeet/InCA.

\subsubsection{Servidor eMeet/InCA}

A Figura 5.4 mostra um diagrama de classes UML (http://www.rational.com/uml) que reflete a implementação feita no servidor $e M e e t / \operatorname{InCA}$. 


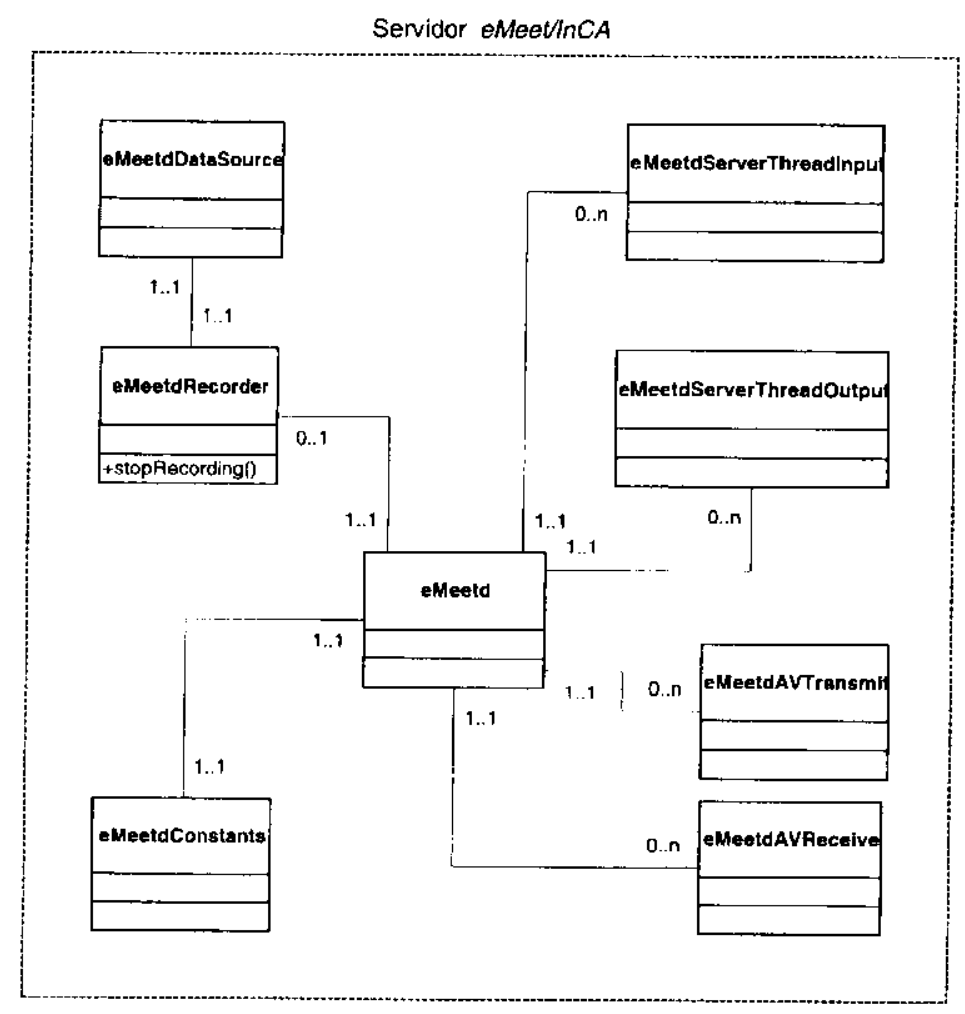

Figura 5.4 - Diagrama de classes UML da estrutura interna do servidor eMeet/InCA.

Como se pode notar pela Figura 5.4, a classe principal é a eMeetd (eMeet Daemon) que gerencia todas as atividades do servidor, funcionando como um daemon (servidor de aplicação) que espera a conexão remota de um cliente $e M e e t / I n C A$ na porta 8000 . A configuração padrão do daemon eMeet/InCA está contida na classe eMeetdConstants, a qual contém valores de constantes que refletem o comportamento interno do daemon, tais como: número máximo de clientes $e M e e t / I n C A$ a serem esperados, a porta na qual deve se esperar as requisições, as portas nas quais as streams de áudio e vídeo dos participantes devem ser esperadas, as portas nas quais estas streams devem ser retransmitidas (um participante de uma reunião deve receber as streams enviadas por outro(s) participante(s), portanto, há a necessidade da retransmissão das streams para manter a consistência da reunião) e se o daemon deve ou não mostrar mensagens do estado do seu funcionamento na tela, para fins de acompanhamento do sistema ou de debug. Esta configuração padrão pode também ser sobreposta caso haja um arquivo de configuração, denominado eMeetd.conf, no mesmo diretório no qual o daemon está sendo executado. $\mathrm{O}$ eMeetd.conf segue uma sintaxe do tipo ATRIBUTO=VALOR. Portanto, cada linha do arquivo tem um atributo de configuração e o seu valor correspondente que sobrepõe a configuração 
inicial da classe eMeetdConstants. Um exemplo de um arquivo de configuração eMeetd.conf é mostrado na Figura 5.5.

\section{SHOWEMEE TDMESS AGES= true \\ RECEPTIONBASEPORT $=5000$ \\ TRANSMISS IONB AS EPORT $=5100$}

Figura 5.5 - Exemplo de um arquivo de configuração eMeetd.conf. A primeira linha instrui ao daemon eMeet/lnCA a mostrar mensagens de debug. As outras linhas setam as portas de recepção e transmissão de streams, respectivamente.

Analisando-se ainda a Figura 5.4, quando há uma conexão com um cliente $e M e e t / I n C A$, as informações do novo participante de uma reunião são gravadas em uma instância (um objeto) da classe eMeetParticipant, sendo guardadas todas as informações referentes ao novo participante (nome, sobrenome, e-mail, comentários, código de identificaçāo na reunião e IP da máquina remota). Há também a instanciação das classes eMeetdServerThreadInput e eMeetdServerThreadOutput para a criação de uma comunicação bidirecional entre o clicnte eMeet/InCA e o servidor. O recebimento e a transmissão das streams de áudio e vídeo dos participantes são feitos a partir da instanciação das classes eMeetdAVTransmit e eMeetdAVReceive, responsáveis pela transmissão das mídias através da rede de comunicação e utilizando o protocolo de transporte RTP (Real Time Protocol).

A gravação da reunião também é controlada pelo daemon eMeet/InCA, que é responsável pelo seu início e término. A determinação de quando começa e quando termina a gravação de uma reunião é feita através do recebimento de comandos de um gerente de reunião que, em geral, é um participante da reunião. A interface gráfica de um gerente de reunião é abordada na seção 5.5.2. No momento, é relevante observar que é o gerente de reunião quem dispara os eventos de instanciação das classes eMeetdRecorder e eMeetdDataSource, sendo a primeira uma thread que, quando instanciada, começa a gravar a reunião e possui um método que chamado determina o término da gravação de uma reunião, o método stopRecording(), como pode ser visto na Figura 5.4. Já a última, a classe eMeetdDataSource, é a classe responsável pela mixagem do áudio dos participantes e da determinação do foco do vídeo a ser gravado (de qual participante da reunião), a fim de que somente o vídco de quem esteja falando, em um determinado momento, seja o vídeo gravado. 


\subsubsection{Cliente eMeet/InCA}

A Figura 5.6 mostra o diagrama de classes que reflete a estrutura organizacional implementada no cliente $e M e e t / I n C A$. A classe principal é a eMeetClient, responsável pelo gerenciamento das funcionalidades do cliente. Uma vez instanciada a classe eMeetClient, esta se conecta ao servidor $e M e e t / I n C A$ e estabelece um canal de comunicação bidirecional entre o daemon eMeet/InCA, através das classes eMeetClientThreadOutput e eMeetClientThreadInput, responsáveis pelo envio de informações de controle do cliente ao servidor e do servidor ao cliente, respectivamente. Uma vez estabelecida a comunicação entre o cliente e o servidor, o cliente recebe um código de identificação único (um ID) para ser identificado durante toda a duração da reunião e recebe as informações de todos os outros participantes existentes, informações estas que são armazenadas em instâncias da classe MeetParticipant.

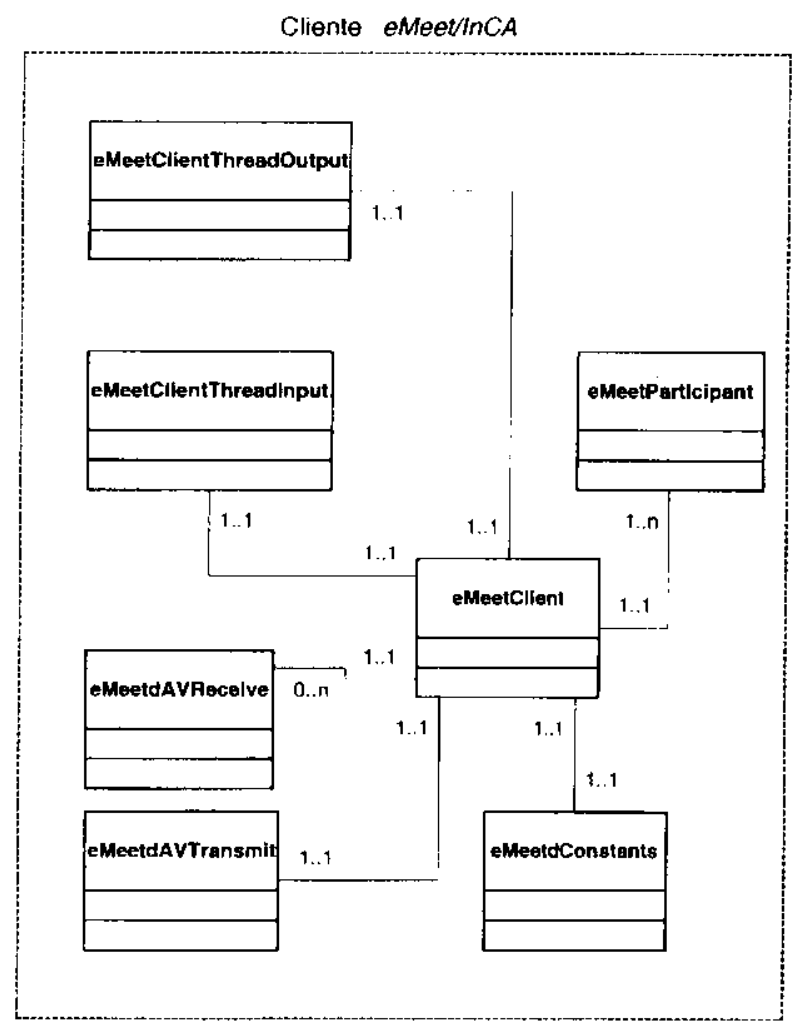

Figura 5.6 - Diagrama de classes UML da estrutura interna do cliente eMeet/InCA.

A transmissão das streams de áudio e vídeo geradas pelo cliente é feita através da classe eMeetdAVTransmit, enquanto que a recep̧̧ão das streams dos outros participantes é conseguida através da classe eMeetdAVReceive. Ambas as classes estão ilustradas na Figura 5.6. 
Caso o cliente seja executado sem a passagem de parâmetros necessários para a configuração do cliente e a conexão com o servidor, o cliente assumirá valores contidos na classe eMeetdConstants. Na versão atual do $e M e e t / \operatorname{InCA}$, os parâmetros de configuração são passados na própria chamada de execução do cliente, através da utilização da tecnologia JAVA Web Start, apresentada na Seção 4.3.3, e da autenticação de usuários feita pelo eMeet/SERVE ${ }^{9}$.

\subsubsection{Servidor e Cliente}

Com base nas explanações feitas nas Seções 5.4.1 e 5.4.2, pode-se mostrar o diagrama de classes completo da aplicação $e M e e t / / n C A$ e que é apresentado na Figura 5.7.

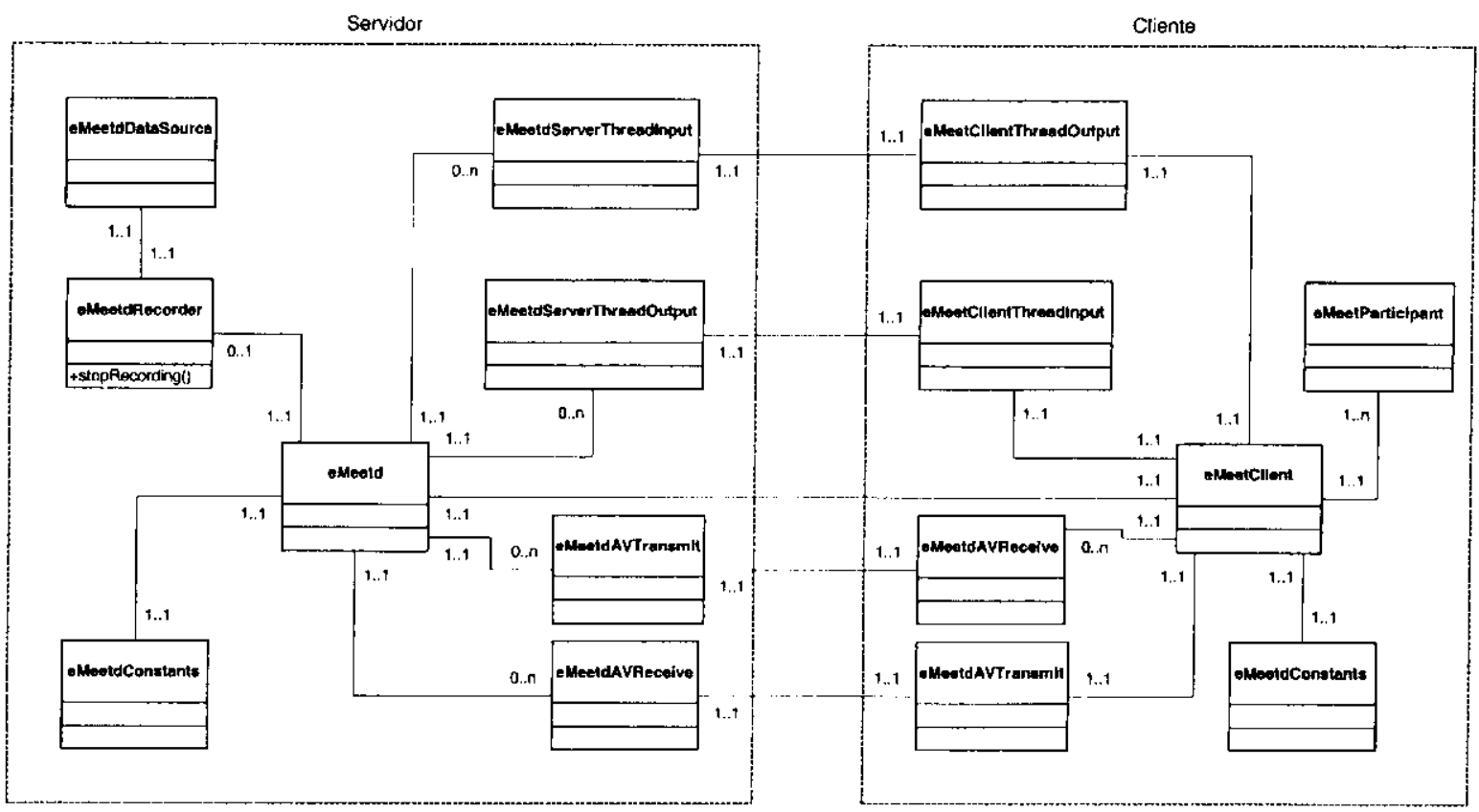

Figura 5.7 - Diagrama de classes UML da estrutura completa do eMeet/InCA atual.

\subsection{INTERFACE GRÁFICA DO eMeet/InCA}

Existem duas interfaces gráficas para o cliente eMeet/InCA: a interface gráfica de um participante e a de um gerente de reunião, as quais são mostradas nas seções seguintes.

\footnotetext{
${ }^{9}$ Trabalho de mestrado rcalizado por Pedro Monteiro da Silva Eleutério.
} 


\subsubsection{Participante}

A Figura 5.8 mostra a interface gráfica do cliente $e M e e t / I n C A$ para um participante de uma reuniāo. Nela, o participante pode ver o seu video local, na janela "My Video", e o video de até outros três participantes, como pode ser observado no lado direito da figura. Há dois ícones posicionados inferiormente a cada janela de visualização de um participante, com exceção do próprio participante que conta somente com um ícone de informações. O primeiro, da esquerda para a direita, é um ícone de informações; clicando-se nele, são mostradas as informaçōes do participante (nome, e-mail, um pequeno comentário, informações das mídias sendo transmitidas, que podem ser áudio e vídeo, e o IP da máquina remota). O segundo ícone possibilita a escuta ou não da informação de áudio do participante, funcionando como um botão mute (inibição do áudio). No caso do próprio participante, o áudio está sempre desabilitado para a escuta local para evitar um possível refluxo de áudio (reverberação), esta é a razão de não haver o segundo ícone para o participante local.

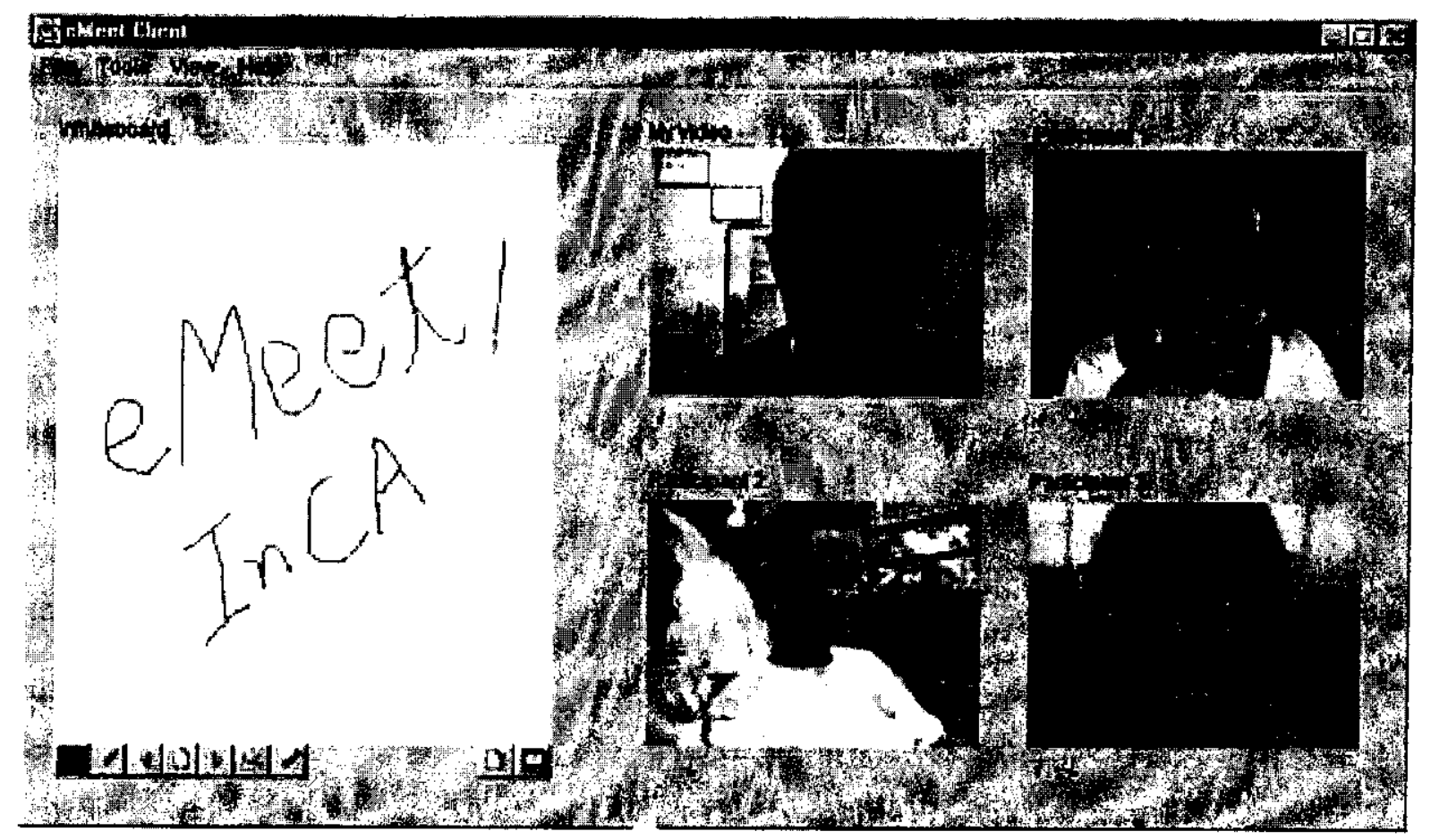

Figura 5.8 - Interface gráfica do cliente $e M e e t / n C A$ para um participante de uma reunião.

Como se pode observar pela Figura 5.8, no lado esquerdo há um whiteboard para o compartilhamento de slides e anotações. As facilidades de whiteboard e chat existentes na opção "Tools" (lado superior esquerdo da figura) sāo resultantes da integração do eMeet/InCA a 
módulos desenvolvidos em outro projeto de mestrado, o qual tem como objetivo estender a atual infra-estrutura $\ln C A$ utilizada no projeto eClass (Cattelan, 2002). Esses módulos estão sendo desenvolvidos por Renan Gonçalves Cattelan e serão abordados com maiores detalhes na Seção 5.6 .

\subsubsection{Gerente de reuniāo}

Como em qualquer reunião há um tempo no qual os participantes se preparam para o seu começo, fica difícil a automação do processo de início da gravação de uma reunião. Além disso, talvez nem todas as reuniões possam vir a ser gravadas (por questões de privacidade, por exemplo). Portanto, optou-se por criar no eMeet/InCA a figura do gerenciador de reunião. O gerenciador de reunião, que é normalmente um dos participantes da reunião, é o responsável por começar o processo de gravação da reunião bem como o seu término. Existe um aplicativo desenvolvido para tal funcionalidade (classe ManagerClient) e que funciona como um cliente eMeet/InCA, tendo toda a estrutura de comunicação cliente/servidor com exceção das implementações de recebimento e transmissão de streams. Nesse caso o código de identificação tem o valor 0 , significando que é um gerente de reuniāo. A janela de gerenciamento do processo de gravação, proporcionada por este aplicativo, é mostrada na Figura 5.9. 


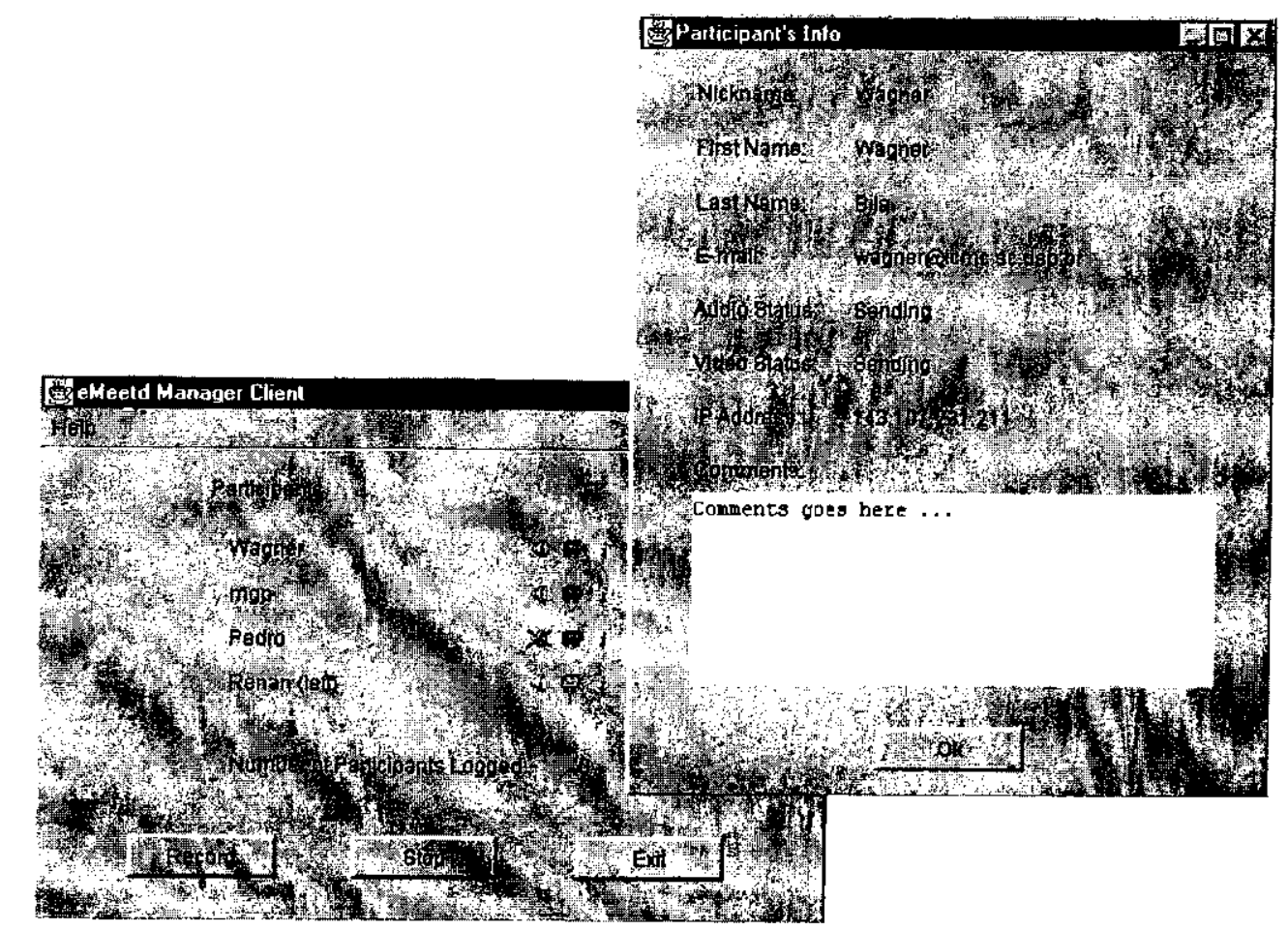

Figura 5.9 - Interface gráfica do gerenciador do processo de gravação da reunião do eMeet/InCA. No lado superior direito tem-se as informaçōes de um dos usuários.

Pode-se notar na Figura 5.9 que o gerenciador tem a visão de quantos participantes há em uma reunião e pode começar a gravação ou termina-la quando achar necessário, através dos botões "Record" e "Stop" localizados na parte inferior da figura. No centro, ao lado da informação de cada participante, há três ícones. Os dois primeiros dizem respeito a inclusão ou não das mídias de áudio e vídeo no critério de sumarização da reunião. Assim, caso não seja interessante gravar a informação de áudio ou de vídeo de um participante, basta apenas clicar no ícone e a stream desejada não será incorporada na gravação da reunião (bastando um novo clique para reabilitar a sua inclusăo no processo), como é o caso da stream de áudio do participante Pedro na Figura 5.9. O último ícone, o ícone mais à direita, possibilita a visualização das informações de um determinado participante, como pode ser observado no canto superior direito da Figura 5.9. Assim, clicando-se nele, aparecerá uma janela com as informações do participante. O botão "Exit" sai da aplicação. 


\subsection{INTEGRAÇÃO COM MÓDULOS DO xInCA}

\subsection{1 $x \ln C A$}

O $x \operatorname{InCA}$ (eXtended $\operatorname{InCA}$ ) é uma proposta de extensão da infra-estrutura InCA, abordada no Capítulo 2, estando em fase de construção. O xInCA é uma camada acima da InCA e é composto por um conjunto de módulos, cada qual sendo responsável por uma funcionalidade específica no contexto de aplicações de captura e acesso, existindo implementações de whiteboard, chat, captura de áudio e captura de navegação de hipertexto (Cattelan, 2002). No contexto do eMeet/InCA, os módulos de chat e whiteboard foram incorporados e a demanda por um módulo de votação era desejável, visto que o $\mathrm{eMeet/InCA}$ é uma ferramenta de suporte à decisão.

\subsubsection{Módulo Chat}

O módulo de chat do $x I n C A$ foi incorporado com muita facilidade ao cliente eMeet/InCA e pode ser acessado através da opção "Tools" na barra de menu da aplicação. A Figura 5.10 mostra a interface gráfica do módulo.

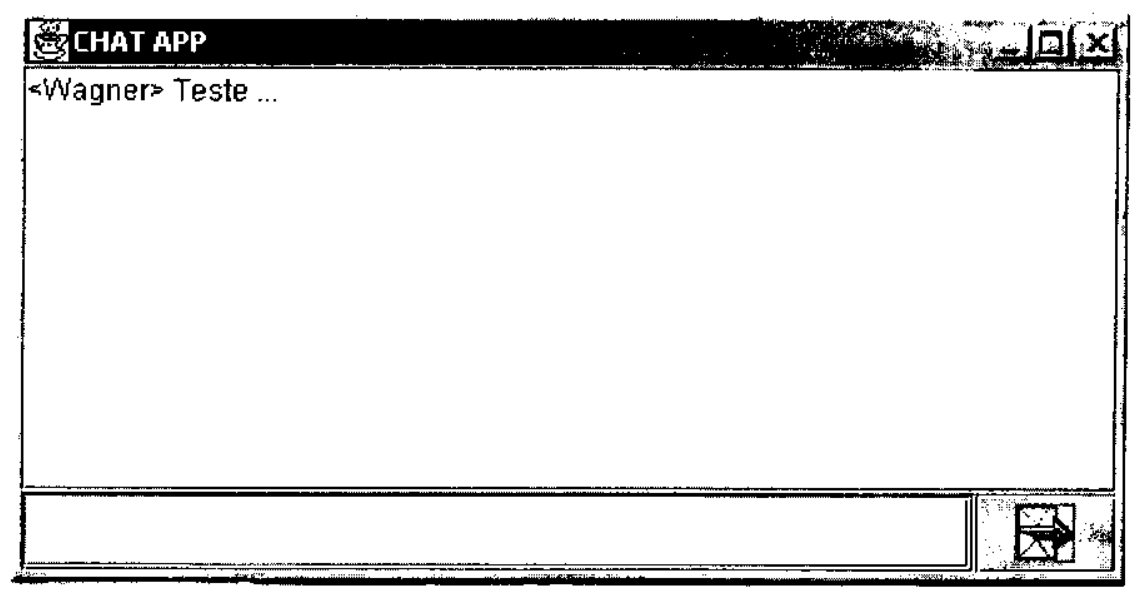

Figura 5.10 - Interface gráfica do módulo de chat do $x \ln C A$.

\subsubsection{Módulo Whiteboard}

O módulo whiteboard do $x I n C A$ implementa uma lousa eletrônica que pode ser compartilhada com vários usuários, a fim de se compartilhar anotaçōes. As anotaçōes também podem ser feitas $\mathrm{cm}$ slides carregados como imagem de fundo do whiteboard. A incorporação do módulo foi feita 
de maneira fácil e rápida, tendo sido customizada a sua interface gráfica a fim de se obter uma interface visual condizente com o restante da interface cliente $e M e e t / I n C A$. A Figura 5.11 mostra a interface gráfica original do whiteboard $x \ln C A$.

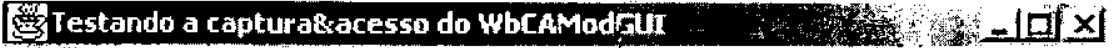

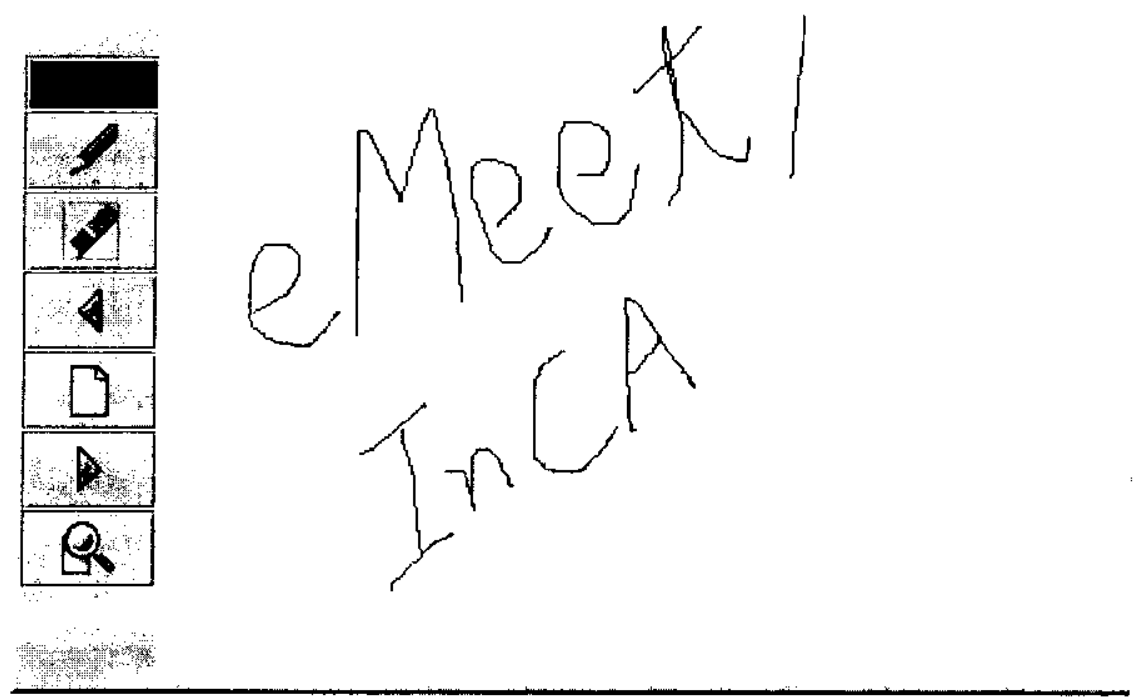

Figura 5.11 - Interface gráfica original do módulo whiteboard do $x \ln C A$.

\subsubsection{Módulo de Votação}

Como o eMeet/InCA é uma aplicação de suporte à decisão, assim como as ferramentas investigadas na Seção 3.3, seria interessante o eMeet/InCA ter um módulo de votação baseado na infra-estrutura $x \operatorname{InCA}$. A análise da construção de tal módulo está sendo feita mas foge um pouco do enfoque dado à construção da mesma, o contexto de suporte a aplicações de captura e acesso em uma sala de aula, como é o caso do eClass.

\subsection{DADOS CAPTURADOS PARA A GERAÇÃO DE HIPERDOCUMENTOS}

A atual versão da aplicação eMeet (eMeet/InCA e eMeet/SERVE) prevê a captura e exibição das streams de áudio, de vídeo e das atividades no whiteboard (anotações e slides) que são geradas durante uma reunião. Portanto, o eMeet/InCA gera um arquivo no formato Quicktime (.mov) contendo toda a gravação da reunião, além de capturar e armazenar todas as atividades do whiteboard na base do eMeet/SERVE, a porção de visualização da aplicação eMeet. A Figura 5.12 mostra a base de dados atual do eMeet/SERVE. A tabela room é a tabela que abstrai o 
conceito de localização geográfica, sendo que um participante pertence normalmente a uma entrada nessa tabela. Portanto, pode haver uma sala chamada "São Carlos" indicando que todos os usuários associados a essa entrada na tabela estão localizados na cidade de São Carlos. A tabela meeting_room é a tabcla que associa usuários a uma reunião, sendo que os detalhes da reunião estão contidos na tabela meeting. Os dados armazenados na tabela meeting compreendem o nome da reunião, uma breve descrição, localização no arquivo do sistema de onde se encontra o arquivo de vídeo gerado pelo eMeet/lnCA, data e hora de início e término de uma reunião, além de um código único identificando aquela reunião. Na tabela slide são armazenados todos os slides utilizados durante a realização da reunião enquanto que as anotações feitas nos slides são armazenadas na tabela penstroke.

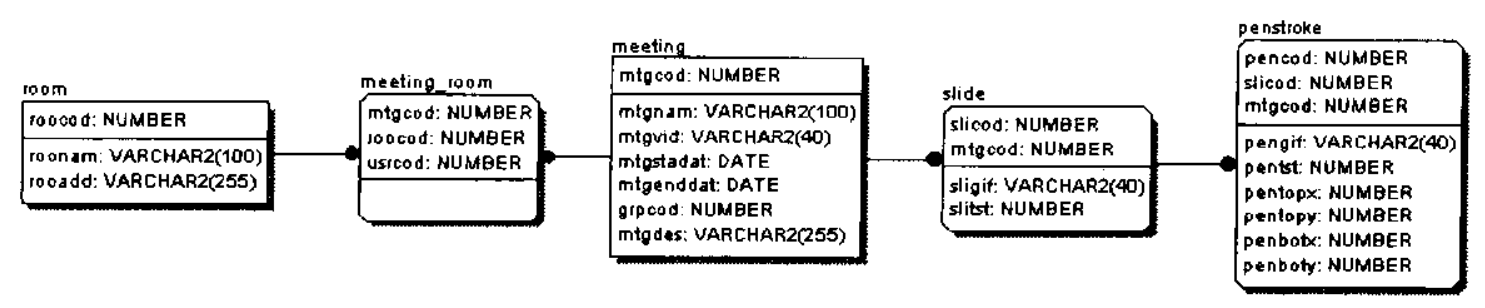

Figura 5.12 - Base de dados do eMeet/SERVE (Eleutério, 2002).

O eMeet/SERVE, além de ser responsável pela visualização de todos os dados capturados pelo eMeet/InCA, também faz o agendamento de reuniões e a autenticação dos usuários do sistema eMeet. $\mathrm{O}$ eMeet/InCA atua diretamente na atualização das tabelas meeting, slide e penstroke para o correto armazenamento das informações geradas durante a captura de uma reunião, possibilitando assim a posterior apresentação da mesma através do eMeet/SERVE. Atualmente, apesar do eMeet/InCA possuir um módulo de chat para a conversação dos participantes, as mensagens trocadas não estão sendo armazenadas. Uma futura versão do sistema deve suportar essa característica. A visão da apresentação dos hiperdocumentos gerados a partir dos dados armazenados pelo $e M e e t / \ln C A$ é mostrada na próxima seção. 


\subsection{HIPERDOCUMENTOS VISUALIZADOS NO EMEet/SERVE}

O $e$ Meet/SERVE é a parte da aplicaçāo eMeet responsável pela apresentação via Web dos dados armazenados pelo eMeet/InCA. A Figura 5.13 mostra a interface de visualização de uma reunião capturada pelo $e M e e t / I n C A$ e recuperada pelo $e M e e t / S E R V E$.

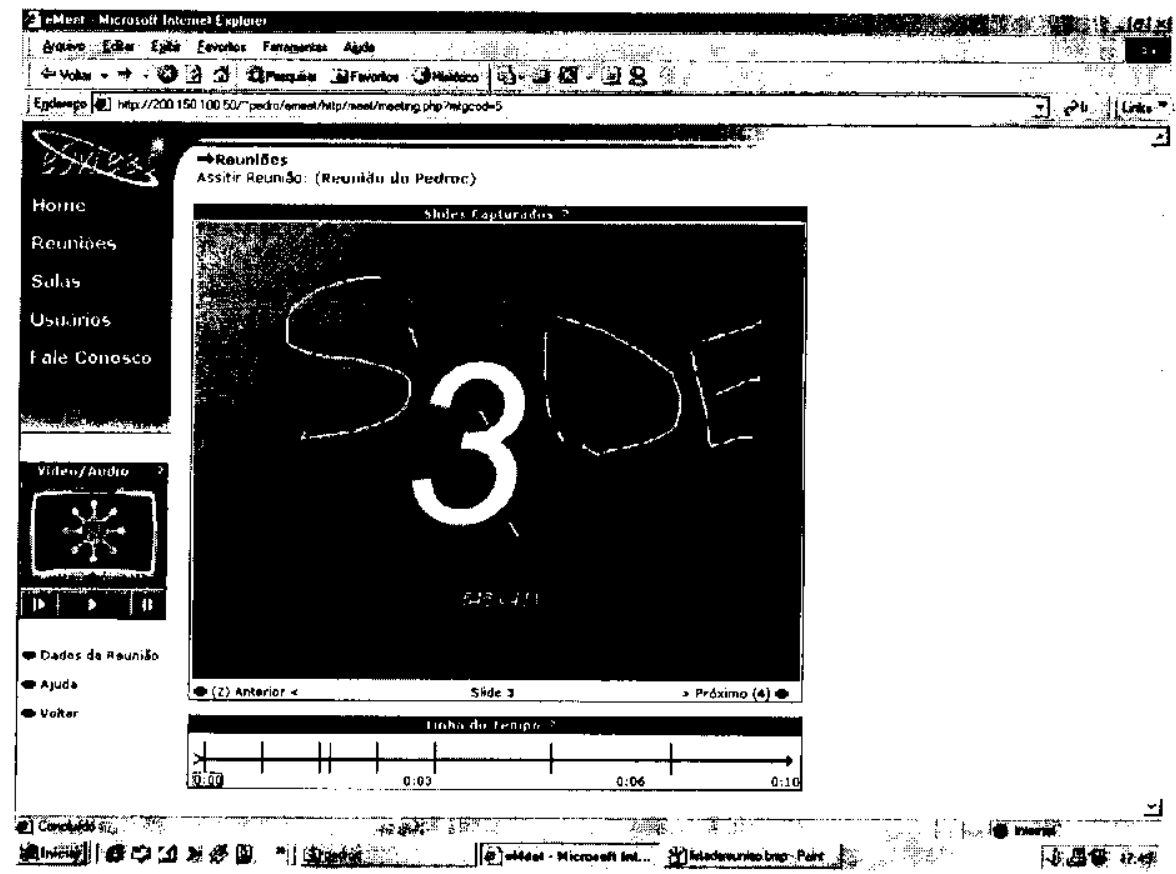

Figura 5.13 - Interface de visualização de uma reunião recuperada pelo eMeet/SERVE (Eleutério, 2002).

Pode-se notar na Figura 5.13 que no lado esquerdo há um espaço para a apresentação do vídeo capturado durante a reunião, com as opçōes de play, pause e stop. No lado direito ocorre a apresentação dos slides e anotações utilizados durante o decorrer da apresentação, ocorrendo a mudança automática de slide à medida que a reunião avança no decorrer do tempo. Na parte inferior temos uma linha de tempo indicando a duração da reunião, bem como os momentos em que há troca de slides (riscos verticais que cortam a linha de tempo).

\section{9 eMeet/nCA EM UM CENÁRIO DE REUNIÕES PRESENCIAIS}

O eMeet/InCA foi concebido para ser utilizado em reuniões distribuídas mas também pode ser utilizado para a captura de informações em reuniões presenciais (reuniões nas quais os participantes se encontram posicionados no mesmo local geográfico). 
Utilizando-se a versão atual do eMeet/InCA para essa finalidade temos uma aplicação nos moldes do PlexCenter (seção 3.4.2). Já com algumas modificações e utilizando-se de dispositivos de computação ubíqua, temos uma aplicação muito similar ao contexto do eClass na captura de reuniōes presenciais. Isso mostra a versatilidade na qual o eMeet/InCA pode ser utilizado para diversos objetivos além do foco principal idealizado na concepção da ferramenta.

\subsection{CONSIDERAÇÕES FINAIS}

Com base na arquitetura ideal do $e M e e t / I n C A$ e a arquitetura real apresentada, pode-se verificar o esforço realizado neste trabalho para que o eMeet/lnCA se tornasse uma aplicação funcional, mesmo em meio a muitas deficiências encontradas na API JMF e a impossibilidade de utilização da API J323 da IBM. A partir do momento em que a API JMF evolua, sendo mais estável e com menos bugs, a viabilidade de se utilizar uma API como a J323 pode fazer com que uma nova versão do $e$ Meet/InCA seja mais robusta e padronizada. 


\section{Genchoses}

Neste capítulo, após uma contextualização da motivação que levou ao desenvolvimento da aplicação eMeet, são discutidos os resultados obtidos durante o seu desenvolvimento e as primeiras utilizações da ferramenta, além dos aspectos de melhorias futuras do sistema, motivando a realização de outros trabalhos.

\subsection{MOTIVAÇÃO}

A motivação principal do presente trabalho foi a investigação de mecanismos para a captura de informação multimídia em ambientes de reuniões de modo a permitir a geração de documentos hipermídia associados na World Wide Web.

\subsection{RESULTADOS}

Foi feita uma análise dos requisitos funcionais que uma aplicação deveria ter para que ela estivesse de acordo com todos os padrões de desenvolvimento de uma ferramenta do gênero do eMeet/InCA. A implementação da recomendação ITU-T H.323 é a mais importante de todas pois é ela que garante a interoperabilidade entre todas as aplicações existentes, voltadas ao foco do eMeet/InCA, além de abranger uma gama enorme de dispositivos de hardware (celulares, PDAs, telefones com suporte a vídeo, etc.) que possam vir a ser clientes da aplicação.

Durante os primeiros esforços de implementação da recomendação ITU-T H.323, através da utilização da API J323 da IBM, foram identificadas várias deficiências nas APIs JMF e JTAPI do JAVA. Isso mostra que várias APIs de suporte do JAVA ainda estão em fase de desenvolvimento contínuo e ainda não chegaram a uma estabilidade concreta, dificultando a implementação de aplicações com características mais abrangentes do que as triviais, como é o caso do $e$ Meet/InCA.

O teórico suporte a múltiplas plataformas, pela utilização da linguagem JAVA, ainda não se mostrou verdadeiro. Isto porque a aplicação $e M e e t / I n C A$ depende, fundamentalmente, das 
características de manipulação e transmissão de mídias da API JMF, que conta ainda com vários bugs de implementação. Características que funcionam no sistema operacional Windows, simplesmente não respondem no Linux, como é o caso de transmissão e recepção de streams de dados utilizando-se o protocolo RTP/RTCP. À medida que as APIs se tornarem mais estáveis, espera-se que se chegue a um suporte a múltiplas plataformas de fato no eMeet//nCA, como foi idealizado na concepção do projeto.

A falta de uma infra-estrutura de suporte para a transmissão multicast (rede MBone Multimedia Backbone), por parte dos provedores de acesso a Internet (ISPs - Internet Service Providers), foi o principal fator desmotivador da implementação de uma difusão multicast na aplicação, pois queria se usar a aplicação com clientes comuns, através de ISPs e com conexão dial-up. Apesar de isto implicar diretamente em um aumento da largura de banda do servidor de reunião da aplicação, o sistema mostrou-se estável, suportando o número desejado de participantes (quatro participantes simultâneos).

A técnica de sumarização em tempo de execução da reunião, com o seu armazenamento em disco (arquivo em formato Quicktime), funcionou perfeitamente, depois de alguns ajustes de sincronismo de áudio e vídeo. O áudio armazenado, que é a soma de todas as informações de áudio dos participantes, foi conseguido através da utilização de um algoritmo de mixagem das streams de áudio, pois a API JMF não suporta tal característica.

O desenvolvimento das APIs JAVA, durante o período de desenvolvimento do projeto, se mostrou muito ativo. Hoje, por exemplo, existe um pedido formal de inclusão do suporte da recomendação ITU-T H.323 a uma API também muito recente, a API JAIN (Java API for Integrated Networks), que não existia há cerca de alguns poucos meses atrás. O que mostra um esforço de realmente se implementar a recomendação e de se padronizar as aplicações na área de tele e videoconferência. Isso é mais um fator que faz com que JAVA seja uma ótima aposta de linguagem de desenvolvimento, em vista do suporte que ela pode dar ao desenvolvimento de uma nova aplicação, mesmo que no inicio do desenvolvimento o seu suporte seja inexistente.

No decorrer da pesquisa bibliográfica para o projeto, que durou praticamente toda a fase de especificação e a de implementação, não foi encontrado nenhum indício de uma ferramenta de suporte a reuniões distribuídas que contivesse um mecanismo de gravação da reunião, sendo uma característica única do eMeet/InCA. 
$\mathrm{O}$ eMeet/InCA se mostrou uma aplicação ideal para qualquer tarefa que exija uma gravação de um encontro ou reunião, podendo ser empregado para qualquer outra finalidade, não necessariamente com o intuito de auxiliar o desenvolvimento de um projeto.

\subsection{TRABALHOS FUTUROS}

O trabalho aqui iniciado pode ser estendido de diversas maneiras, a fim de proporcionar uma aplicação mais ampla e flexível. As principais características que podem ser exploradas, em projetos futuros, são destacadas a seguir :

- suporte a recomendação H.323, a fim de se ter uma aplicação padronizada e ser possível a integração de vários tipos de clientes, que possuam diversos dispositivos de hardware, tais como: celulares, PDAs, telefones com suporte a video, etc.;

- suporte à difusão multicast, à medida que a estrutura para a difusão multicast seja mais ampla, para que se possa racionalizar a largura de banda e o processamento exigido para o servidor de reunião da aplicação;

- suporte a mais de quatro participantes, com estudos de como seria sua nova interface gráfica;

- sumarização da reunião com visualização de todos os participantes. Atualmente, na sumarização de uma reunião, a informação de áudio é o conjunto de informações de todos os participantes (áudio mixado), mas o vídeo é um chaveamento de quem está falando no momento. Isso pode ser melhorado com a introdução de uma visualização picture in picture dos outros participantes que não estão com a palavra, em um determinado momento;

- armazenamento das mensagens do chat nas tabelas do eMeet/SERVE;

- estudo da viabilidade de uma implementação peer to peer da aplicação, contrastando as vantagens e desvantagens, bem como a eficácia do novo sistema em relação ao original;

- suporte a novas mídias de dados que possam ser interessantes de serem integradas;

- testes de utilizaçāo do sistema em reuniões presenciais, a fim de averiguar sua eficácia e utilidade;

- estudo de novas finalidades para a aplicação. 


\subsection{CONSIDERAÇÕES FINAIS}

Acredita-sc que o propósito fundamental do projeto tenha sido alcançado. Foram investigados mecanismos para a captura de informação multimídia em ambientes de reuniōes de modo a permitir a geração de documentos hipermídia associados na World Wide Web, através do eMeet/SERVE. Apesar de terem sido encontradas várias limitações quanto a implementação em JAVA de uma ferramenta desse porte (o eMeet/InCA), a evolução da tecnologia JAVA e de suas API's têm sido constantes e rápidas o suficiente para que este trabalho, do ponto de vista do autor, não seja motivo de frustração mas sim de uma possível visão do que pode ser implementado em um futuro muito breve. 
(Abowd et al., 1998a) ABOWD, G.;ATKENSON, C; BROTHERTON, J; ENQVIST, T.; GULLY, P.; LEMON, J. Investigating the Capture, Integration and Access Problem of Ubiquitous Computing in NY Educational Setting. Proceedings of CHI'98, ACM, NEW YORK, p. 440-447, 1998.

(Abowd et al., 1998b) ABOWD, G.; BROTHERTON, J; BHALODIA, J. CLASSROOM 2000: A System for Capturing and Accessing Multimedia Classroom Experiences. CHI '98, May 1998.

(Abowd, 1999) ABOWD, G. CLASSROOM 2000: An Experiment With the Instrumentation of a Living Educational Environment. IBM Systems Journal, V. 38, N.4, p. 508-530, Oct. 1999.

(Abowd \& Mynatt, 2000) ABOWD, G. and MYNATT E. Charting Past, Present and Future Research in Ubiquitous Computing Special issue on HCI in the new Millenium, 7(1):29-58, March 2000.

(Abowd et al., 2001) Abowd, G., Truong, K., Brotherton, J. Who, What, When, Where, How: Design Issues of Capture \& Access Applications. In the Proceedings of UBICOMP 2001 (September 31-October 2, Atlanta, GA), 2001.

(Altium, 2001) http://www.altiumtech.com/pdfs/h.323.pdf; Co.H323, Altium Technologies, 2001 .

(Arrowood, 1996) ARROWOOD, A. - "CU-SeeMe Communications in an Emergent Technology" - LCC/IDT, OIT/NS GRA, Georgia Institute of Technology, Fevereiro de 1996.

(Arruda Jr., 2001) ARRUDA Jr., C. R. E. Integrando Web Services, Semantic Web e Arquitetura tipo Peer-to-Peer às Aplicações do Projeto InCA-SERVE. Pedido de bolsa de mestrado à FAPESP, out. de 2001.

(Borges et al., 1995) BORGES, M.R.S.; CAVALCANTI, M.C.R.; CAMPOS, M.L.M. Suporte por Computador ao Trabalho Cooperativo, XV Congresso da Sociedade Brasileira de Computação, Canela, RS, 1995.

(Brotherton et al., 1998a) BROTHERTON, J.A. E ABOWD, G.D. Room Takes Notes! In Working Papers of AAAI '98 Spring Symposium, March 1998.

(Brotherton et al., 1998b) BROTHERTON, J; BHALODIA, J. ABOWD, G. CLASSROOM 2000: A System for Capturing and Accessing Multimedia Classroom Experiences. CHI '98, May 1998.

(Cadiz et al., 1999) CADIZ, J.J.; BALACHANDRAN, A.; SANOCKI, E.; GUPTA, A.; GRUDIN, J.; JANCKE, G. Distance Learning Through Distributed Collaborative Video 
Viewing. ACM Multimedia 1999, p. 135-144, Out. 1999.

(Cattelan, 2002a) CATTELAN, R. G. xInCA: explorando a construção modular de aplicações de captura e acesso. Plano de mestrado encaminhado à comissão do programa Trilha Graduação-Mestrado do ICMC. Fevereiro de 2002.

(Chen et al., 1999) CHEN, H.Y.; CHIA, Y.T.; CHEN, G.Y.; HONG, J.S. An RTP-based Synchronized Hypermrdia Live Lecture System for Distance Education. ACM Multimedia '99, Oct. 1999.

(Conklin \& Begeman, 1987) COOKLIN, J; BEGEMAN, M. GIBIS: A Hypertext Tool for Team Design Deliberation. Hypertext'87, 1987.

(Conklin \& Burgess, 1991) CONKLIN, J. \& BURGESS, Y. A Process-Oriented Approach to Design Rationale. Human-Computer Interaction, 6, 3\&4 1991.

(Dorcey, 1995) DORCEY, T. - "CU-SeeMe Desktop Videoconferencing Software" Connections, Volume 9, n. 3, Março de 1995.

(Eleutério \& Pimentel, 2001) ELEUTÉRIO, P.M.S.; PIMENTEL, M.G.P. Geração Sob Demanda de Hiperdocumentos Multimídia a Partir de Informação Capturada em Reuniões Distribuídas. Anais do I Workshop de Teses e Dissertações do SBMídia`2001, October 2001.

(Eleutério, 2002) ELEUTÉRIO, P.M.S. Geração Sob Demanda de Hiperdocumentos Multimídia a Partir de Informação Capturada em Reuniões Distribuídas. Dissertação de mestrado em andamento.

(Ellis et al., 1991) ELLIS, C.A; GIBBS, S.J.; REIN, G.L. Groupware: Some Issues and Experiences. Communication of the ACM v.34, n.1, p. 1-29, 1991.

(Equivalence, 2002) http:/www.openh323.org; The openh323 Homepage, Equivalence Pty Ltd, Fev. 2002.

(Grudin, 1994) GRUDIN, J. CSCW: History and Focus. IEEE Computer, n.5, p.19-26, May 1994.

(Guzdial, 1999) GUZDIAL, M. Collaborative Websites Supporting Open Authoring. Submission to Journal of the Learning Sciences. 1999.

(Haake et al., 1994) HAAKE, J.M; NEUWIRTH, C. M.; STREITZ, N. A. Coexistence and Transformation of Informal and Formal Structures: Requirements for More Flexible Hypermidia Systems. In proceedings of ECTH'94, p. 1-12.

(Horizon, 2001) http://www.horizoncompanies.com/sections/products/h323/h323.html; H.323 Home Page, Horizon Companies Inc., 2001.

(Hürst \& Müller, 1999) HÜRST, W.; MÜLLER, R. A Synchronization Model for Recorded Presentations and its Relevance for Information Retrieval. ACM Multimedia, Oct. 1999. 
(IBM, 2000) http://www.zurich.ibm.com/csc/distribsys/j323/j323-9.html; Media subsystem plugins for the J323 engine. IBM, Jul., 2001.

(IBM, 2001) http://www.alphaworks.ibm.com/tech/j323engine; J323 Engine Home Page. International Engineering Consortion publication, IBM, 2001.

(IEC, 1999) http://www.iec.org; H.323. International Engineering Consortion publication, 1999.

(Isaacs et al., 1994) ISAACS, E. A.; MORRIS, T.; RODRIGUEZ, T.K. A Forum for Supporting Interactive Presentations to Distributed Audiences. Proceedings of CSCW'94. ACM Press, p. 405-416. Communications of the ACM, Agosto de 1994, Vol. 37, n. 8, p. 84-97.

(Isaacs \& Tang, 1997) ISAACS, E.A.; TANG, J.C. Studying Video-Based Collaboration in Context: From Small Workgroups to Large Organizations. In K.E. Finn, A.J. Sellen \& S.B. Wilbur(Eds.), Video-Mediated Communication, p. 173-197. Elbraum.

(Ishii et al., 1994) ISHII, H.; KOBAYASHI, M.; ARITA, K. Iterative Design of Seamless Collaboration Media.

(Izeki, 2000) IZEKI, C. (2000) Anotações em Hiperdocumentos: Um Estudo de Caso no eClass. Monografia de Qualificação para Mestrado apresentada no ICMC/USP, Out., 2000.

(Jancke et al., 2000) JANCKE, G.; GRUDIN, J.; GUPTA, A. Presenting to Local and Remote Audiences: Design and Use of the TELEP System. CHI Letters, vol. 2, issue 1, p. 384-391, Apr. 2000.

(Kausar \& Crowcroft, 1998) KAUSAR, N.; CROWCROFT, J. General Conference Control Protocol, IEEE Telecommunication, 1998.

(Lee, 1990) LEE, J. SIBYL: A Tool for Managing Group Decision Rationale. Proc. 3rd Conference on Computer Supported Cooperative Work, p. 79-92, 1990.

(Lee \& Lai, 1990) LEE, J. SIBYL: A Qualitative Decision Management System, P. Winston e S. Shellard (eds.), Artificial Intelligence at MIT: Expanding Frontiers, MIT Press: Cambridge, MA, 1990.

(Lee \& Lai, 1991) LEE, J.; LAI, K. What's in Design Rationale?. Human-Computer Interaction, $6(3 \& 4), 251-280,1991$.

(Macaulay, 1995) MACAULAY, L. Human-Computer Interaction for Software Designers. International Thomson Computer Press, p.136-172, 1995.

(Macedo et al., 1999) MACEDO, A.A.; KUTOVA, M.A.S.; PIMENTEL, M.G.C. Ambientes Cooperativos: Tendências e Exemplos. Notas Didáticas - ICMC-USP/São Carlos, fev. 1999.

(MacLean et al., 1991) MacLean, a.; et al., Questions, Options, and Criteria: Elements of Design Space Analysis, Human-Computer Interaction 6(3\&4), p. 201-250.

(Minneman et al., 1995) MINNEMAN, S.; HARRISON, S.; JANSEEN, B., KURTENBACK, G.; MORAN, T.; SMITH, I.; VAN MELLE, B. A Confederation of Tools for Capturing and Accessing Collaborative Activity. ACM Conference on Multimedia (Multimedia'95). 
(Mukhopadhyay \& Smith, 1999) MUKHOPASDYAY, S.; SMITH, B. Passive Capture and Structuring of Lectures. ACM Multimedia '99, Oct. 1999.

(Oliveira, 1996) OLIVEIRA, J. C. TVS: Um Sistema de Videoconferência, Dissertação de mestrado, PUC-RJ, Brasil, Agosto 1996.

(Palacharla et al., 1997) PALACHARLA, S.; KARMOUCH, A.; MAHMOUD, S. A. Design and Implementation of a Real-Time Multimedia Presentation System Using RTP. IEEE, 1997.

(Pimentel et al., 1999) PIMENTEL, M.G.C.; ABOWD, G. Development and Understanding of Automated Capture Environments to Support Long-Term Use. Projeto de Cooperação Internacional do PROTEM-CC-CNPQ/BRASIL E NSF/EUA, Out. 1999.

(Pimentel et al., 2000a) PIMENTEL, M.G.C; ABOWD, G; BROTHERTON J. Automated Capture as a Paradigm for Authoring Multimedia Information: Torwards Evolutionary Multimedia. Artigo em Preparação.

(Pimentel et. al., 2000b) PIMENTEL, M.G.C.; ABOWD, G. ISHIGURO, I. Linking by Interacting: A Paradigm for Authoring Hypertext. Proceedings of ACM Hypertext 2000.

(Pimentel et al., 2001) PIMENTEL, M.G.C.; ABOWD, G.; KERIMBAEV, B.; ISHIGURO, Y.; GUZDIAL, M. Supporting Long-Term Educational Activities Through Dynamic Web Interfaces. Journal Interacting With Computers, To Appear in 2000.

(RADVision, 2001) http://www.radvision.com/f_products/H323/H323.pdf; H.323 Protocol Toolkit, RADVision, 2001.

(Schulzrinne et al., 1996) SCHULZRINNE, H.; CASNER, S.; FREDRICK, R.; JACOBSON, V. RTP: A Transport Protocol for Real-Time Applications. RFC 1889, Jan. 1996.

(Shum \& Hammond, 1994) SHUM, S.; HAMMOND, N. Argumentation-based Design Rationale: What use at what cost?. International Journal of Human-Computer Studies, n.40, 1994.

(Soares et al., 1995) SOARES, L.F.G.; RODRIGUEZ, N.L.R.; CASANOVA, M.A. Nested Composite Nodes and Version Control in an Open Hypermedia System, Information Systems vol. 20, n. 6, p. 501-519, 1995.

(Streitz et al., 1997) STREITZ, N.A.T.; GEIBLER, J.; HAAKE, J.M.; HOL, J. Dolphin: Integrated Meeting Support Across Local and Remote Desktop Environments and Liveboards. In proceedings of CSCW'94, p. 345-358.

(Sun, 1999a) http://java.sun.com/products/java-media/imf/2.1.1/guide/; Java Media Framework API Guide, Nov. 1999.

(Sun, 1999b) http://java.sun.com/products/jatapi; Java Telephony API, Ago. 2000.

(Sun, 2001a) http://java.sun.com/products/java-media/jmf/2.1.1/formats.html; Java Media Framework Documentation, Set. 2001. 
(Sun, 2001b) http://java.sun.com/products/javawebstart/architecture.html; Java Web Start Page, Abr. 2001.

(Truong et al, 2001) Truong, K.; Abowd, G.; Brotherton, J. Who, What, When, Where, How: Design Issues of Capture \& Access Applications. In the Proceedings of UBICOMP 2001 (September 31-October 2, Atlanta, GA), 2001.

(Weiser, 1991) WEISER, M. The Computer for the $21^{\text {st }}$ Century. SCI. Am. 265, 3, p. 94-104, Out. 1991.

(White et al., 1998) WHITE, S.A.; GUPTA, A.; GRUDIN, J.; CHESLEY, H.; KIMBERLY, G.; SANOCKI, E. (1998) A Software System for Education at a Distance: Case Study Results. Microsoft Research Technical Report MSR-TR-98-61, Redmond, WA, November, 1998.

(White et al., 2000) WHITE, S.A.; GUPTA, A.; GRUDIN, J.; CHESLEY, H.; KIMBERLY, G.; SANOCKI, E. (1998) Evolving Use of a System to Support Education at a Distance. A ser publicado nos anais de HICSS-33, IEEE. 